\title{
ON INTIMACIES AND INFRASTRUCTURES: Sex Work and Spatial Politics
}

by

\author{
Alexandra Pereira-Edwards
}

A thesis submitted to the Faculty of Graduate and Postdoctoral Affairs in partial fulfillment of the requirements for the degree of

Master of Architecture

Azrieli School of Architecture and Urbanism

Carleton University

Ottawa, Ontario

(C) 2021

Alexandra Pereira-Edwards 


\section{Abstract}

Cities are constituted by overlapping networks of infrastructures and intimacies. These networks form the often-overlooked space of the everyday for many, yet for sex workers these networks have the capacity to reproduce patterns of violence and marginalization. A deep reading of Canadian sex work legislation exposes an interconnected web of power, policing, and exclusionary tactics with harmful repercussions-essentially making it illegal for sex workers to exist in either "public" or "private" spaces as defined by Western logic.

Situated within sex-positive feminist discourse and an ongoing infrastructural turn across disciplines, this thesis engages sex work as a lens through which to assess acceptable forms of intimacy within the space of the city, and to recognize numerous affective infrastructural networks that subvert dominant stigmas associated with the profession. The work seeks to examine the politics of visibility within the built environment by delving deeper into the notion of exposure as an analytic tool, explored through the production of a scripted performance in two spatial acts. These acts, as tools of exposure, express the plurality of space and ultimately ask how reframing oppressive narratives surrounding sex work and intimacy can offer new ways of existing in collective space. 


\section{Acknowledgements}

Thank you first and foremost to my advisor, Piper Bernbaum, for your invaluable guidance, encouragement, and friendship. Your willingness to work through the unknowns helped me to approach the work with conviction, and your honest and enthusiastic communication has pushed me further as a researcher, writer, and designer. I feel lucky to have had the chance to get to know and learn from you this year.

To my friends, both within and outside of the world of architecture, who always seem to call at just the right time-thank you for listening to my ideas, for sharing yours, and for supporting me through this strange year. I can't wait to see you all in person soon.

Thank you to Alena for being a constant source of inspiration and support, even from across the world. I'd be hard pressed to find someone else who "gets it" quite like you.

Thank you to Brendan, for the incredible patience and care that you showed me throughout the year. Thanks for acting as a sounding board as I worked through ideas, for being an extension of my brain when I hit a wall, and for making me laugh, always.

Lastly, thank you to my family for all of the sporadic video calls, the advice, the cookies in the mail, the knitting lessons, the proofreading, the much-needed distractions, and the neverending support you have shown me all my life. And, of course, for laughing at all of my "allyisms." I am inspired by all of you, every day. 


\section{Contents}

$\begin{array}{ll}2 & \text { Abstract } \\ 3 & \text { Acknowledgements } \\ 5 & \text { Glossary } \\ 8 & \text { Preface } \\ 13 & \text { Introduction } \\ & \\ 18 & \text { Part 01: Situating Theory and Sex Work } \\ 20 & \text { On Intimacy } \\ 25 & \text { On Infrastructure } \\ 28 & \text { On Sex Work and Spatial Politics } \\ 39 & \text { A Brief Timeline of Sex Work Laws in Canada }\end{array}$

Part 02: Sex and the City

45 Geographies of Control

$47 \quad$ Mapping Power

53 Recognizing Space and Place

Part 03: Intimacy as Infrastructure

69 Exclusion and Autonomy

73 Public Bodies

$78 \quad$ Acts of Exposure

$106 \quad$ Epilogue

110 List of Figures

114 Bibliography

117 Appendix I: Timeline of Sex Work in Canada 


\title{
Glossary
}

\author{
Action* The process or act of doing. / The space of encounter that forms the \\ exchange between space, bodies, and place. \\ Affect $^{*} \quad$ The site of embodied experience that influences thought and perception \\ while fundamentally forming relations. Highlighting a separation from \\ conscious knowing, affect shifts understandings of power to the realm \\ of experience, encompassing both aesthetic and political sites through \\ visceral attachment.
}

Canada The settler colonial state that serves broadly as the site for the work of this thesis. Indigenous peoples have lived, and continue to live, on the land that is presently known as Canada for thousands of years, and references to Canada imply ongoing processes of settler colonialism that continue to deeply impact lands and bodies within the country's borders.

Care An ethical and political space of action. / The radical act of compassion.

Desire A feeling of want, embodied through time.

Everywhere A quantification of limitless space.

Exposure* The process of making visible. / The act of uncovering the plurality of space.

Human Trafficking

A form of forced labour that often involves sexual exploitation and coercion. Trafficking differs fundamentally from sex work, and the terms are not interchangeable.

Infrastructure*

Material and immaterial networks that facilitate sociospatial patterns, and that imbue built and social forms with relational meaning. 
Intimacy

Marginalized

Performance

Power*

Protest

Sex Work
An intangible space understood through the affective connections between bodies, things, and places. / A figural relation and orientation onto which power is enacted and through which power is catalyzed.

Forced into a peripheral space or condition.

The outward expression of being that is formed by space. / The carrying out of an act in space, in turn activating place.

A lived space that has been activated through intimate connection.

A capacity for control that is operationalized through various forms of regulation and governance. The sources of power vary in their visibility, and it can manifest as domination and violence or can arise from the cultivation of knowledge and autonomy.

The term used in Canadian law to refer to the exchange of sexual services for money or goods. While used frequently in casual conversation, legislation, and academia, the use of the term in this thesis is limited to specific references to Canadian legislation or the words of Canadian lawmakers.

A tool for populations to mobilize and transgress public space to call for reform and recognition.

A consensual sexual exchange between adults for money or goods. This terminology specifically denotes that sex work is work, and remains a valuable and legitimate form of labour. The industry involves women, men, trans, and non-binary individuals. It can occur through a variety of methods and locations, including but not limited to escort work, stripping, street-based 
work, and domination, and work in brothels, massage parlours, the internet, and beyond. Sex workers often engage in multiple forms of work across physical and virtual territories.

Space* A pluralistic dimension of life that is inherently formed through distinct social structures and in turn negotiates action and perception.

Stigma A societal form of disapproval that reproduces structures of hegemony.

Third Party

Anyone involved in a commercial sex transaction who is neither sex worker nor client. Third parties can include someone who provides transportation or web space, an agency owner who handles scheduling, or someone who acts as a sex worker's safe call, among many others.

Violence* An act or entity, whether visible or intangible, that causes harm and is deeply tied to power structures. Violence remains a broad and vague category of understanding which must be traced to its spatial, political, physical, emotional, and/or systemic roots in order to be adequately addressed.

* these terms remain fluid as a result of their inherent plurality. The effort to define them is not intended to limit their broader scope, but rather to contextualize them within this work. 


\section{Preface}

"The ultimate mark of power may be its invisibility; the ultimate challenge, the exposition of its roots."

- Michel-Rolph Trouillot, Silencing the Past:

Power and the Production of History

The decision to begin this work with a quote from late Haitian anthropologist Michel-Rolph Trouillot's Silencing the Past is perhaps somewhat misleading, as his ideas do not explicitly manifest themselves elsewhere within this thesis. Nevertheless, his writing has offered me a gentle, persistent hum of guidance throughout the contemplative processes of researching, writing, and imagining that I have deeply embedded myself within. At its core, his book is a meditation on the inequalities of power-an exercise in tracing its imbalances to the source, in offering anatomized renditions of its role within the process of history-making, and in unmasking the relationship between knowledge and its representation. Through the reckoning of historical silences, Trouillot created a work of amorphous logic, simultaneously hyperspecific and timelessly universal. Likewise, I have engaged with various silences throughout the process of this thesis, recognizing both the ways in which hegemonic structures proliferate them, and the points that they threaten to enter into the argument I am portraying. I have returned to Silencing the Past numerous times, read and re-read its pages, and sought to consistently uncover new questions to ask of myself and of my work. And, unsurprisingly, this process of asking questions has always led to more questions. In many ways this thesis is simply a pursuit of endless questioning.

My initial ambition for this work was to investigate the area that has been claimed as the Canadian North. As thoughts on my thesis topic were forming, I was participating in a fellowship with the Canadian Centre for Architecture that involved research into the swimming pools of Nunavut and consequently 
the role of infrastructure in processes of settler colonialism. The geographic and cultural context of Nunavut was relatively unfamiliar to me, but I was poised to have a smooth continuity between this summer research and the coming thesis year. Not long into the fellowship did my two research colleagues-also Masters of Architecture students studying in Ontario-and I realize that we were working toward something larger than a simple inquiry into swimming pools. Our investigations led us to a place of deeply critical reflection on architectural research, practice, and pedagogy, namely on what it means to undertake these processes with a critical awareness of the ethical responsibilities that are often overlooked in design disciplines. Our work evolved into the production of an open-ended and collaborative syllabus, intent on unsettling power dynamics and identifying how they continually shape, and are shaped by, architectures and infrastructures.

It soon became clear that for me, as a settler of colour, to pursue research into an Indigenous culture I had not been invited to study nor would I be able to deeply engage with-both as the result of the ongoing global health crisis and the limited time-frame of the thesis year-would ultimately be deeply antithetical to my growing understanding of ethical practices. Soon the seamless transition that I had been expecting evaporated, leaving me with a nebulous array of interests and no subject to channel them toward. What followed was a long process of critical reflection as I sought to situate my agency, a process which ultimately led me to focus on sex work and the built environment. It is here that I would like to make some critical distinctions about the line of inquiry that stemmed from this process of critical reflection. I hope to outline my responsibility in addressing this topic by providing answers to a series of questions about my role and my intentions as they relate to conducting architectural research and studying the topic of sex work.

Why did I choose to engage with sex work as a topic?
I was not, from the onset, intent on addressing sex work and the built environment and looking for analytic lenses through which to do so. Rather, I was intent on addressing notions of infrastructure, power, intimacy, and affect within the context of the settler colonial territory presently known as Canada-a territory fundamentally formed by violent processes of silencing 
in both the past and present tense. My options as to how to address these topics were vague and varied, but my intentions were always oriented around questions of social and spatial justice.

Additionally, I have always been interested in the ways in which society seeks to control female sexuality and existence. My initial interest in sex work activism arose from a desire to expand my personal understandings through a sex-positive feminist lens, an interest that pre-dates my thesis work. It was only after reading a legal analysis of the legislation that governs sex work in Canada by Indigenous lawyer Naomi Sayers-in which she exposes the weaponization of space and power's invisible violencethat I began to understand the deep relationship between sex work and space. More specifically, I began to consider sex work as a lens through which these notions of infrastructure, power, intimacy, and affect could be understood in theoretical conjuncture, and with a pressing urgency.

Sex work also serves as a powerful lens through which to understand the nuanced patterns of heteronormative patriarchy and the ways they manifest in space, bias, and built form. I see sex work as a valuable and legitimate form of labour and actively support its decriminalization. I selected this thesis topic as a way of educating myself and my audience about both the theoretical background I am situating myself within and the work and struggles that sex work advocates engage with each and every day. I wanted to know who was asking questions about sexuality and space, how they were asking them, and what I could learn from their findings. The sheer volume of academic research into sex work is immense, but it is only recently that this research has been conducted through a spatial lens, let alone through an architectural one. The field within which this thesis work resides remains extremely narrow, and the work is a step in opening up new conversations about spatial justice while proposing productive critical lenses through which to understand the built environment. It seeks to uncover new understandings that can contribute to existing research on sex work and space, as well as on intimacy and infrastructure, and to bring established understandings into the architectural discipline. 
What are the power dynamics at play within this research?
I do not have lived experience as a sex worker. I do not viscerally understand what it means to do sex work; let alone what it means for sex workers with disabilities, or trans, queer, Indigenous, Black, Asian, cash poor, or migrant sex workers. I do, however, have lived experience as a woman of colour and thus as someone who has experienced objectification, fetishization, and marginalization throughout my life. When I speak of more equitable and inclusive cities, I am also speaking of cities that will better accommodate me and all others who have similar experiences.

Within architectural work there remains a critical distinction between proposing a solution and exposing a process. Throughout this thesis I situate myself firmly within the latter of these two methods, primarily as a result of my distance from the field. I do not seek to speak for anyone, but rather hope to posit a framework for working alongside those whose lives revolve around decriminalizing their survival. As someone pursuing a graduate degree, I recognize my immense privilege in engaging with these topics. I have made every effort to prioritize sources written, compiled, or produced by sex workers $-27 \%$ of my sources come directly from people who identify as either current or former sex workers. Yet I have also relied heavily on writings and theories by non-sex workers who are deeply embedded within Western worldviews. No matter how critical of this viewpoint many of these authors and I may be, we still cannot elide the formative origins of our words and ideas. We must inherently learn from that which we criticize, but we also have to imagine new forms that do not yet exist.

I have attempted to expose my role in this power structure in hopes of offering transparency and reassembling the silences that weave into and out of architectural work. The intent of this thesis is not to propose tactical design solutions to address the structural and visceral violence faced by those in the sex industry and beyond. Rather, its purpose is to recognize the states of compression and expansion enabled by the built environment; to analyze the gradations of publicity and visibility that constitute the city space of the everyday; and to question what an infrastructure of intimacy is and can be. I cannot provide solutions to this violence, but I can raise critical consciousness and put forth the conceptual tools to build new and alternate futures. 


\section{GET YOUR FUCKING LAWS OFF OUR BODIES}

We want the cops off our backs and out of our business. We want decriminalization. This means no anti-prostitute laws.

Decriminalization means we'd be allowed to work inside and to solicit on the street like politicians, encyclopedia salesmen, born again Christians and everybody else. It does not mean we'd be above the law; it means we'd have the same rights other people have.

Fig. 1

Statement from CORP (The

Canadian Organization for the

Rights of Prostitutes), which was

officially founded in 1983

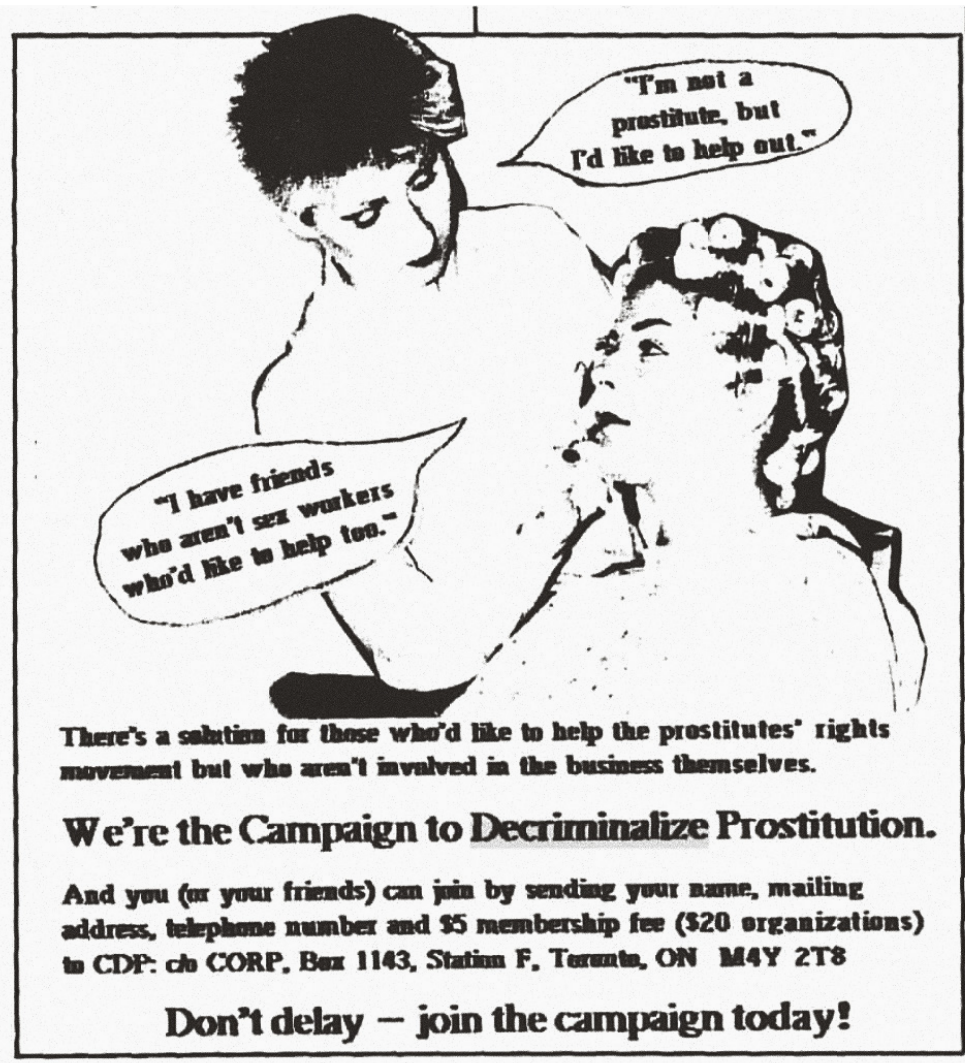




\section{Introduction}

In Canada, as in other colonized territories, power takes on ubiquitous forms; it constructs the fabric of the everyday from a thread of dominance that often goes unnoticed. These power structures shape the freedom of the public domain. Sex work is embroiled within these extractive structures; supremacy, domination, and capitalism stem from colonization and all work to keep marginalized populations in ever-liminal positions (figure 3). Understood as spatial phenomena, these power structures influence atmospheres of place and presuppose ontologies through access, aesthetic, and agency. This thesis utilizes concepts of infrastructure and intimacy to frame these relationships of power, and to address the laws, stigmas, and actions that govern sex work within city space. Although commonly conceived as private and personal, intimacy is deeply entwined with power structures that in turn have spatial repercussions. It works infrastructurally as an emancipatory tool for some but a limiting factor for others, a disjuncture that underlies much of the work of this thesis.

This thesis is both a project and a process. Situated within sex-positive feminist discourse, it is a deliberate contemplation on what it means to expose the roots of power and to conceive of past, present, and future world-making otherwise. It focuses on commonly held assumptions about sex work and intimacy while seeking to unfold, expose, and reconfigure them. It begins at the scale of ubiquity through the assessment of legal infrastructures, and seeps slowly into the saturated environment of bodily place, activating space through action and setting the scene for affective attachments. Through addressing sex work and spatial politics, it recognizes the ways in which power exists at numerous scales and levels of visibility, how it moves in multiple directions, and how it ultimately shapes the world we feel around us. 
The first section of the work, "Situating Theory and Sex Work," introduces the contextual basis of the thesis. It speaks of cultural hegemony by exposing the fallacy of many of the preconceived notions held about sex work and sex workers as portrayed in media and popular discourse. It then introduces foundational notions of infrastructure and intimacy, expanding beyond their commonly conceived definitions and exposing them as critical to the formation of space. Infrastructural networks and intimate connections constantly shift bodies and things into new social, material, and affective constellations, the likes of which exist at multiple scales and within multiple temporalities. Within this understanding, the first section speaks to the ways in which Canadian law (since colonization) has regulated how patterns of intimacy unfold, parsing apart specific legislations to expand upon the ways that space is weaponized through legal stricture.

The second section of the thesis, "Sex and the City," delves deeper into the ways that these hegemonic preconceptions and legal strictures play out tangibly within the space of the city. It begins first with a geographic assessment of sex work in Vancouver, Toronto, and Montreal, addressing the ways that mapping power exposes its multiple methods of enforcement in systemic confluence. It addresses the notion of 'everywhereness' to articulate the landscape of sex work in the city, harnessing Henri Lefebvre's theory of the three fields of space to analyze four spaces as they relate to sex work, and essentially fusing legal understandings with spatial production. The second section culminates in an assessment of the theoretical constructions of space and of place, recognizing that a shift toward the scale of the body is necessary in articulating a place-based analysis of intimacy.

The final section of the thesis, "Intimacy as Infrastructure," exposes the need to expand beyond solely conceiving of the violence enacted on sex workers, and instead to consider the landscapes of care and intimacy that the profession can enable. It shifts the conversation into the space of autonomy and visibility by reflecting upon notions of space and place, and the ways in which they facilitate action. The resulting response 
to these provocations is the production of a performance in two acts, actualized through scripts and drawings, that activate space and place. These acts acknowledge the multiplicity inherent in the infrastructures and built worlds of the everyday. As provocations rather than design solutions, the acts activate the space of the city through understandings of plurality and exposure through spatial narrative.

The dominant knowledge structures that are prevalent within architectural education and practice have the distinct capacity to enforce the Western, heteropatriarchal norm, and to render divergent practices as 'other'. This work seeks to express all that can be gained by fundamentally accepting 'otherness' and recognizing it as a fertile space to gain new perspectives. Alterity is often mobilized as a weapon as it moves consistently through the city's social structures-casting aside those whose actions and bodies do not fit within the traditional mould of heteronormative patriarchy-yet it also has the capacity to transform entrenched social orders. Accepting 'otherness' and thereby restructuring how sex work and intimacy are perceived is the essential goal of many sex work advocates who strive for safety and dignity for the marginalized. This thesis lies within these sexpositive understandings, with a recognition that new forms of collectivity are required to expose and embrace new ways of existing together. 


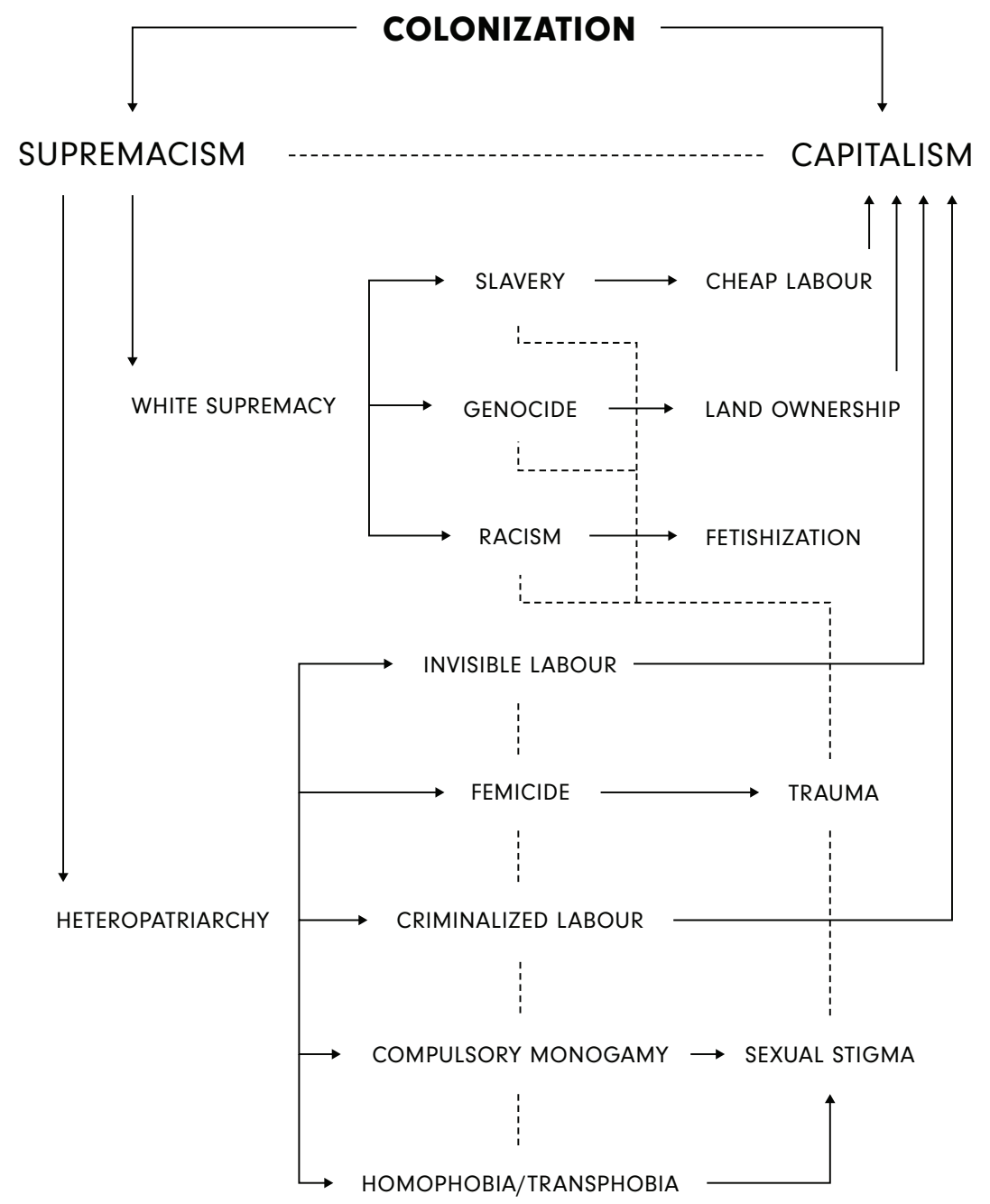

Fig. 3

Diagram expressing dominant power structures that stem from colonization 


\section{Part 01:}

Situating Theory and Sex Work 


\section{On Context}

This thesis deals with the wide and varied methods, locations, and people involved in consensual sex work. Beyond this section, it does not address human trafficking or sexual exploitation. Sex work is a consensual sexual exchange between adults for money or goods; trafficking is forced, exploitative, and/or coerced labour. The distinction between sex work and acts of human trafficking is critical, and their terminologies are not interchangeable despite their common conflation in both public and legal discourse. As has been shown time and again by both Canadian and international sex workers and sex work advocates, this conflation often undermines efforts to address the very real and critical human rights issues of trafficking. Funds and resources are continually put toward criminalizing sex workers by reinforcing policing and surveillance tactics instead of focusing specifically on traffickers. ${ }^{1}$ This heightened control furthers the stigma against those who choose to engage in sex work, thereby making their positions in society and space more marginalized.

The current Canadian legislation in place to regulate-read: eradicate-sex work, the Protection of Communities and Exploited Persons Act (PCEPA), contains both sex work and trafficking-related amendments which render sex workers as inherently exploited and their jobs as inherently violent. Perpetually depicting sex workers as victims removes them from the space of labour and autonomy, and places them instead in a space that sex worker rights activist and scholar Alex Tigchelaar characterizes as that of the 'viminal': "victim if one does not agree to be criminalized by the state, criminal if one does not agree to be victimized by the state, ever in a liminal position."2 Similarly, with the introduction of PCEPA in 2014, then-Minister of Justice and Attorney General of Canada Peter MacKay equated clients with "perpetrators, perverts and pimps, ${ }^{13}$ thereby reducing the very human pursuit of sexual intimacy to the level of exploitation, or more coarsely relating clients to traffickers. 
Victimized renditions are typically fraught with gendered presumptions and characterize sex workers as young and female, helpless to their exploitation. This depiction essentially negates the vast experiences of male, trans, and non-binary sex workers, as well as those of adult women. ${ }^{4}$ Additionally, the figure of the trafficked female oft-employed by governing powers embodies an anxiety about the erosion of national sovereignty. ${ }^{5}$ Understood within feminist scholar Sara Ahmed's articulation of "affective economies"-in which affect and emotion gain traction as they circulate across social and psychic fields ${ }^{6}$-this anxiety is reified by a populous who equates the movement of foreign bodies into and out of national boundaries as the dissolution of sovereignty. Citizens policing sex workers through stigmatic perception and vocal opposition often do so under the guise of care for the exploited, covertly working to secure a sovereign future free of foreign and deviant 'others'.

Viewing sex work as inherently exploitative and thereby conflating it with trafficking has been vehemently opposed by those whose lived experience and choices prove otherwise. The vast and varied methods and locations of sex work can be sources of independence and autonomy, however the Canadian government has yet to alter their stance or adjust the law. These laws are imminently spatial: they utilize space as a factor to control the bodies and working conditions of sex workers with a covert violence that is fundamentally shaped by skewed perceptions and portrayals of the profession. These violent intentions can be made no clearer than through the statement of Conservative Senator Donald Plett: "Of course we don't want to make life safe for prostitutes; we want to do away with prostitution. That's the intent of the bill."

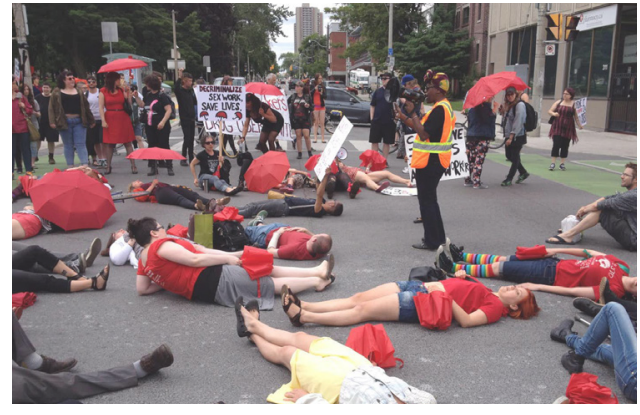

Fig. 4

Protestors gather in a Toronto intersection for a "die in" to honour missing and murdered sex workers 


\section{On Intimacy}

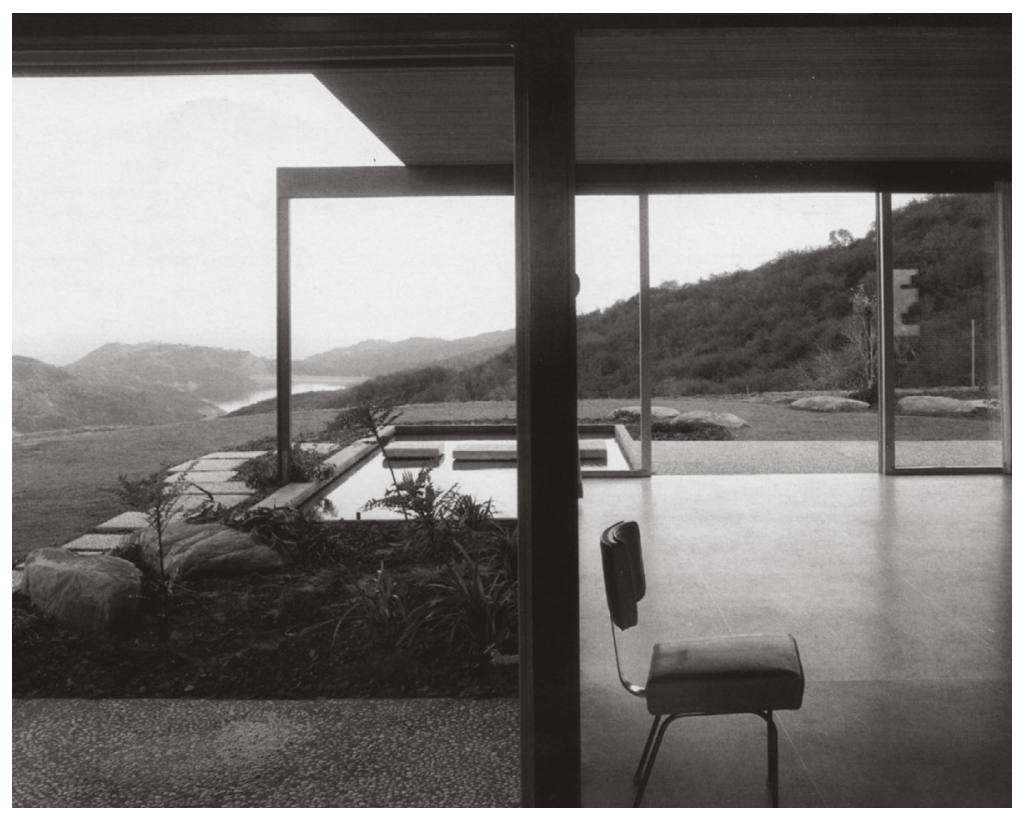

Fig. 5

Richard Neutra, Singleton House, Los Angeles, 1959

Intimacy is an intangible currency of contemporary life-it is real, felt, and coveted, but it is also ephemeral, shifting, and deeply powerful. Although often perceived as something private and proximate, intimacy extends fluidly into each facet of city space, forming social, material, and affective patterns that create the texture of everyday life. The common understanding of intimacy as something inherently internal, whether physically or mentally, has forged a divisive line between the private and public realms. This line is repeatedly realized through built form, creating a binary and often gendered separation between intimate and collective spaces.

Architectural historians have dealt time and again with notions of intimacy and the ways that intimate spaces have been designed and constructed. References to intimate space within prevalent analyses typically denote the domestic interior, understood as a space separate from that which exists in the public realm. The home itself is often considered a space of 
intimacy, while the bedroom constitutes the most intimate space of the home. Through this domestic lens, intimacy is often traced as it unfolds, choreographed through space, creating a dichotomous opposition to the publicity of the exterior.

This understanding has been attached to the work of many modern architects and the homes that they have designed. In professor and critic Sylvia Lavin's assessment of the work of architect Richard Neutra, she expands on the impact of psychoanalysis on the architect's postwar domestic projects, noting the cultivation of an eroticized domesticity that bleeds into outdoor space through window-wall corners. ${ }^{8}$ Intimate domestic space unfolds from the body into the environment, creating a gradation between the psyche, the house, and the open air. While the boundary between indoor and outdoor space in Neutra's homes becomes indeterminate, the interiority of intimacy remains intact as its locus oscillates between domestic space and the psyche. The work of Le Corbusier has also been understood through its intimate unfolding, notably seen within Pierre Chenal's 1929 film L'architecture d'aujourd'hui. In the film, Le Corbusier's epochal Villa Savoye becomes a backdrop for the sequential movement of a female figure. With her body fragmented and framed by the house itself, the architectural promenade shifts her from inside to out as she moves toward the roof garden and ultimately disappears from view. The perspective of the viewer is that of the voyeur, while the house itself serves as a vessel to contain the female character and enforce an intimate connection.

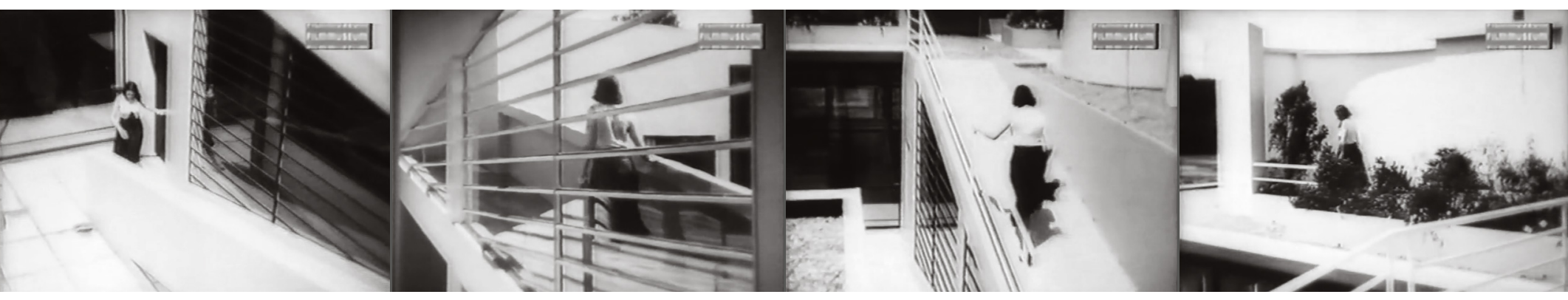

Fig. 6

Stills of Le Corbusier's Villa Savoye from film L'Architecture d'aujourd'hui (1929), directed by Pierre Chenal 

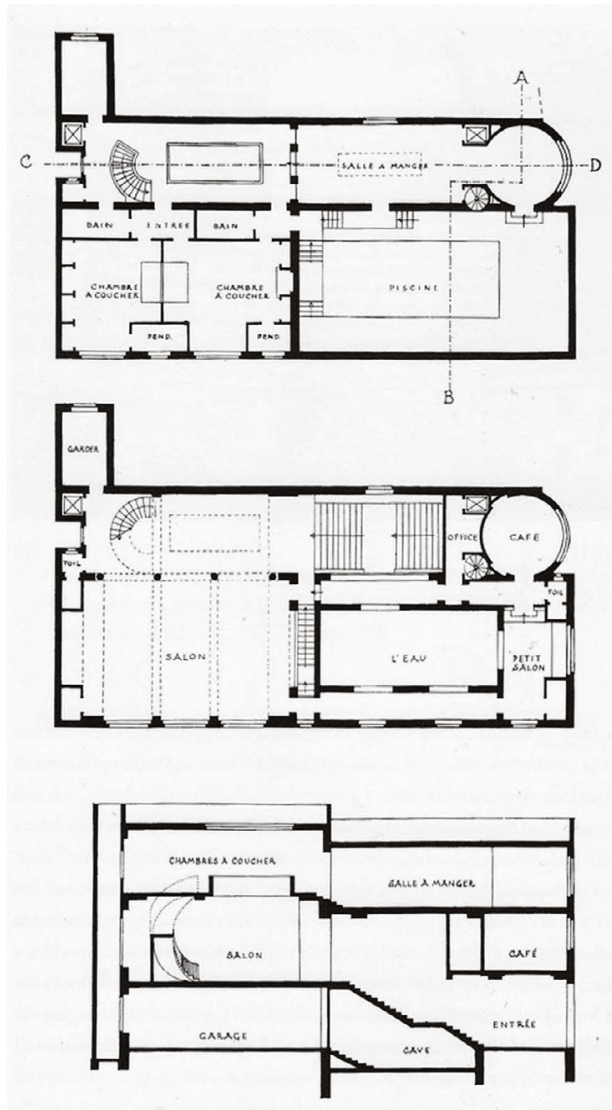

Fig. 7

Josephine Baker house plans

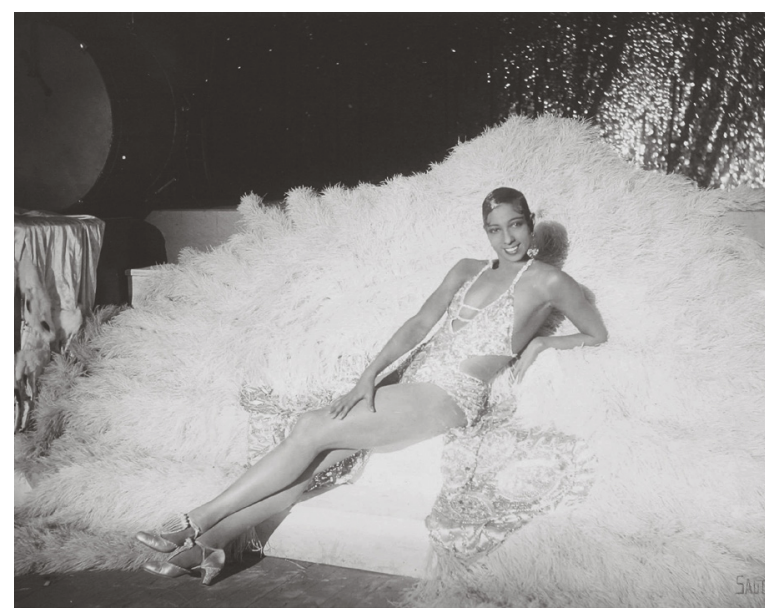

Fig. 8

Josephine Baker, France, ca. 1920s

Perhaps the most evocative example of this theoretical and spatial unfolding is within architectural historian Beatriz Colomina's assessment of the work of Adolf Loos. Colomina elucidates the cinematic and theatrical nature of this choreography through numerous examples of Loos' architectural work, but her analysis becomes particularly poignant in addressing the unrealized 1928 design of the Josephine Baker House. Baker was an entertainer, activist, spy, and queer Black woman whose life was complex and whose legacy persists well into the present day. Yet in Loos' unrealized house, she is distilled down to a sex symbol and an object of desire architecturally relegated to the most central and sensual space of the home: the swimming pool. A series of rooms surrounding the pool, and 
a skylight above it, hint at the fact that the house is meant less for Baker and more for watching her. Intended to operate as an erotic centrepiece swimming under the voyeuristic gaze, as if seen through a peep hole, Josephine Baker becomes an intimate and eroticized object existing solely in the space of saturated interiority and salacious visibility. ${ }^{10}$

While these and similar analyses are salient, they do little to expand the ways in which architecture may be able to broach the subject of intimacy in broader and more collective terms, and with more emancipatory outlooks. Intimate space in the architectural sense often becomes the space of vulnerability, introspection, and exposure, yet spaces designed to facilitated curated intimacies differ greatly from those organically created. Architectural understandings analyze intimacy as a separation, necessitating a contrast between bodies and gazes, and most critically between domestic and collective spaces. The question of what it is that makes the space of privacy and intimacy different from the space of the commons becomes an important one, for it is through this questioning that the fallacy of intimacy as synonymous with privacy comes to light. Space's inherent multiplicity means that any space can be activated through intimate attachment, regardless of its level of exposure. In expanding beyond the binary divisions between private and public life, this thesis seeks to question the slippery nature of intimacy and its capacity to erode the present limits of sociality, at the same time recognizing the marginalization imposed on its non-normative expressions.

The notion of unfolding, elaborated on in the architectural sense, can also be mobilized to understand new forms of intimacy and their capacities to imagine the world otherwise. As Sara Ahmed notes:

The starting point for orientation is the point from which the world unfolds: the 'here' of the body, and the 'where' of its dwelling. Given this, orientations are about the intimacy of bodies and their dwelling places. If orientations are about how we begin from 'here', then they involve unfolding. At what point does the world unfold? ${ }^{11}$ 


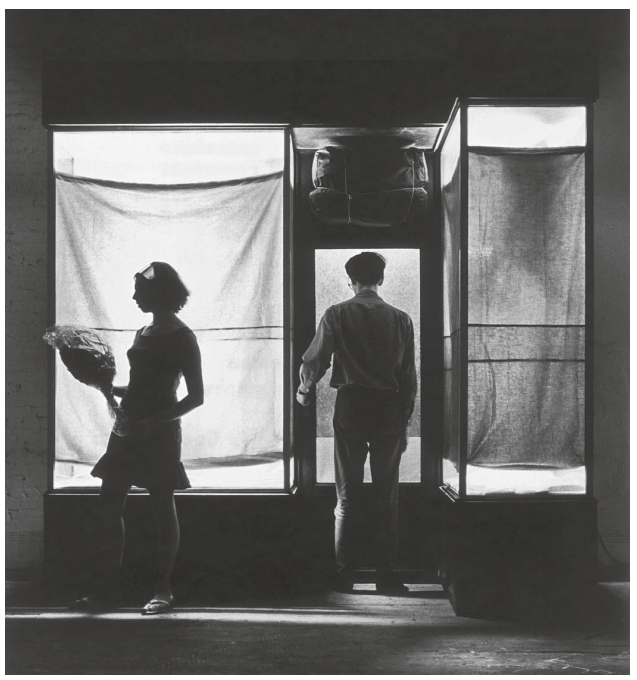

What this thesis interests itself in is the ways in which intimacy remains either a binding or divisive factor of collective life, and by recognizing intimacy as a locus of power we are required to ask these and similar questions:

Where does intimate interiority extend from, and what are its limits? How can we make space for the complexity of intimate expressions? How do we cultivate new forms of collectivity that are inherently intimate? And how can intimacy lead to new ways of existing in space? For, if we consider the words of theorist Lauren Berlant, "intimacy builds worlds; it creates spaces and usurps places meant for other kinds of relation."12 How can we foster this world-building?

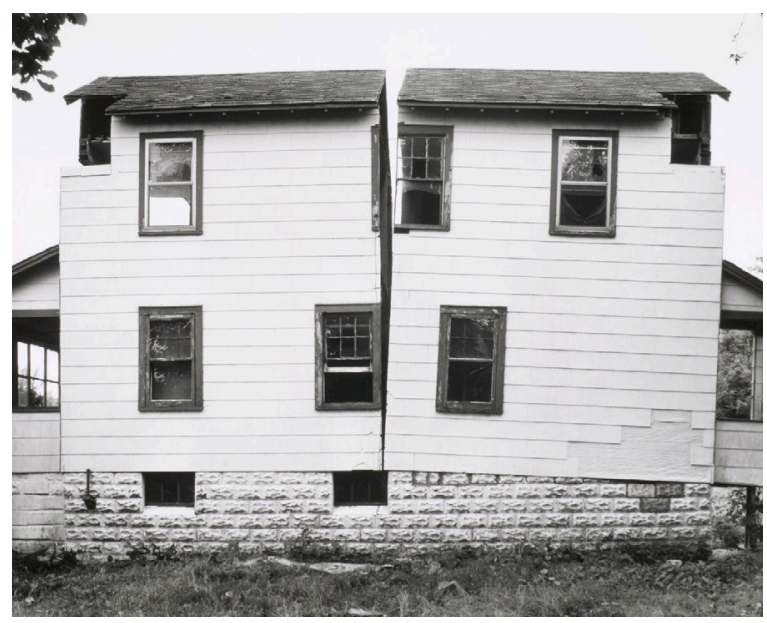

Fig. 10

Gordon Matta-Clark, Splitting (1974) cracks open domestic space

Fig. 9

Christo and Jean-Claude in Christo's

studio, in front of "Green Store

Front, 1964), 1966. The work hints

at ambiguous relationship between

private and public space 


\section{On Infrastructure}

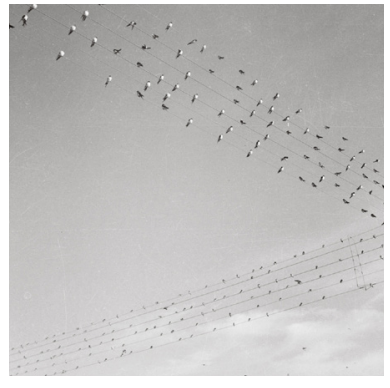

Fig. 11

Jeet Malhotra, 1951-61

Birds on telephone wires,

making visible the thin lines of connection
Theoretical frameworks surrounding intimacy as a field of power resonate with queer and feminist scholarship ${ }^{13}$ and become particularly potent when considered alongside critical analyses of infrastructure. These queer and feminist understandings bring up the "who" of infrastructure: who is impacted, who benefits, and who is disadvantaged? ${ }^{14}$ Since the 1980 s the concept of infrastructure has come to take on a myriad of new, charged meanings that aim to address these questions. Infrastructure is now largely understood and theoretically constructed as not just latent object, but rather as active element in the built environment and the political formation of space. The divisive capacity of infrastructure can be seen in the material manifestation of things like roads, bridges, sewers, and telephone lines, but can also resonate deeply through intangible systems. Legal infrastructures, although unseen, reinforce a particular status quo yet create dynamic shifts for those whom they disenfranchise, while affective infrastructures govern sociality itself through the regulation of intimacy and collectivity. ${ }^{15}$

While there has been a recent influx of literature on the ethnographic, anthropological, geographic, and sociological studies of infrastructure, there remains no cohesive definition of the term-and the same can be said of intimacy. As a premier scholar of infrastructural politics, Susan Leigh Star wrote that infrastructure "is both relational and ecological-it means different things to different groups and it is part of the balance of action, tools, and the built environment, inseparable from them."16 Star's definition implies that infrastructures are both relational and situational, and that the bonds between their constituent parts are fragile. Another pertinent definition comes from Canadian technoscience studies scholar Michelle Murphy, who defines infrastructures as "spatial arrangements of relationships that draw humans, things, words and non-humans into patterned conjunctures. ${ }^{\prime 17}$ Focusing not on form but rather on convergences, Murphy's definition also allows for infrastructure to be understood as inherently relational. Furthermore, this relationality can be grasped through 


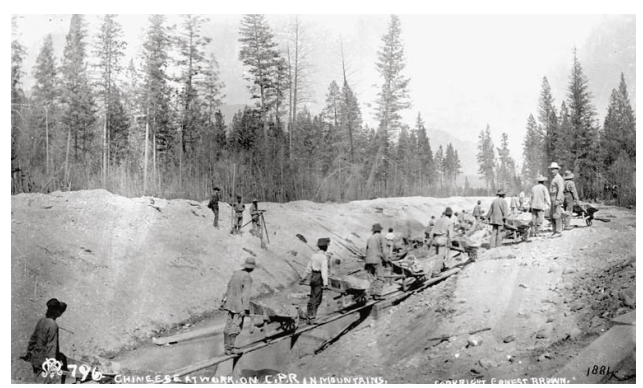

Fig. 12

Workers constructing the Canadian

Pacific Railway the understanding that infrastructures can be seen as 'things' that enable the operation of other 'things'-objects, emotions, or otherwise-and they thus create dynamic and symbolic systems with the innate capacity to uphold particular social orders. In essence, space is scripted through the presence of infrastructures.

While the physical and material traces of infrastructure can have noticeable effects on the construction of social space, exposing the relationality of tangible and intangible forms enables infrastructure to breach the threshold between privacy and publicity as conceived by Western logic. Infrastructure becomes a way to assess the unraveling of the ideologically-constructed private into the public, to puncture its divisive walls, and to turn interiority inside-out. It becomes a conceptual and practical vehicle through which to understand the plurality of built and social spaces, and a very tangible rubric to unpack the binding attachments that we have to the world and how we move through it-not to mention how the world remains bound to itself. ${ }^{18}$

In thinking through conceptions of infrastructure in Canada, it is important to consider the linear history of the country's settler colonial construction. Infrastructure has always been the "how" of settler colonialism, ${ }^{19}$ from the early colonial construction of the Canadian Pacific Railway to the ongoing pipeline projects that seek to carve up unceded Indigenous territories. But these settler colonial transgressions also come in smaller and less tangible forms, and sex work legislation serves as an apt example. The 2013 introduction of Bill C-36 (also known as the Protection of Communities and Exploited Persons Act (PCEPA)) by the Canadian government shifted Canadian sex work legislation toward a system that technically legalizes selling sexual services, but makes it increasingly difficult to do so. While sex workers themselves are no longer technically criminalized under Bill C-36, their clients and other related parties are; so while the law attempts to uphold the hegemonic fantasy of a sex workfree world, there are real people whose livelihoods and existences are under constant attack. Compounded by the fact that Indigenous women are overrepresented and criminalized as sex workers in Canada, ${ }^{20}$ it 
becomes difficult to see these laws as anything but the reinforcement of patriarchal, white supremacist ideology and spatial planning, deeply bound to the settler colonial project. More broadly, the infrastructures implicated in spaces of sex work come in obvious and invisible forms. This thesis deals largely with the intangible systems of the law, the likes of which aim to maintain visible order for some but to criminalize the labour of others, but also with the aesthetic and material dimensions of everyday infrastructures and their capacities to shift bodies in space. It speaks both about infrastructures and about thinking infrastructurally, which necessitates adopting a sex-positive feminist conception of built and intangible spaces and places.

While the power relations enacted by infrastructure are quite often hidden from view (as infrastructure is, by virtue, invisible for those whom it serves) ${ }^{21}$ their capacities to shape histories, delineate access, and further an agenda are palpable. Within these understandings, there is also room to reappropriate infrastructures, or to repurpose them to enable a range of intimate attachments; "pipelines can carry fresh water as well as toxicity." ${ }^{22}$ How can we (re)activate infrastructure as a social and political tool to imagine and create other forms of living? How can infrastructural networks, which remain invisible for those whom they serve, become exposed as conduits that further the distance between the privileged and the marginalized? And more generally, what do we gain from calling something infrastructure, or characterizing it as infrastructural? 


\section{On Sex Work and Spatial Politics}

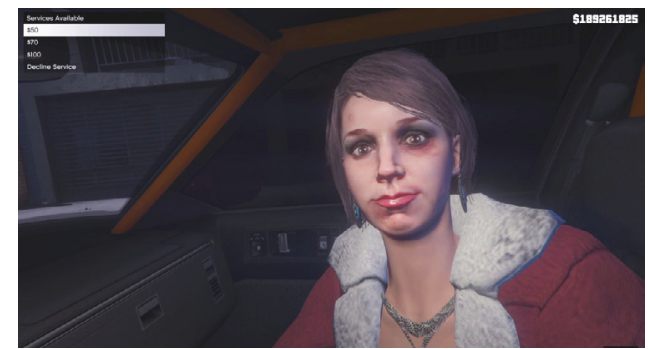

Fig. 13

Sex worker as victim of violence in Grand Theft Auto

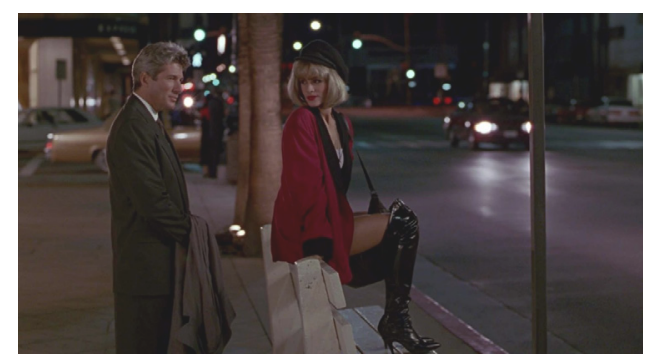

\section{Fig. 14}

A sterile and sugar-coated portrayal

of sex work in Pretty Woman

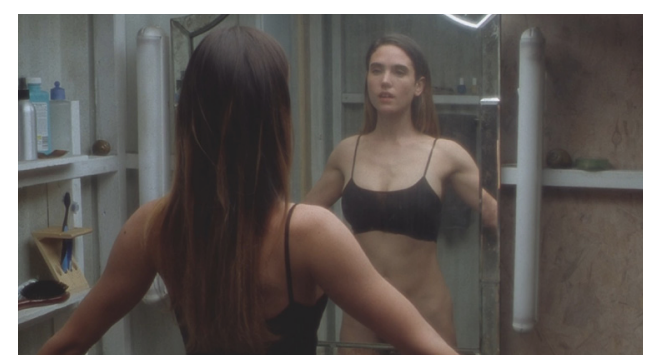

Fig. 15

Sex work portrayed as a means

to fuel drug addiction in Requiem for a Dream
The intersection of infrastructure and intimacy, and thus the disruption of commonly-conceived divisions of intimate and collective space, become palpable when associated with sex work. Understood as the exchange of goods or money for sexual acts between consenting adults, sex work remains a dangerously stigmatized profession and both physically and legally marginalizes those who benefit from it. It activates the infrastructure of the city through intimate connection while also depriving sex workers of any truly private space, as even their homes are subject to legal surveillance. Within this legal framework, educator and community organizer Red Schulte exposes this 'fantasy' of private space by referring to it instead as 'limited-intimate' space, noting that so long as aspects of sex work remain criminalized, the terms of privacy remain fundamentally limited..$^{23}$ Blurring the boundary between public, private, and virtual spaces, sex workers occupy and reinvent place depending on the presence of other actors such as clients, friends, or police. The inherent spatiality of sex work actualizes concrete and abstract barriers that ultimately play a role in weaving the fabric of the city.

Hollywood depictions of the profession often fail to grasp the vast and varied lived realities of many sex workers, whose lives and bodies exist beyond simply what they do to make money. Sex workers are typically portrayed as either objects of affection who ultimately get saved by heterosexual love, ${ }^{24}$ or as drug addicts or victims of violence whose lives are destitute. The sources of these parochial portrayals are extensive. Video games such as Red Dead Redemption and Grand Theft Auto have offered various forms of rewards for kidnapping, murdering, and abusing sex workers, ${ }^{25}$ while similar narratives of abuse and physical violence-commonly referred to as the 'disposable sex worker trope'-often anchor crime dramas or serve as the punchline in dark comedy. These cinematic depictions, in which sex workers are often nothing more than clichés or plot devices, perpetuate prevalent stereotypes that reinforce 
discriminatory understandings of the profession while reinforcing trenchant ideas of morality. In more severe terms, these portrayals depict violence, precarity, and marginalization as inevitabilities that go hand in hand with the job. Common across all of these depictions is the fact that sex workers are typically characterized as social and spatial outcasts, and their presence signifies the fringe or edge of dignified and proper urban space. These stereotypical understandings are, of course, fundamentally damaging and limiting. 'Liminal' spaces are often only liminal insofar as they are stereotypically perceived to be. The presence or absence of certain infrastructure is often a determining factor in how these liminal spaces are both socially and spatially constructed, creating a reciprocal relationship between stereotypes and marginality. Furthermore, while some do turn to sex work as a result of restricted options due to a wide variety of circumstances, the issue is not the choice they have made to engage in sex work but rather the socioeconomic factors that have limited their options for alternative sources of work. Perpetual victimization through these stereotypical representations fails to encompass the fact that sex work can be an incredibly empowering and lucrative job. No matter the reason that someone decides to engage in sex work, their working conditions should be embedded with safety, dignity, and autonomy that is not often afforded in stereotypical renditions.

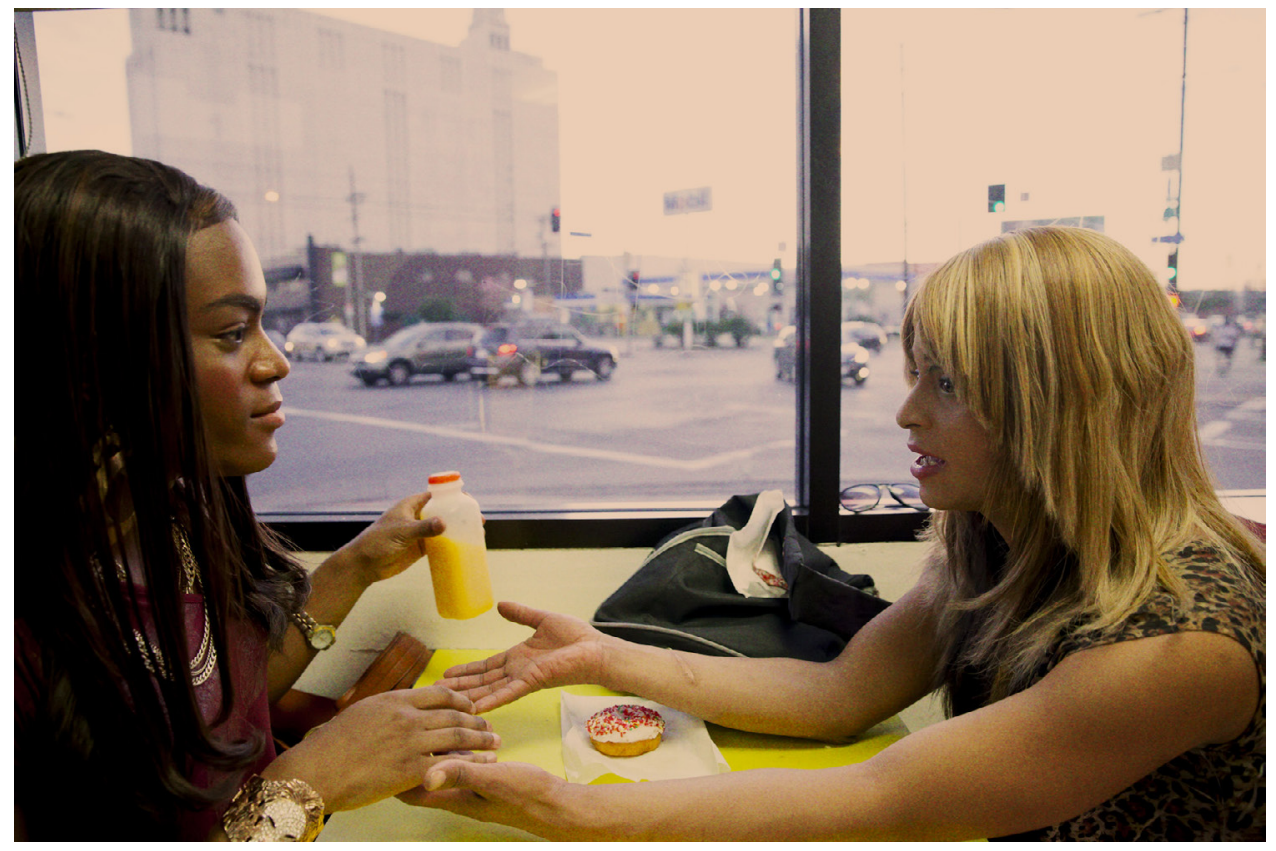

Fig. 16

Tangerine main characters sit in a Donut Time, against a backdrop of infrastructural space 


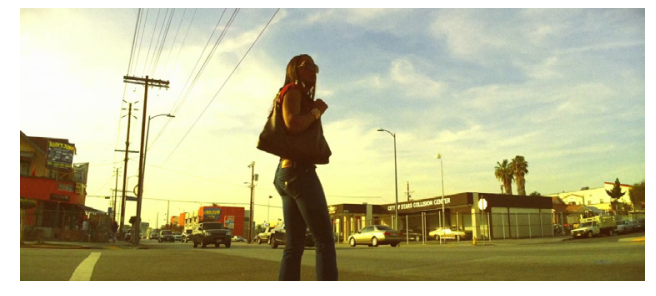

Fig. 17

Tangerine implicates

infrastructure in its portrayal of marginalized sex workers
Among the depictions more positively received by sex workers is Sean Baker's film Tangerine, commended by sex work advocate Siouxie $Q$ for its humanized portrayal of marginalized sex workers and its focus on community and camaraderie-tools that she notes are essential for sex worker survival. ${ }^{26}$ Tangerine follows Sin-Dee Rella and Alexandra, two Black, trans sex workers, as they navigate through the city and occupy a host of public spaces: a Donut Time, a nightclub, a car wash, and a laundromat, to name a few. The use of public infrastructures in Tangerine is particularly pertinent in bridging the gap between built and social forms. It is through Sin-Dee Rella and Alexandra's occupation of these material and infrastructural spaces that we can begin to recognize the flow of capital and the circulation of dreams amidst the racialized and gendered backdrop of everyday space. ${ }^{27}$ Tangerine's infrastructural entanglements-the structures, systems, and networks of transportation, communication, and pleasure-link "blow jobs to urban planning and capital accumulation, revealing how official intentions can be betrayed by a plurality of uses, including the way men, transwomen, and sex workers repurpose public spaces for sexual transactions. ${ }^{28}$ This plurality of uses is essential to an infrastructural analysis.

While popular media's role in the formation of cultural hegemony is undeniable, the intangible infrastructures of the law also play a major part in actualizing stratification. Globally, there are four prominent legal models that exist to regulate sex work: criminalization, legalization, decriminalization, and the 'Nordic model' which aims to criminalize the purchasing, but not selling, of sexual services. ${ }^{29}$ The vast majority of sex work advocates support decriminalization, which differs from legalization and criminalization in that it involves the total removal of criminal penalties from sex work rather than its legal regulation or outright prohibition. As a recent adopter of the Nordic model-based legal framework Bill C-36 (also known as The Protection of Communities and Exploited Persons Act (PCEPA)), Canada has become potent example of the disjuncture between politics and sexual acceptance; and this disjuncture runs deep. Canada's first 'anti-prostitution' laws were amended to the Indian Act in 1879 and specifically sought to regulate and police 
the bodies of Indigenous women-a distinct form of colonial social control aimed at limiting the role of the Indigenous woman within settler society. ${ }^{30}$ One such Act provision read:

If any person, being the keeper of any house, allows or suffers any Indian woman to be or remain in such house, knowing, or having probable cause for believing, that such Indian woman is in or remains in such house with the intention of prostituting herself therein, such person shall be deemed guilty of an offence against this Act... ${ }^{31}$

The ambiguities inherent in this Act were intentional and illustrated Indigenous women as criminal not as the result of "prostituting themselves" but rather as a result of having the intention to do so-with intention being an incredibly subjective tool. It is also important to note that these sections of the Indian Act were revised numerous times and were eventually inserted into the Criminal Code, creating a regulatory lineage that seeps into the present day. ${ }^{32}$

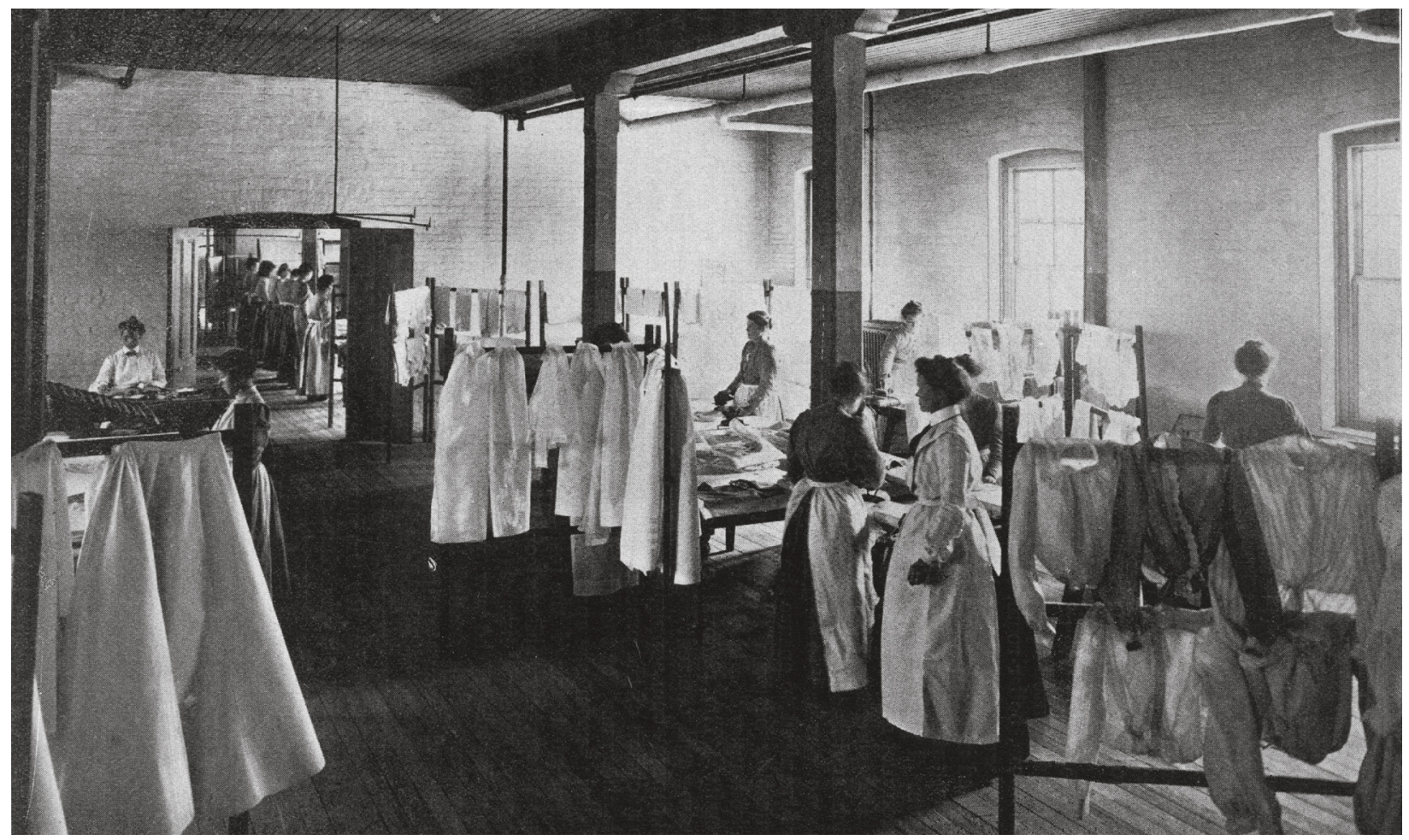

Fig. 18

The laundry room at Toronto's Mercer Reformatory for Women, an institution that aimed to "save" sex working women through prayer, hard labour, and punishment. 
The intentional vagueness of the Indian Act legislation resonates with numerous instances of anti-sex work laws that have existed since. Figures 19-23 outline five such laws which both use and have used space as a tactic of exclusion:

The Vagrancy Act (figure 19) made it allowable for police to arrest a woman if she "could not give a satisfactory account of herself"33 when in a public space. Notably, this law focused its attention on the bodies of street-based workers, and both the definition of space and of personal conduct were left violently vague. Bill C-49 (figure 20) made it an offence to buy or sell sexual services in any 'public place', but a public place also included any space accessible only by invitation. A 'public place' therefore included spaces typically considered to be within the private realm, such as a hotel, a car, or even a sex worker's home. As has been noted, the division between privacy and publicity for the sex worker is rendered nonexistent. Keeping a Common Bawdy-House (figure 21) was one of the prominent provisions struck down prior to the introduction of the current legislation, Bill C-36. The provision prohibited the operation or occupation of common bawdy-houses, defined as "a place that is kept or occupied, or resorted to by one or more persons for the purpose of prostitution or the practice of acts of indecency. ${ }^{134}$ Again, a 'public place' becomes a loosely-defined space that is defined solely by its repeated occupation, while a 'practice of indecency' was, again, a subjective tool. The Communicating provision (figure 22), also struck down prior to the introduction of Bill C-36, prohibited public communication between sex workers and their clients. Here, the public becomes the space of visibility, a safety tool used by sex workers to screen their clients, and yet the intent of the provision was to limit these safety measures. Finally the current legislation, Bill C-36 (figure 23), although heralded as an effort to 'help' sex workers, is no exception to this lineage. While Bill C-36's alleged aim is to prevent sexual exploitation, the actual impact of the Bill is the marginalization and dehumanization of sex workers. Those who buy or sell sex remain perceived as community outsiders whose invisibility is key to the functioning of public space, and Bill C-36 seeks to make it legally impossible for sex workers to exist in either public or private places. 


\section{Vagrancy Act (1867-1972)}

$$
-14-
$$

only to the night walker.

We would recommend that prostitution be dealt with as a health and social problem, not as a criminal offence.

2. Vagrancy

Section 164 (1)(a)

This section makes it a criminal offence for anyone, male or

female, found wandering without any visible means of support - all equation of poverty with crime. This is totally unacceptable to us. We are particularly concerned about the consequences of enforcing this law as it affects young women. A young person who leaves home, without adequate support, may be trying to break away from an unhealthy, unhappy home situation. It may be that she is going through an unhappy, disturbed adolescent period in which she is trying to find out who she is and where she belongs. An arrest and trial may well convince her that she is "no good" and belongs with the so-called "criminal group" even though she may not be found guilty. If she is found guilty, she now carries the added burden of having a criminal record.

We support the suggestion in the Ouimet Report that Canadian society should be "developing alternate social resources for women, particularly for young women who are without lodging or visible means of support under health or welfare, rather than correctional auspices".

Fig. 19

Excerpt from letter by the National Ad Hoc Action Committee on the Status of Women in Canada, to the Government of Canada, 1972 
Bill C-49 (1987-1990)

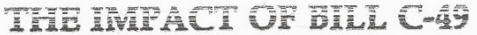 ON STREET FROSTIUTION: "WHAT'S LAW GOT TO DO WITH IT?"
}

\author{
Sneliagn $u$ connei"
}

"...the legislation deals with the problem of soliciting for the purposes of prostitution in public places. It does not pretend to deal with anything but the probiem of street soliciting; the nuisance caused to ordinary members of the public."

Hon. John Crosbie, Minister of Justice and Attorney-General of Canada, Opening Statement to the Legislative Committee on Bill C-49, Oct. 10, $1985^{i}$

"Those who are obsessed by a frenzy for legislative measures achieve contentment and futility. The slow way is the only way here: education, a changed social outlook, a gradual reorganization of economic conditions, these may remove such causes as are within our control."

Teresa Billington-Greig,

on the passing of the 1912 Criminal Law Amendment Act to expand prostitution laws under the Code, $1913^{2}$

\footnotetext{
* Copyright (c) 1988 Shellagh $O^{\prime}$ Connell. Shellagh $\sigma^{\prime}$ Connell is a student at Osgoode Hall Law School in Downsview, Ontario. This paper was written for the Intensive Program in Poverty Law and is published here as part of the special arrangement which the journal has with that program. As part of the program, students work at Parkdale Community Legal Services in Toronto, Ontario. Selected papers written by students in the program are reviewed by the Journal for possible publication.

I Canada, House of Commons, Minutes of Proceedings and Exidence of the Legislative Committee on Bill C-49, Issue 1:12 (10 October 1985) Hon. John Crosbie,

2 Teresa Billington-Greig, "The Truth about White Slavery" (1983) 14 English Review $428-429$.
}

Fig. 20 
Keeping a Common Bawdy-House (1867-2013)

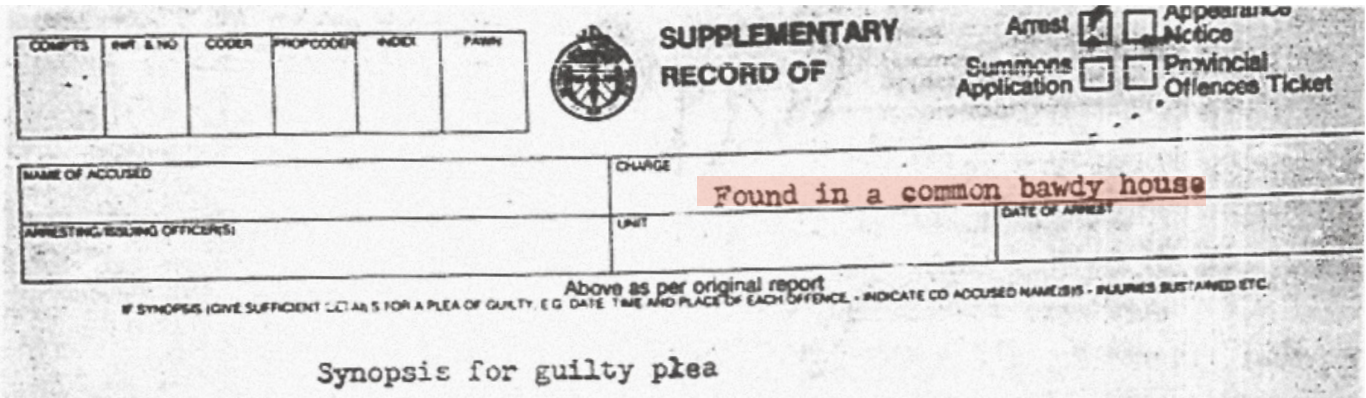

For six months ending February 5/81 Undercover IX Police Officers took observations inside the prems ses known as the Romans located at 742 Bay St. While on the premises the officers observed acts of indecency, aral sex, buggery and group sex taking place in the open. While on the premises the officers were also sollixted by male prostitutes who offered acts of sex for a fee. On Pebruary $5 / 81$ a disorderly house search warrant was executed on the premise-. The accused man was one of several men found on the premises. The accused had no lawful. excuse for being on the premises. In order to gain admission to the premises patrons were required to rent either a room or a locker for a fee.

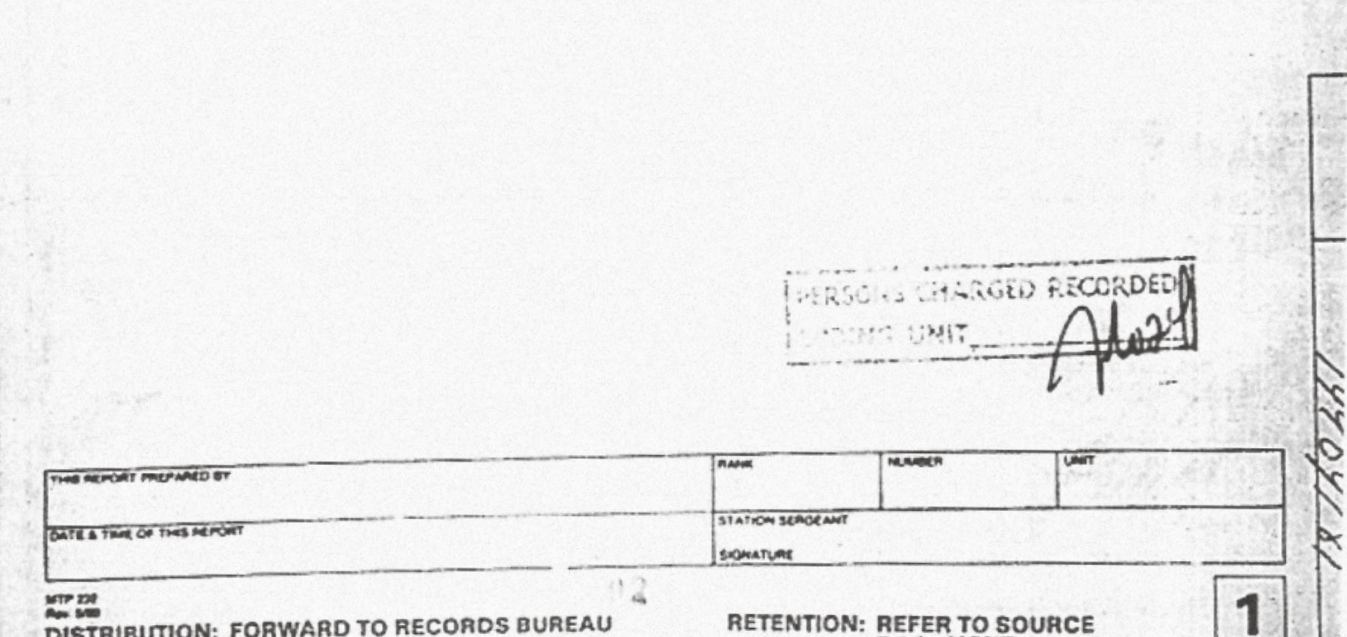

Fig. 21

Police record of a bawdy-house arrest 


\section{Communicating (1867-2013)}

sanction. Prostitution, including legal out-call work, may be made less dangerous if a prostitute is allowed to hire an assis tant or bodyguard, yet such business relationships are illegal under s. 212(1)(j). Finally, s. 213(1)(c) prohibits street prostitnted, who are largely the most winerable prostitutes and who face an alarming amount of violence, from screening their clients at an early stage of a potential transaction, thereby putting them at an increased risk of violence.

The impugned provisions, acting in concert, are arbitrary. Sections 210 and $212(1)(j)$ are overbroad. The effects of the impugned provisions are grossly disproportionate to identified state interests. The deprivations of liberty and security of the person are not in accordance with the principles of fundamental justice.

The violation of $s .7$ of the charter is not justified under s. 1 of the Charter. The provisions are not proportionate and do not minimally impair the applicants ' rights to liberty and security of the person.

The prohibition on communicating for the purpose of prostitution in s. 213 (1)(c) of the code is a prima facie infringement of $\mathrm{s} .2(\mathrm{~b})$ of the charter. The language of $\mathrm{s}$. $213(1)(c)$ is broad enough to capture communications that serve to screen customers for safety purposes. The objective of $\mathbf{s}$. $213(1)(\mathrm{c})$ is to control the social nuisance associated with street prostitution. Section $213(1)(c)$ is rationally connected to the objective of controlling the social nuisance associated with street prostitution. However, it does not minimally impair freedom of expression, and its minor salutary effects are substantially outweighed by its deleterious effects. Section $213(1)(c)$ is not saved under s. 1 of the Charter. [page323]

Striking the impugned provisions would not leave a legal vacuum. There are a number of legal provisions capable of addressing many of the harms associated with prostitution. The danger faced by prostitutes greatly outweighs any harm which may be faced by other members of the public. A temporary suspension of a declaration of invalidity would not be appropriate. However, a stay of up to 30 days was granted to 


\section{Bill C-36 (PCEPA) (2014-Present)}

6

C. 25
Criminal Code

62-63 ELIZ. II

voyeuristic recording or the advertisement of sexual services available, the court shall order that the electronic copy be returned to the custodian of the computer system and terminate the order under paragraph $(1)(b)$.

2012, c. 1, s.21 8. Paragraph 171.1(1)(a) of the Act is replaced by the following:

(a) a person who is, or who the accused believes is, under the age of 18 years, for the purpose of facilitating the commission of an offence with respect to that person under subsection 153(1), section $155,163.1,170$, 171 or 279.011 or subsection $279.02(2)$ 279.03(2), 286.1(2), 286.2(2) or 286.3(2);

2012,c.1, 9. Paragraph 172.1(1)(a) of the Act is replaced by the following:

(a) a person who is, or who the accused believes is, under the age of 18 years, for the purpose of facilitating the commission of an offence with respect to that person under subsection 153(1), section $155,163.1,170$,

171 or 279.011 or subsection $279.02(2)$ 279.03(2), 286.1(2), 286.2(2) or 286.3(2);

2012, c. 1, s.23 10. Paragraph 172.2(1)(a) of the Act is replaced by the following:

(a) under subsection 153(1), section 155 , $163.1,170,171$ or 279.011 or subsection $279.02(2), 279.03(2), 286.1(2), 286.2(2)$ or $286.3(2)$ with respect to another person who is, or who the accused believes is, under the age of 18 years;

2004, c. 15, 11. (1) Subparagraphs $(a)(\mathbf{x \times x v})$ to (xxxviii) of the definition "offence" in section 183 of the Act are repealed.

(2) The definition "offence" in section 183 of the Act is amended by adding the following after subparagraph $(a)(i i)$ :

(lii.1) 286.1 (obtaining sexual services for consideration),

(lii.2) 286.2 (material benefit from sexual services),

(lii.3) 286.3 (procuring),

(lii.4) 286.4 (advertising sexual services), pornographie juvénile, l'enregistrement voyeuriste ou la publicité de services sexuels accessible, il doit ordonner que la copie électronique soit remise au gardien de l'ordinateur et mettre fin à l'ordonnance visée à l'alinéa (1)b).

8. L'alinéa 171.1(1)a) de la même loi est remplacé par ce qui suit :

a) à une personne âgée de moins de dix-huit ans ou qu'il croit telle, en vue de faciliter la perpétration à son égard d'une infraction visée au paragraphe 153(1), aux articles 155 , $163.1,170,171$ ou 279.011 ou aux paragraphes 279.02(2), 279.03(2), 286.1(2), 286.2(2) ou $286.3(2)$;

9. L'alinéa 172.1(1)a) de la même loi est remplacé par ce qui suit:

a) une personne âgée de moins de dix-huit ans ou qu'il croit telle, en vue de faciliter la perpétration à son égard d'une infraction visée au paragraphe 153(1), aux articles 155 , $163.1,170,171$ ou 279.011 ou aux paragraphes 279.02(2), 279.03(2), 286.1(2), 286.2(2) ou 286.3(2);

10. L'alinéa 172.2(1)a) de la même loi est remplacé par ce qui suit :

a) soit une infraction visée au paragraphe 153(1), aux articles $155,163.1,170,171$ ou 279.011 ou aux paragraphes 279.02(2), 279.03(2), 286.1(2), 286.2(2) ou 286.3(2), à l'égard d'un tiers âgé de moins de dix-huit ans ou qu'il croit tel;

11. (1) Les sous-alinéas $a)(\mathrm{xxxv})$ à (xxxviii) de la définition de «infraction », à l'article 183 de la même loi, sont abrogés.

(2) La définition de «infraction », à l'article 183 de la même loi, est modifiée par adjonction, après le sous-alinéa $a$ )(lii), de ce qui suit :

(lii.1) l'article 286.1 (obtention de services sexuels moyennant rétribution),

(lii.2) l'article 286.2 (avantage matériel provenant de la prestation de services sexuels',

(lii.3) l'article 286.3 (proxénétisme), 2012 , ch. 1,
art. 21

2012, ch. 1,

par. $22(1)$

2012 , ch. 1,
$\operatorname{art} .23$ art. 108

Fig. 23

Excerpt from Bill C-36

The current legislation is essentially a culmination of old legislations, repackaged 
Within these legislative strictures, space and place are activated as loci to be controlled, and as tools to control the female body. These laws are eminently spatial, as space can be understood as both fundamentally constructed by social and political forces, and fundamentally constructive of social life. These laws tap into the material and affective dimensions of space concurrently, accessing it both within physical locations and in the abstract and omnipresent 'any place'. The power of these and other laws is not only their capacities to affect a particular order through their enforcement, but also their lasting effects. This power becomes located and felt at numerous temporalities and scales: that of the city, of place, and of the body, each considered as sites upon which an exchange is made.

Activists and scholars have opposed Bill C-36 since its inception. Based on the Nordic model and introduced in 2014 after the Supreme Court of Canada struck down three provisions for being in violation of the Canadian Charter of Rights and Freedoms, the Bill prohibits purchasing, advertising, communicating about, or receiving material benefits from sexual services. ${ }^{35}$ While it claims to protect sex workers, it is in effect simply a recalibration of the numerous laws that existed before it that sought to render sex work invisible, immoral, and ultimately criminal (see timeline). Spatially, the legislation spans across physical and virtual terrains by prohibiting these transactions "in any place," 36 whether that be the street, a car, a home, the internet, or beyond. In effect these tactics of surveillance, policing, and stigma force sex workers to conduct their business in more and more marginal-and thus dangerous-locations. According to Canadian criminology professor Chris Bruckert, Bill C-36 continues to "push the sex industry even further into the shadows and create a perfect storm of danger in which all sex workers, regardless of sector or method of working, will confront increased risk of violence, have reduced access to harm reduction mechanisms, experience heightened stigma and be subject to even greater social/civic isolation. ${ }^{\prime 37}$ The politics of visibility and the dangers of invisibility within the built environment are furthered by the harnessing of infrastructure and intimacy, creating socio-spatial forms to be either cherished and protected or strictly guarded against. 


\section{7}

Canada inherets British

anti-prostitution laws

with the creation of the

new federal governmen

at Confederation. These

laws prohibit "common

prostitutes," keeping or

frequenting a bawdy

house, and supporting

oneself by the avails of

prostitution. The Vagrancy

Act is also passed at this

time, stating that police

had the authority to arres

a woman "if she could

not give a satisfactory

account of herself. ${ }^{138}$
1981

Following the

decriminalization of

homosexuality in 1969, Prime

Minister Pierre Trudea

was quoted saying that

there was "no place for

the state in the bedrooms

of the nation. ${ }^{139}$ However

in 1981, over 100 police

officers armed with crowbars

and sledgehammers raid

multiple gay bathhouses in

Toronto, arresting nearly

300 people. The raids are

a catalyst for the gay rights

movement and for the fight

against bawdy-house laws.

\section{5}

Bill C-49 in passed.

The new bill made it

an offence to buy or

sell sexual services in

a public place, with

the aim to diminish the

"nuisance caused to

ordinary members of the

public." ${ }^{40}$ Public places

included places that

were only accessible by

invitation, such as hotels,

vehicles, clubs, etc. After

C-49 was passed, there

was an increase in

violence against street-

based sex workers.

\section{7}

Sex workers Terri Jean

Bedrofd, Amy Lebovitch,

and Valerie Scott initiate a

case to strike down three

provisions of the law for

violating the Charter:

s. 210 - Keeping a

common bawdy-house

s. 212 (1)(j) - Living on

the avails of prostitution

s. 213 (1)(c) -

Communicating in public

for the purpose of

prostitution

\section{3}

The Supreme Court of

Canada throws out all

three provisions (s. 210;

s. $212(1)(j) ;$ s. 213 (1)

(c)) in a unanimous ruling

after deciding they are

unconstitutional. The

justices give parliament

one year to craft a set

of replacement laws tha

comply with the Chat

This is a milestone win for

sex workers, as it signals

the total decriminalization

of sex work, should no

further legislation be

introduced. ${ }^{41}$

\section{4}

Following the 2013

Supreme Court decision, Bill C-36, the Protection of Communities and Exploited Persons Act (PCEPTA) is introduced. C-36 targets those who purchase sex. PCEPA makes it illegal to obtain sexual services, to receive materia benefits for sexual services, benefts tor sexual senvices, and to advertise for sexu services. Sex workers
adamently argue that these new restriction will make their jobs considerable more dangerous.

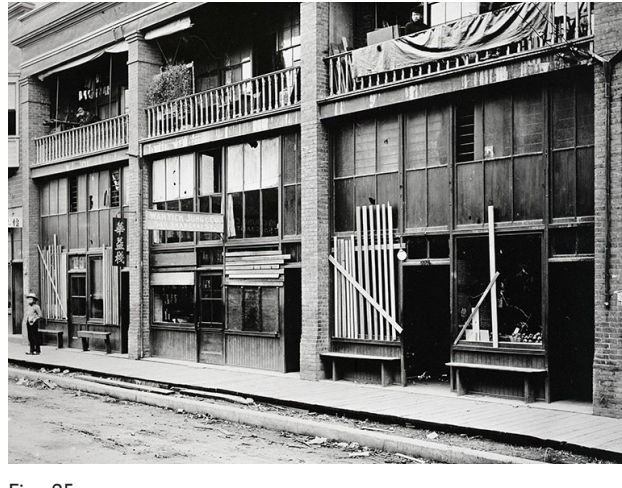

Fig. 25

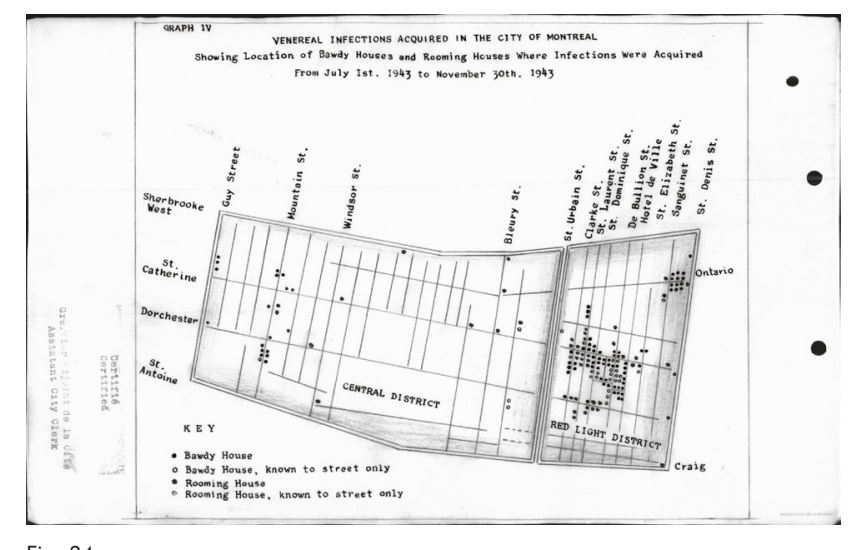

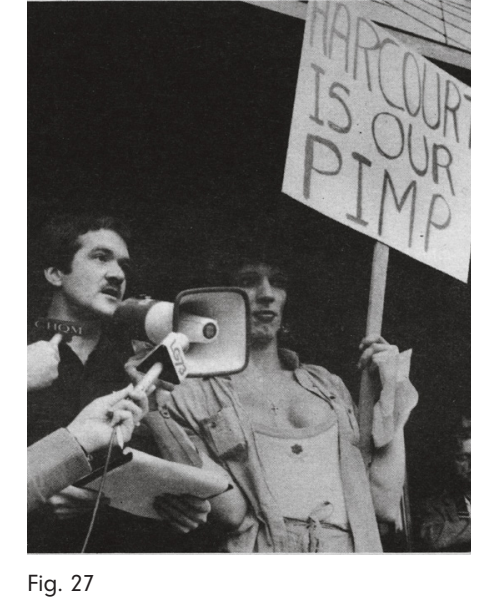

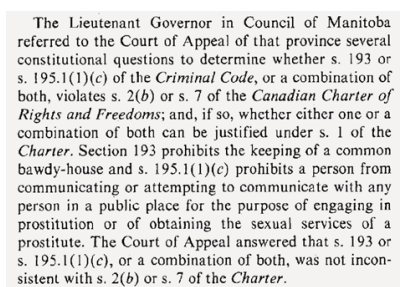

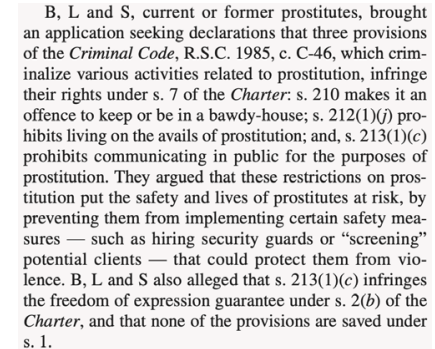

Fig. 2

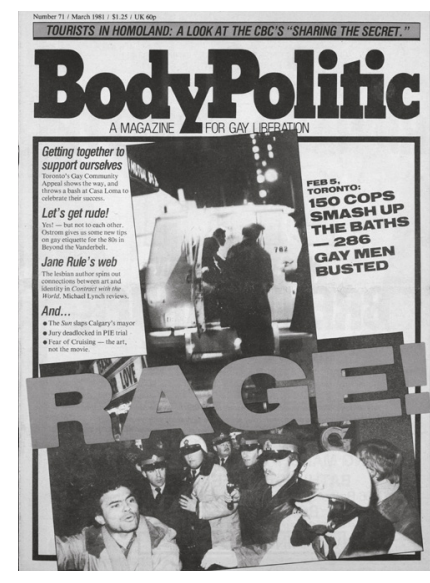

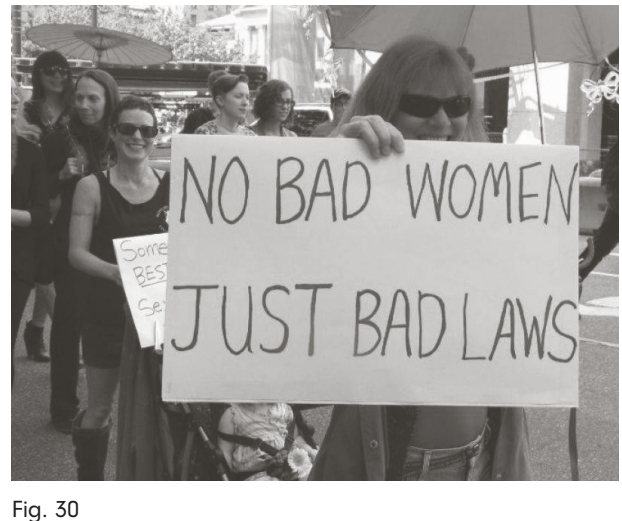

* see appendix I for expanded timeline 

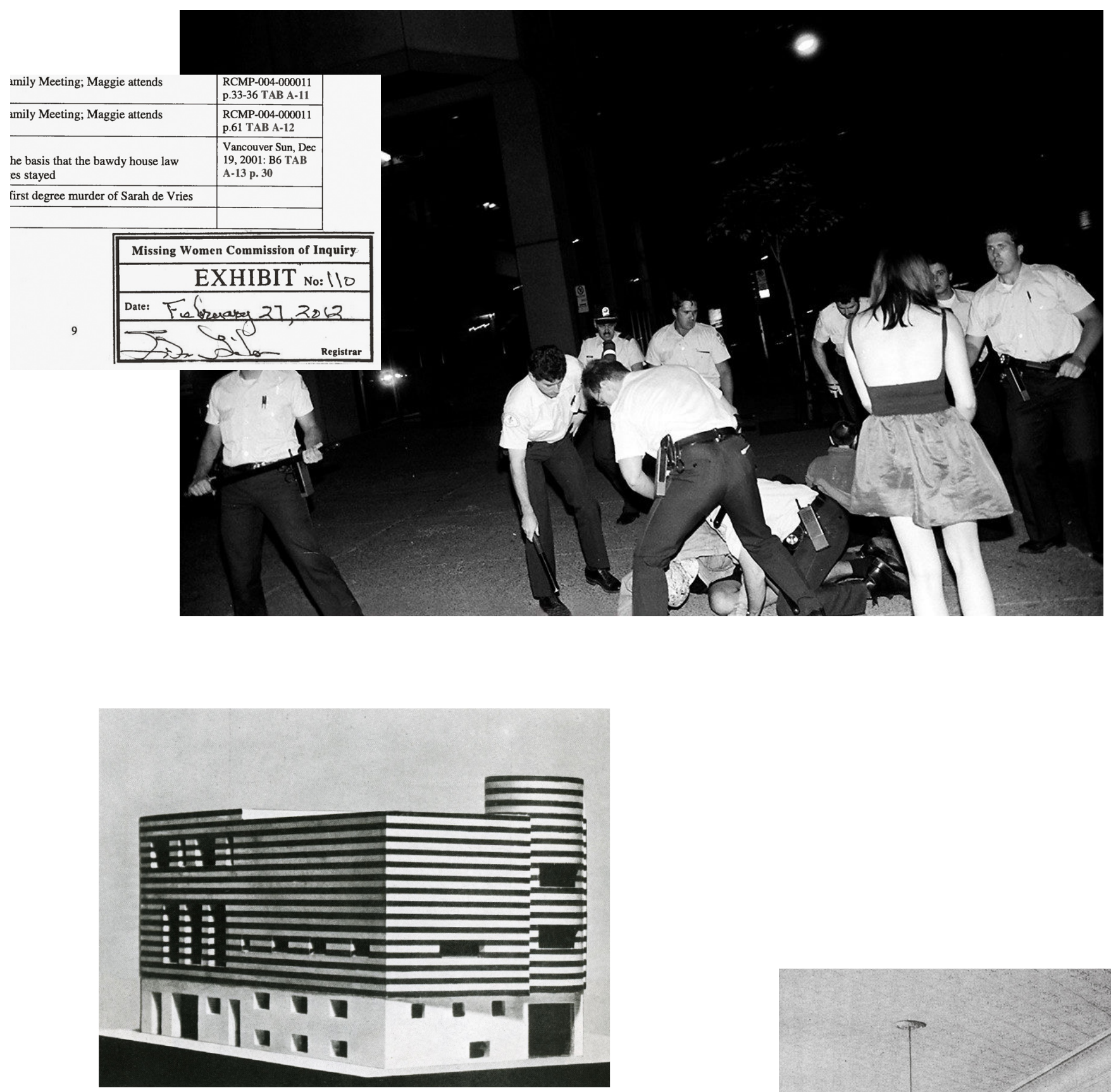

Fig. 31 


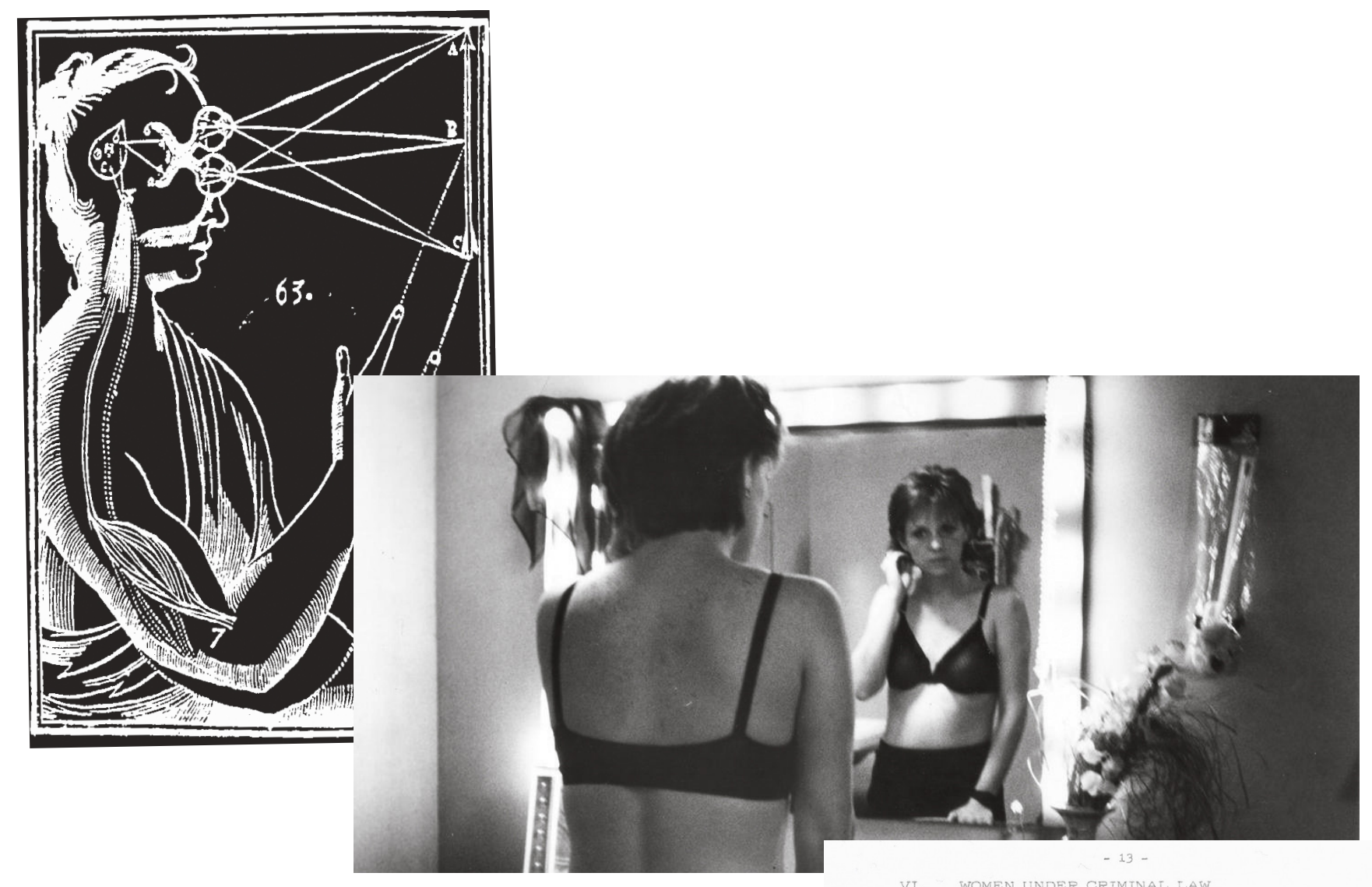

VI. WOMEN UNDER CRIMIMAL LAW

We strongly support Recommendations $\# 150$ and $\# 151$ which call for repeal of Section $164(1)(c)$ and Section 164 (1)(a) now $\# 175(1)(2)$ and (3) of the Criminal Code. R.S.C. 1970 . c. 34 .

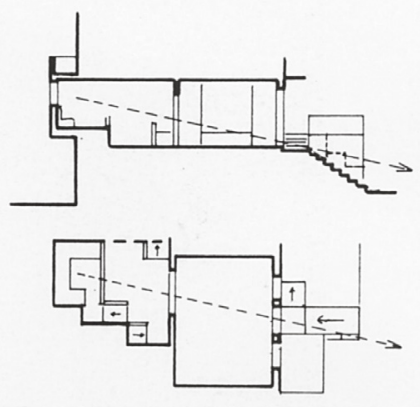

- Prostitution

We are concerned about the use of vagrancy in the criminal law In order to regulate the activity of women prostitutes. We recommend that Section $164(1)(c)$ be repealed for the following reasons:

(i) It is inappropriate for the law to be used as a rogulator of morals. Experience has shown that the law is ineffectual when it attempts to do so.

(ii) This opens the door to the arbitrary application of the law by the police, to the setting of traps, and to other hlghly dubious practices.

(iii) This law discriminates in three significant ways;

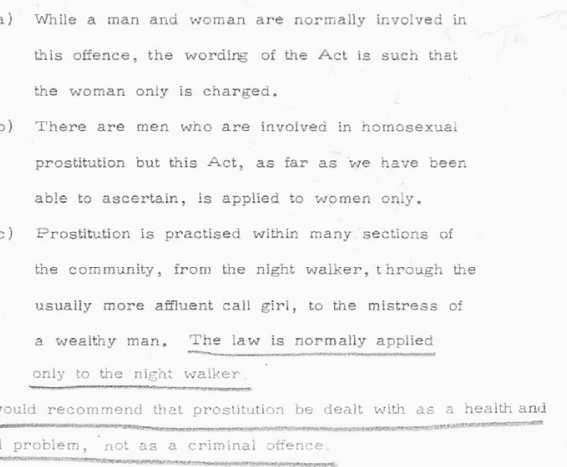




\section{Part 01: Endnotes}

1 "Open Letter: 300 Researchers Call for Decriminalization of Sex Work in Canada," Action Canada for Sexual Health \& Rights, https://www.actioncanadashr.org/news/2014-03-26-open-letter-300-researcherscall-decriminalization-sex-work-canada.

Alex Tigchelaar, "Sex Worker Resistance in the Neoliberal Creative City: An Auto/ethnography," AntiTrafficking Review 12 (2019): 20.

Jacqueline M. Davies, "The Criminalization of Sexual Commerce in Canada: Context and Concepts for Critical Analysis," The Canadian Journal of Human Sexuality 24, no. 2 (2015): 82.

Jane Pitcher and Marjan Wijers, "The Impact of Different Regulatory Models on the Labour Conditions, Safety and Welfare of Indoor-Based Sex Workers," Criminology \& Criminal Justice 14, no. 5 (2014): 550

Phil Hubbard, Andrew Gorman-Murray, and Catherine J. Nash, "Cities and Sexualities," in Handbook of the Sociology of Sexualities, ed. J DeLamater and R.F. Plante (Switzerland: Springer International Publishing, 2015), 297.

Sara Ahmed, "Affective Economies," Social Text 22, no. 2 (2004): 119.

Carlito Pablo, "New prostitution law leaves sex workers "invisible and anonymous," advocate says," The Georgia Straight, November 6, 2014, https://www.straight.com/news/347526/new-prostitution-law-leaves-sexworkers-invisible-and-anonymous-advocate-says.

Silvia Lavin, "Open the Box: Richard Neutra and the Psychology of the Domestic Environment," Assemblage no. 40 (1999): 18

Beatriz Colomina, "The Split Wall: Domestic Voyeurism," in Sexuality and Space (New York: Princeton Architectural Press, 1992), 104

Ibid, 89

Sara Ahmed, "A Phenomenology of Whiteness," Feminist Theory 8, no. 2 (2007): 151

Lauren Berlant, "Intimacy: A Special Issue," Critical Inquiry 24, no. 2 (1998): 282.

Numerous theorists whose work is referenced within this thesis exist within this realm of queer and/or feminist theory, and serve as potent lenses through which to address theory through a sex-positive lens. See Berlant, Wilson, Cowen, Star, Ahmed, Schulte, McRuer, Russell.

Ara Wilson, "The Infrastructure of Intimacy," Signs: Journal of Women in Culture and Society 41, no. 2 (January, 2016): 247.

Deborah Cowen, "The City and the City (and the City): Infrastructure in the Breach," Society and Space, October 10, 2017, https://www.societyandspace.org/articles/the-city-and-the-city-andthe-city-infrastructure-in-the-breach.

Susan Leigh Star, "The Ethnography of Infrastructure," The American Behavioral Scientist (Beverly Hills) 43, no. 3 (1999): 377

Michelle Murphy, "Chemical Infrastructures of the St. Clair River," in Toxicants, Health and Regulation since 1945, ed. Soraya Boudia and Nathalie Jas (London: Pickering \& Chatto, 2013), 104. Lauren Berlant, "The Commons: Infrastructures for Troubling Times," Environment and Planning D: Society and Space 34, no. 3 (2016): 394

Winona LaDuke and Deborah Cowen, "Beyond Wiindigo Infrastructure," The South Atlantic Quarterly 119, no. 2 (2020): 245

Amnesty International, "Stolen Sisters: A Human Rights Response to Discrimination and Violence against Indigenous Women in Canada," Amnesty International (October 2004): 13, https://www.amnesty. $\mathrm{ca} /$ sites/default/files/amr200032004enstolensisters.pdf. 
Star, "The Ethnography of Infrastructure," 382

LaDuke and Cowen, "Beyond Wiindigo Infrastructure," 264.

Red Schulte, "Sex Working Economies of Space," The Funambulist 33 (2021): 37-38.

Robert McRuer, Crip Theory: Cultural Signs of Queerness and Disability (New York: New York University Press, 2006), 24.

Noah Berlatsky, "Pixelated Prostitution: Feminist Sex Work Debate Bleeds Into Video Games," Newsweek, December 20, 2014, https://www.newsweek.com/pixelated-prostitution-feminist-sex-work-debate-bleeds-videogames-293311.

Antonia Crane, "The Most Realistic Sex-Worker Portrayals in Pop Culture, According to Sex Workers," Mel Magazine, 2019, https://melmagazine.com/en-us/story/the-most-realistic-sex-worker-portrayals-inpop-culture-according-to-sex-workers.

Alison Zhou, "The Sweetening of Public Infrastructures, Or Tangerine," Society and Space, November 27, 2018, https://www.societyandspace.org/articles/the-sweetening-of-public-infrastructures-or-tangerine.

Wilson, "The Infrastructure of Intimacy," 259.

Cecilia Benoit et al., "'Well, It Should Be Changed for One, Because It's Our Bodies": Sex Workers' Views on Canada's Punitive Approach Towards Sex Work," Social Sciences 6, no. 2 (2017): 52.

Naomi Sayers, "Canada's Anti-Prostitution Laws: A Method for Social Control," kwetoday, December 28, 2013, https://kwetoday.com/2013/12/28/canadas-anti-prostitution-laws-a-method-for-social-control/.

Archived - CHAP. 34. An Act to amend "The Indian Act, 1876," assented to May 15, 1879, https://www.aadncaandc.gc.ca/eng/1100100010264/1100100010266.

Yvonne Boyer, "First Nations Women's Contributions to Culture and Community through Canadian Law," in Restoring the Balance: First Nations Women, Community, and Culture, ed. G. G. Valaskakis, Madeleine Dion Stout, and Eric Guimond (Winnipeg: University of Manitoba Press, 2009), 78.

The Criminal Code, 1892 , S.C. 1892 , c. 29 , University of Toronto Libraries, https://exhibits.library.utoron to.ca/ exhibits/show/bawdy/early-criminal-code.

Court of Appeal for Ontario, Canada (Attorney General) v. Bedford, 2012 ONCA 186, March 26, 2012.

Naomi Sayers, "The (Un)Constitutionality of PCEPA: A Necessary Discussion," in Sex Work Activism in Canada: Speaking Out, Standing Up, ed. Amy Lebovitch and Shawna Ferris (Winnipeg: Arp Books, 2019), 21.

Bill C-36, An Act to amend the Criminal Code in response to the Supreme Court of Canada decision in Attorney General of Canada v. Bedford and to make consequential amendments to other Acts, 2nd session, 41st Parliament (assented to November 6, 2014): 2, https://www.parl.ca/Content/ Bills/412/Government/C-36/C-36_4/C-36_4.PDF. 


\section{Part 02:}

Sex and the City 


\section{Geographies of Control}

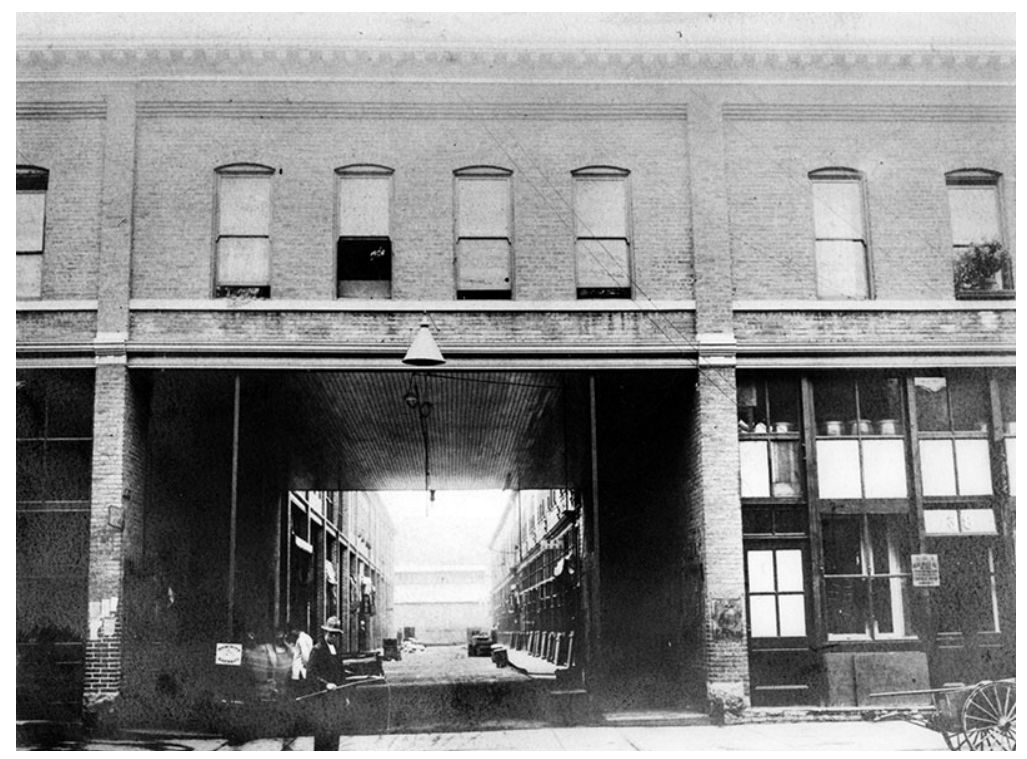

Fig. 33

Canton Alley, one of Vancouver's early sex work districts, 1910

Uncovering the spatial dimensions of sex work in Canada requires an understanding of the tension between scales of city life beyond the legislative divisions of public and private space. There is a violence inherent in the scalar shifts between the local or embodied and the regional or national, in that when legislatives decisions are made in one geographic or hierarchical location, they can have deep impacts on lives and bodies in another. The detrimental potentials of these decisions are only heightened by the misconception that spaces of sex work are inherently liminal, dilapidated, and immoral.

Thinking geographically about the sexual landscape of city space requires these scalar shifts to be actively recognized. Marxist geographers understand space as the product of power relations, the likes of which have the capacity to reproduce capitalist values through zoning and regulations. As noted by geographer Phil Hubbard, it may seem as though areas with sex shops, strip clubs, or even brothels-what Hubbard refers to as 


\section{Mapping Power}

The spatial planning that lays the foundation for city space can be seen to be deeply embroiled in power structures. The explicit socio-spatial implications of power can be understood by adding regional specificity to the discussion, in this case by mapping downtown Vancouver, Toronto, and Montreal-three Canadian cities whose layered relationships to the sex industry have been a central focus for advocacy groups across the country. While cartographic representations of city life are often capable of sustaining dividing lines or making concrete what is in fact shifting and ephemeral, the charting of geographies of policing and protest in figures 36-38 utilize mapping to expose the very real power relations that have regulated sex work within the Canadian city. These drawings, as geographic representations of resistance through protest and of the spatial violence ascribed through policing structures, help to bridge the gap between intangible law and mobilized material practice by discussing the historical and the contemporary in conjuncture. Most critically, the drawings seek to expand beyond simply mapping along a historical trajectory, and instead can be understood as a way to explore the patterns of occupation that reinforce prevailing socio-spatial power dynamics through the collapsing of time-scales.

The maps themselves focus largely on records of bawdy-house arrests within the loosely-defined historical 'red light districts' that now comprise the downtown of each respective city. The offence of keeping or occupying a common bawdy-house, although now defunct, is of particular interest in peeling back the layers of privacy and publicity as they relate to the occupation and control of city space. In the words of Canadian sex worker and advocate Valerie Scott:

The bawdy-house legislation prevented even one woman or man from working out of their own home. That is the way many sex workers operated. We always feared being 
Fig. 35

Views of streets in Vancouver,

Toronto, and Montreal, situated in what used to be the concentrated sex working areas of each city, as outlined in figures $36-38$
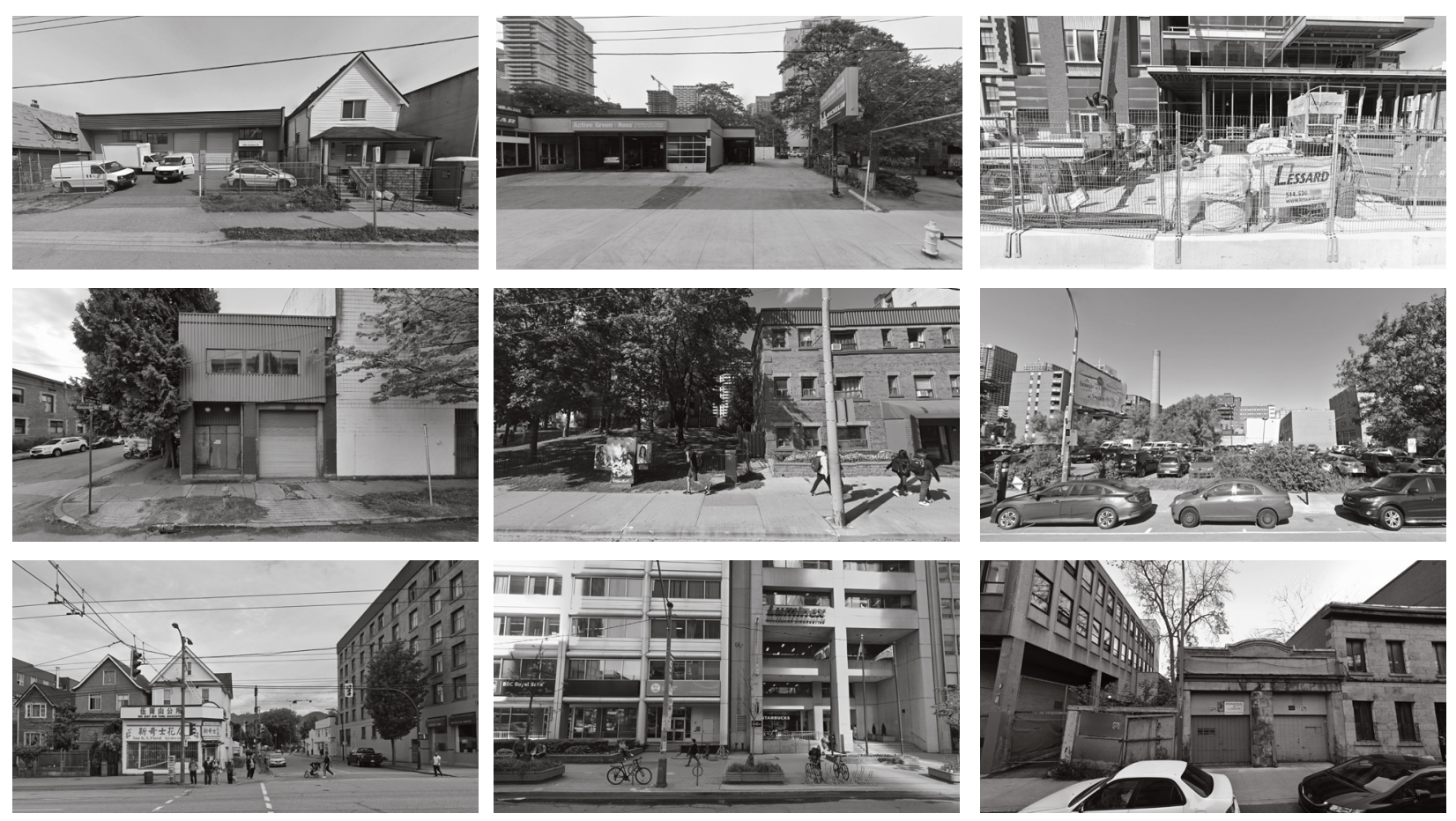


\section{Sex and the City}

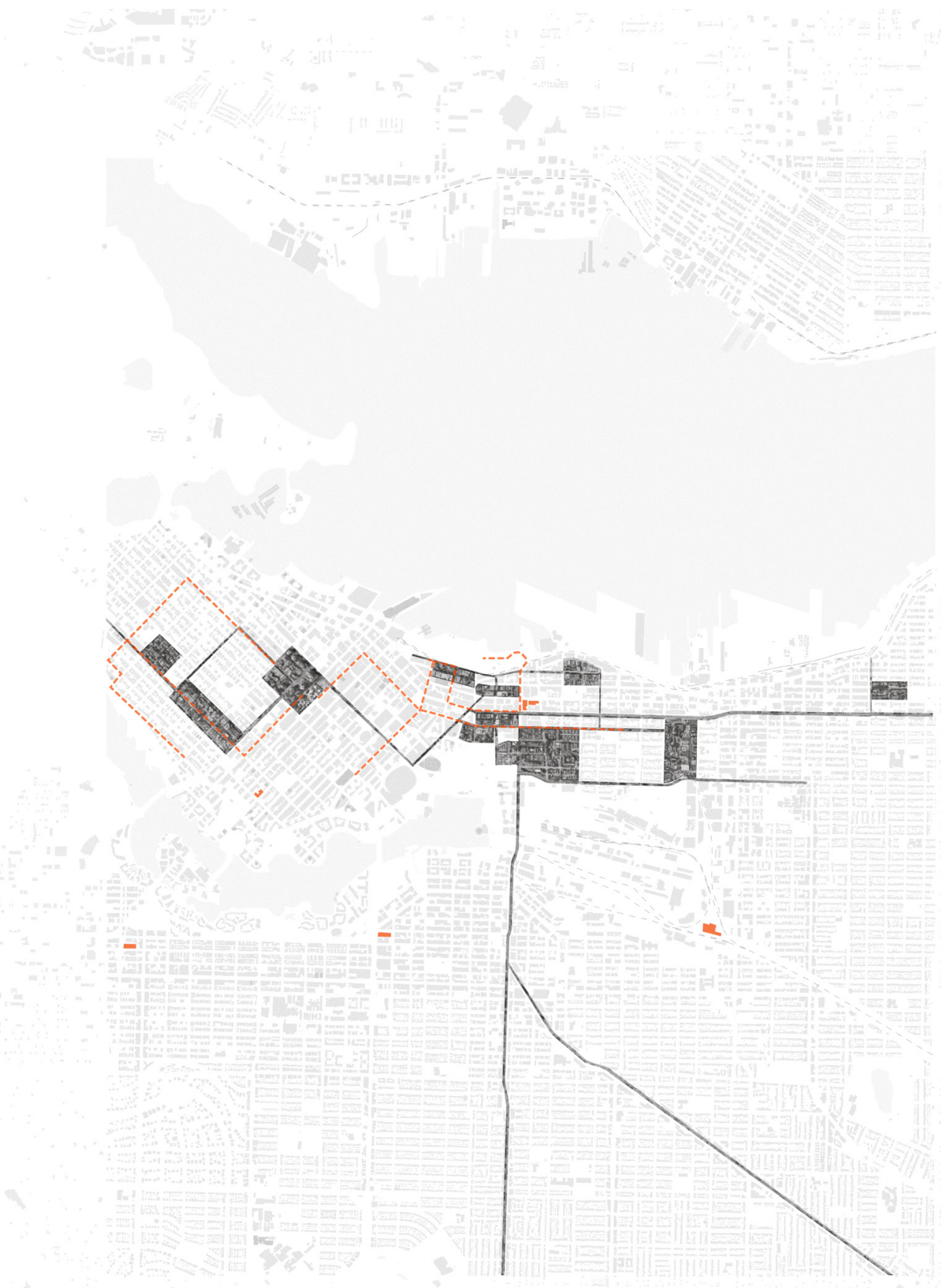

Fig. 36

Map of Vancouver

An Areas where bawdy-house

arrests have occured

Police stations

Protest routes for sex

work activism 


\section{Sex and the City}

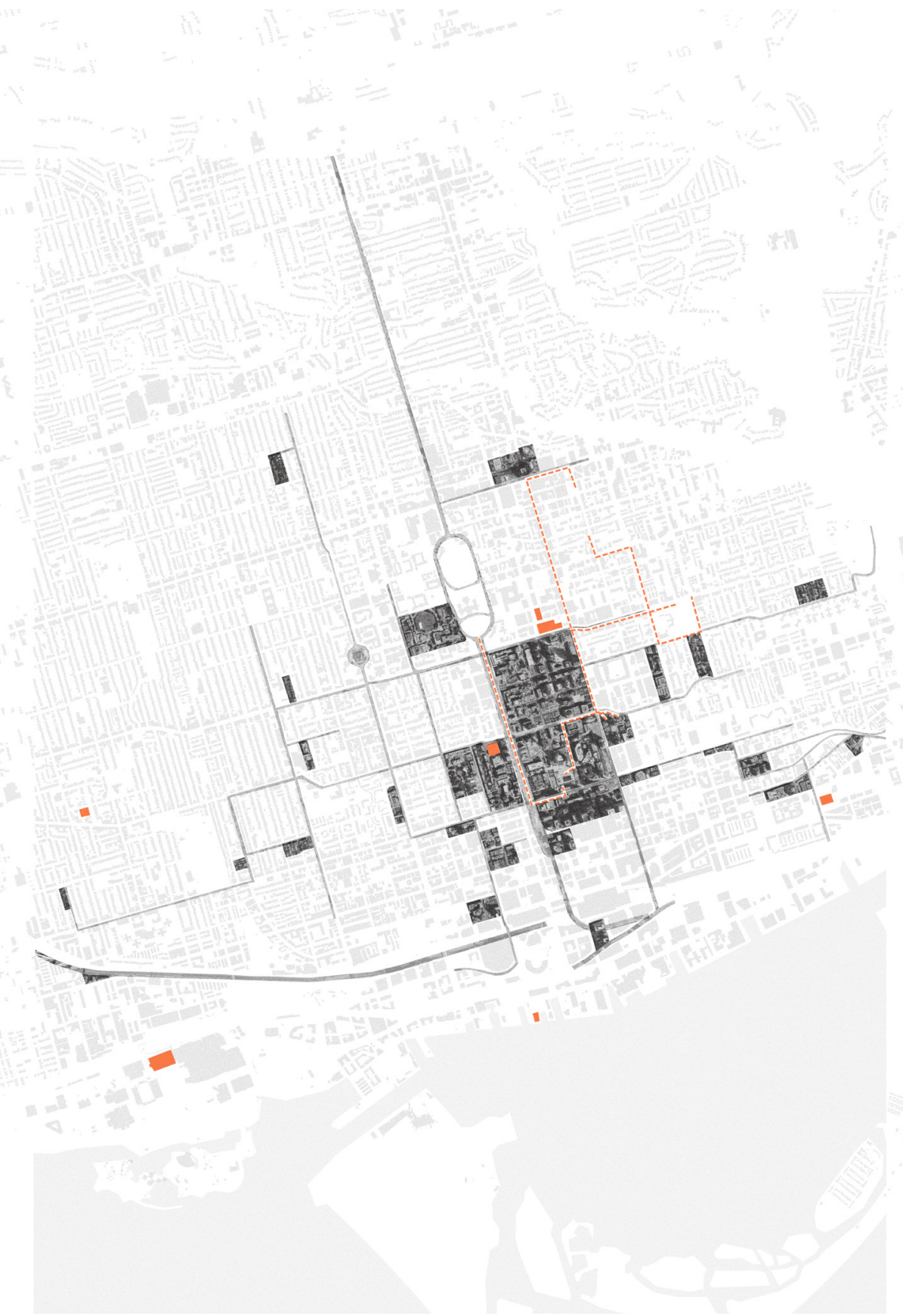

Fig. 37

Map of Toronto

10: Areas where bawdy-house

arrests have occured

Police stations

Protest routes for sex

work activism 
Sex and the City

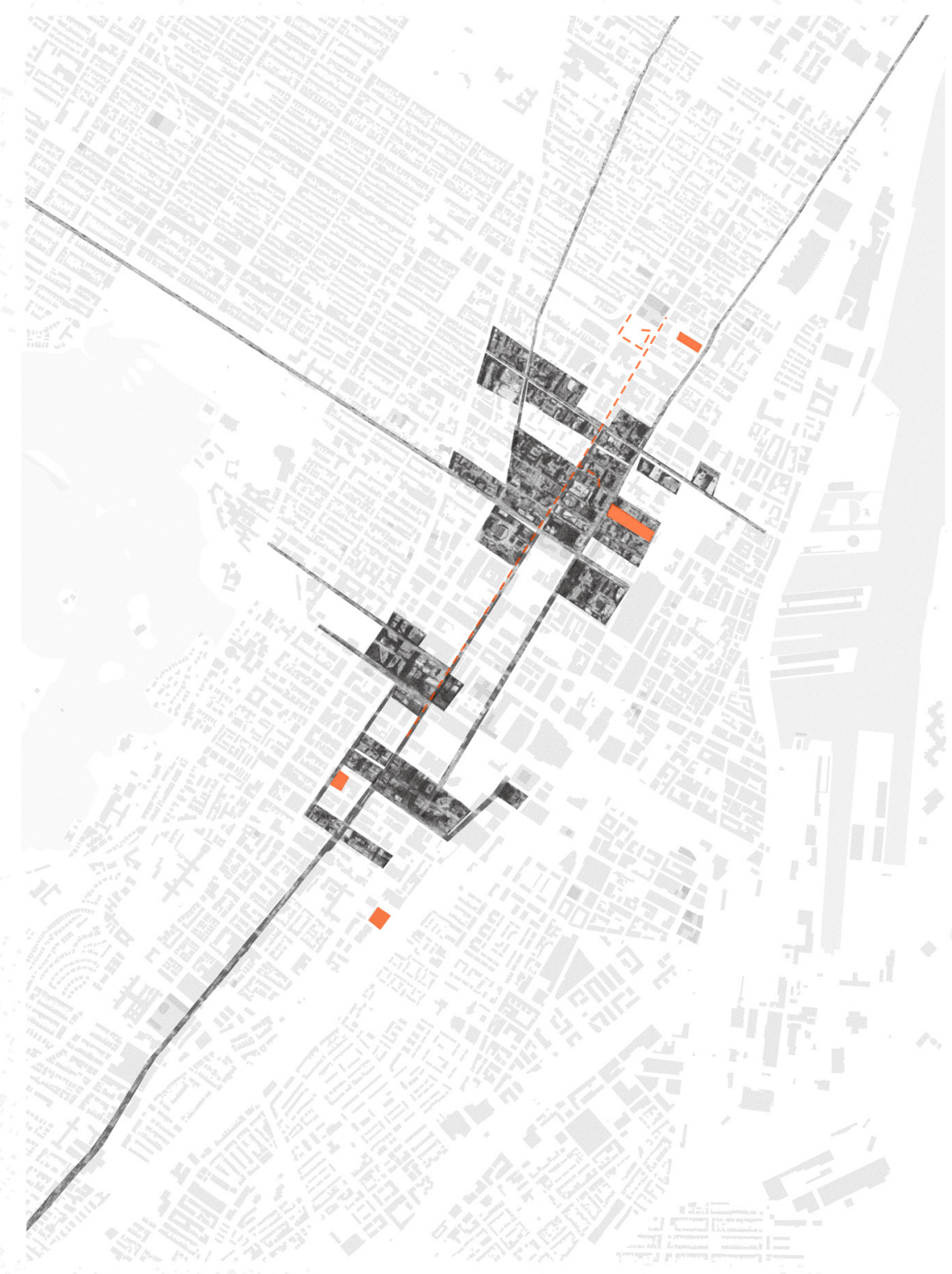

Fig. 38

Map of Montreal

Areas where bawdy-house

arrests have occured

Police stations

Protest routes for sex

work activism 


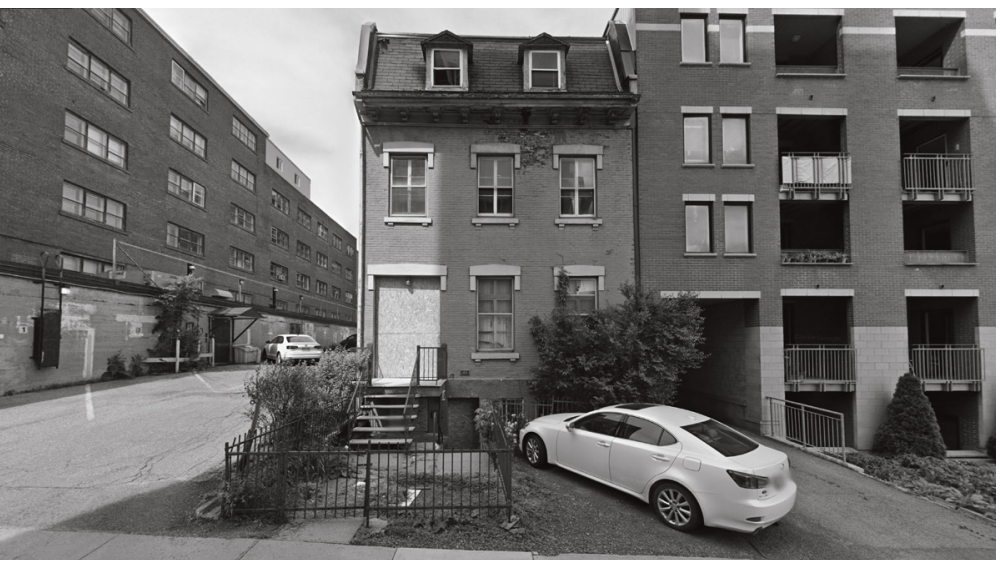

Fig. 39

What was once a Montreal bawdy house, still standing

despite nearby urban developments, 2019

While the presence of street-based sex work is often what labels a space as 'normal' or 'deviant', it is through tracing the regulation of indoor sex working environments-specifically those deemed as bawdy-houses-that it becomes possible to dig deeper into the ways that the industry is spatially policed and surveilled. This surveillance is also forged through a certain panopticism, in the Foucauldian sense; ${ }^{7}$ by ensuring that intimacy remains in the realm of personal and private life, the prevalence of monogamous culture limits the capacity to build explicit or non-normative (read: nonmonogamous) public sexual cultures and geographies. ${ }^{8}$

Despite the perceived concentration of sex working spaces, the landscape of sex work has actually become much more dispersed. Whereas sex work was once concentrated to the 'red light districts' of major cities, it now operates in virtually every facet of the city. This dispersal is caused by both violent and liberatory effects. In one sense, the shifting geographies of sex work are the result of mobility and an increased reliance on the internet to both meet and screen clients, effectively taking out much of the risk that can be associated with street-based sex work. The internet offers new forms of intimacy and connection, ones forged through a virtual vulnerability that allows for individuality, collectivity, and coalition-building to germinate. ${ }^{9}$ Yet in another sense, surveillance, policing, and stigma held by city dwellers often forces sex workers into marginal, isolated, or industrialized areas, each of which can be linked to increased violence. ${ }^{10}$ Canada's history of uprooting sex working spaces, whether by brute police force or through the soft power of gentrification, is circumscribed on the landscape of the city. 


\section{Recognizing Space and Place}

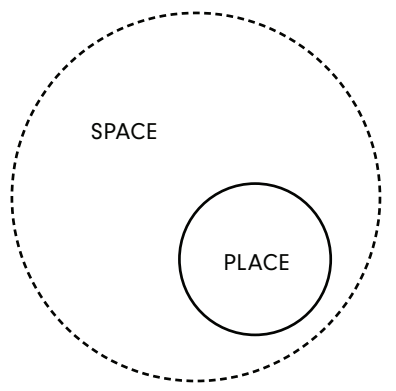

Fig. 40

Diagram expressing that place exists amidst spatial conditions, or as an elaboration of space.

Place can be understood

as space activated through

intimate attachment
The terms space and place are often used interchangeably in both common dialogue and academia. However, their definitional forms are vast and varied. While space is largely legislative, geographic, and socially-constructed, place is affective and embodied. And although abstract space remains vitally important as a lens of analysis and elaboration, it falls victim to its critical distance from the subject by which it operates. Anthropologist Setha Low notes that it is "the spatial location of subjectivities, intersubjectivities, and identities that transform space into places... While place may be studied phenomenologically through individual or collective experiences, it also derives its meaning from the social, political, and economic forces and class relationships that produce its spatial, material, and social forms."11 Essentially, space graduates toward place through intimate association.

In recognizing the role of place in the lives of sex workers, Alison Grittner and Kathleen Sitter identify that "place offers a critical lens to understand how the hierarchical sociostructural powers of gender, sexuality, colonialism, and capitalism-among others-coalesce and interpenetrate local sex work environments." ${ }^{\prime 2}$ This localized dimension is critical, because it is at the local level that space and place begin to react back upon one another. It is also at the local level that the violent ripple effect between the labour of creating places, the censorship of that labour, and the regulation of space that thereby limits the actions of criminalized labourers get activated and felt. ${ }^{13}$

Considering both space and place is necessary to expose the ways that sex work is controlled within the city. While street-based sex work is often concentrated to specific strolls, other methods of work-including working in massage parlours, online, independently, for agencies, or in strip clubshave come to be prevalent throughout city space. This dispersion forms a hidden dimension to sexuality within the city. The prevalence of internetbased sex work has in many ways catalyzed this dispersal, creating new 
methods of procurement and practice that may be less visible-but remain no less infrastructurally, spatially, and legally-bound. Whether soliciting sex work on the internet, working exclusively online, or simply engaging with the dispersed industry, the tangible landscape of sex work begins to erode and expresses a certain 'everywhereness'. Yet this 'everywhereness' is far from signalling sexual liberation. Red Schulte refers to this paradox as a "limited-intimate" geography: as long as sex work exists under a shroud of criminalization, there are no truly private spaces for the sex worker, even if they remain unseen within visible public space. ${ }^{14}$

This limited-intimate geography also transcends the scale of the city to denote a much more personal ontology, signalling a politics of location that transfers understandings of infrastructure, exposure, and power from birds-eye cartographic views and intangible systems to the scale of the human body. It is at this bodily scale where the tactile and aesthetic dimensions of the everyday become activated. Anthropology scholar Brian Larkin elaborates on the importance of material, aesthetics, and tactility-what he refers to as the 'poetics of infrastructure'-in the formation of political space, noting that this dimension of infrastructure is what produces "the ambient conditions of everyday life: our sense of temperature, speed, fluorescence, and the ideas we have associated with these conditions.."15 This sensorial understanding of space is inherently architectural, and inherently tied to place. Yet to recognize these dimensions in spaces of ubiquity pushes this architectural logic further by recognizing the presence of power in space's formation.

The presence of infrastructure within the construction of everyday spatial orders resonates with a 2018 study conducted in southern Ontario, which found that sex workers would often use the term 'everywhere' to denote their spatial proximities. The women who took part in the study would use 'everywhere' specifically to remark on their frustration with the lack of civic engagement they are entitled to and the unsafe conditions that can govern their work. ${ }^{16}$ To assess 'everywhere' at both the scale of the city and of the local block is to recognize the transcendence of infrastructure in shaping socio-spatial patterns and civic life-'everywhere' becomes an explicitly spatial moniker. In the case of the southern Ontario study, everywhere 
existed as both a recognition of existing spatial orders and of a new conception of space otherwise, resonating with Marxist philosopher Henri Lefebvre's theory of the three fields of space by activating the space of the "perceived" and the "conceived." Lefebvre's spatial triad-the perceived, the conceived, and the lived-becomes a fertile ground within which to situate discussions of spatial-everywhereness in relation to sex work in the Canadian city. In discussing representational spaces, Lefebvre is careful to describe this understanding of bodily space as a triad, noting that two elements alone are bound to equate to binary opposition or dichotomy. ${ }^{17}$ In other words, by activating three fields of space, these systemic, material, and symbolic orders coalesce to establish a social space as such.

The space of the perceived is that which arises through established spatial practices and the repetitive patterns of daily life. These patterns demarcate a specific spatial order and are governed by mores and social norms that enable certain actions yet limit others. In relation to sex work, the perceived involves the way that stigma governs the bodies of clients, sex workers, and the wider populous, each in different ways. The conceived exists within the space of representation, meaning space as it is configured by decisionmaking bodies such as architects, lawmakers, or city officials. Sex work in the realm of the conceived is heavily regulated and policed, relegating the industry to certain zones and attempting to enforce its invisibility. As has been seen, this forced invisibility contributes greatly to the violence enacted on sex workers. Last in the triad is the lived, which acts as the space of everyday interaction and everyday life, but also as that of aspiration. The representational space of the lived encompasses both the perceived and the conceived, while remaining a function of them. It is "space as directly lived through its associated images and symbols, and hence the space of 'inhabitants' and 'users', but also of some artists and perhaps those, such as a few writers and philosophers, who describe and aspire to do no more than describe." ${ }^{18}$ Essentially, the lived is the symbolic order that weaves into and out of spatial and material forms, and the realm of possibility where spatial plurality flourishes. It is through the coalescence of Lefebvre's three fields of space that the hidden means of spatial production can be exposed, and that revolutionary action can occur. ${ }^{19}$ 
Figures 41-48 are an exercise in parsing each of these three fields of space in order to understand sex work beyond simply its geographic forms. In order to harness this human scale within the Canadian city and thereby ground legislative forms in space, the drawings begin to slip from 'everywhereness' toward 'anywhereness'. In order to maintain the anonymity of sex workers and the specific spaces that they tend to occupy as they work, the city is made recognizable through pervasive ambiguity rather than geographic specificity. In this framework, 'anywhere' simply refers to the ways in which place can be understood beyond its presence within a specific geographic location. Instead, placeness is present within the drawings through the material presence of everyday infrastructures and the intimacies that they enable.

The drawings expose spatial dynamics at numerous scales of visibilitydynamics which can ultimately be understood as continual oscillations between scales as they unfold. As the physical space of the everyday and the space of invisible power, the perceived $(\mathbf{A})$ is represented through satellite imagery whose place-ness is left purposefully ambiguous and whose spatial vagueness expresses broad understandings of how space is organized. The conceived (B) represents the presupposed ideas of space that stem from power relations. Taking cues from choreographic notation, the conceived is rendered as a series of diagrammatic representations of the legislations that govern place for sex workers, clients, and the numerous other actors who may be involved in sexual exchange. The lived (C) is the space of desires, dreams, place, and memory, rendered to evoke the tactility of bodily space and to tie the urban syntax into sex work narratives. Although represented as finite frames, it is necessary to acknowledge that these representational spaces exist within the expansive network of city space. It becomes as important to consider what occurs within these frames, as it is to consider the ways in which people move between them. Combining each component of Lefebvre's spatial triad allows for the city to be understood as a series of constellated forms whose material and atmospheric qualities continually shift bodies into regulated hierarchical arrangements. Through the rendering of each space and its infrastructures, the intimate attachments that constitute place also become exposed. 


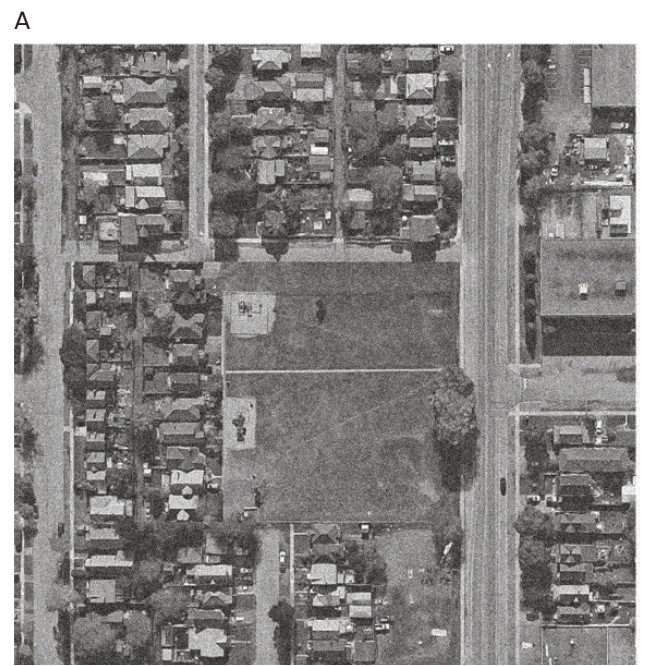

B

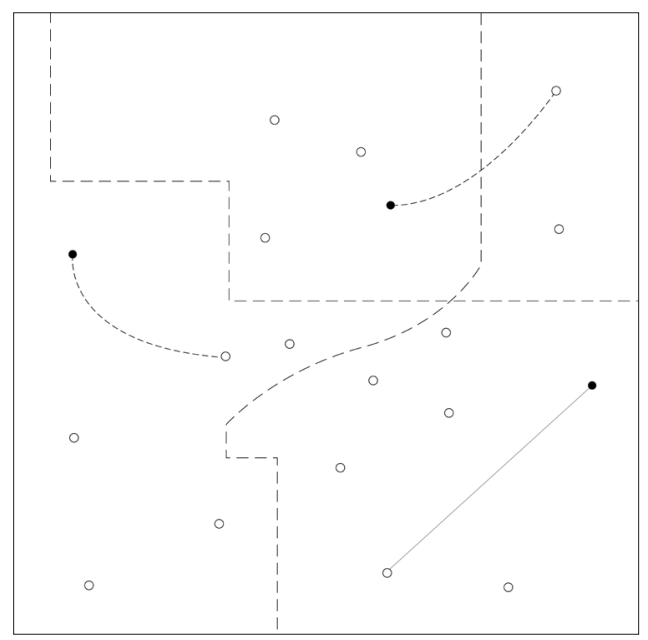

c

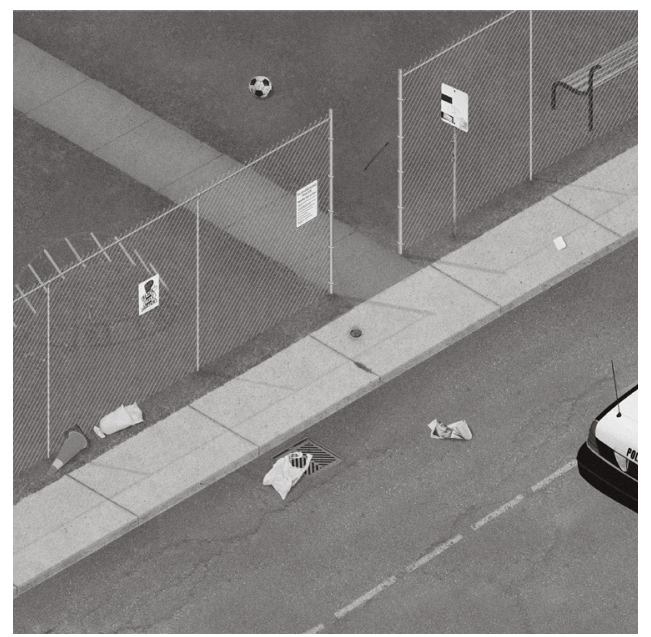

Fig. 41

Triad - Park 


\section{Sex and the City}

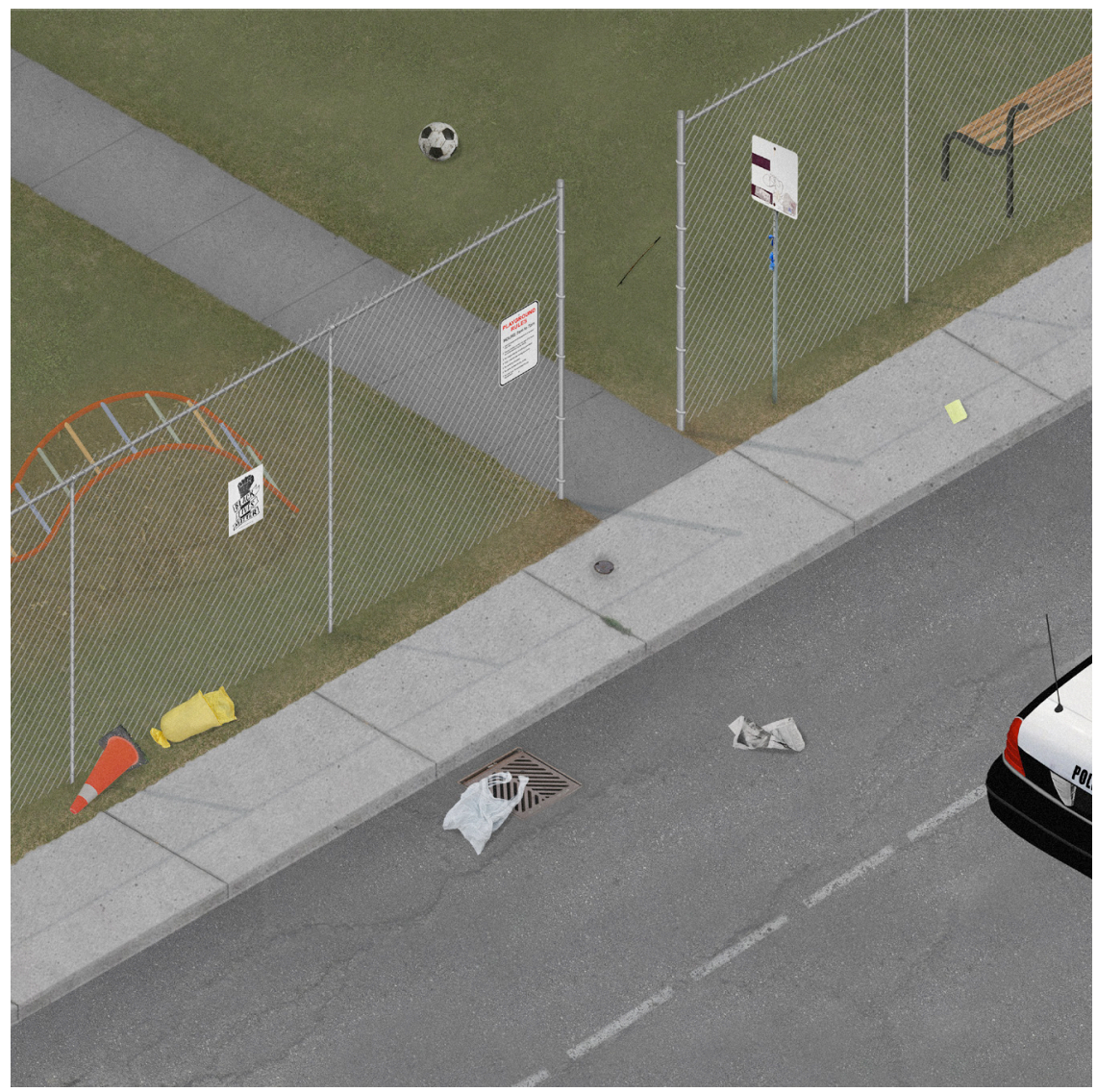

Fig. 42

"Working together is better for safety, sharing of expenses, and for each other's company but the law prohibited us from working that way. ${ }^{20}$

Parks exist as a grey area of legal control. Under Bill C-36, communicating with clients or third parties remains illegal in any 'public place' or any place open to public view, particularly if it is next to a 'playground'. The broad and ambiguous vocabularies of 'playground' and of what can be considered 'next to' one allow police to utilize their discretionary powers to enforce these laws against sex workers at will. The fines associated with communicating in a public place doubles if there is any possibility that someone under the age of 18 could be present, ${ }^{21}$ essentially forcing sex workers to work solely in hidden conditions. 


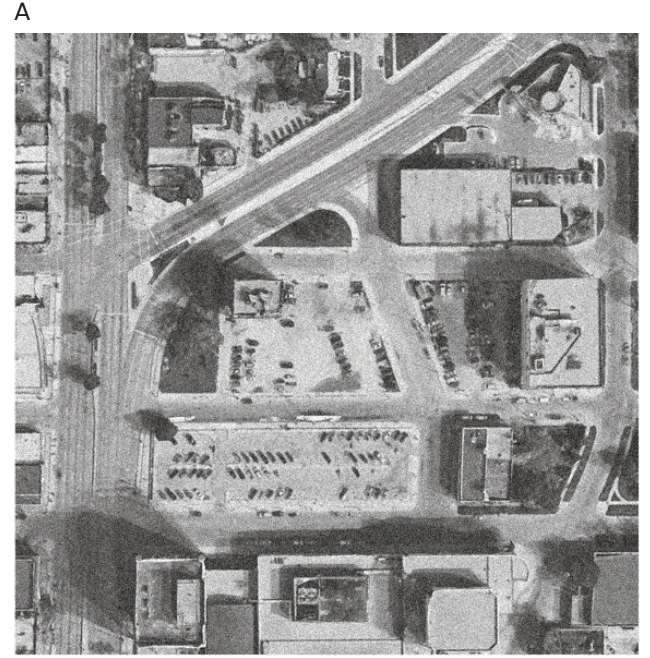

B

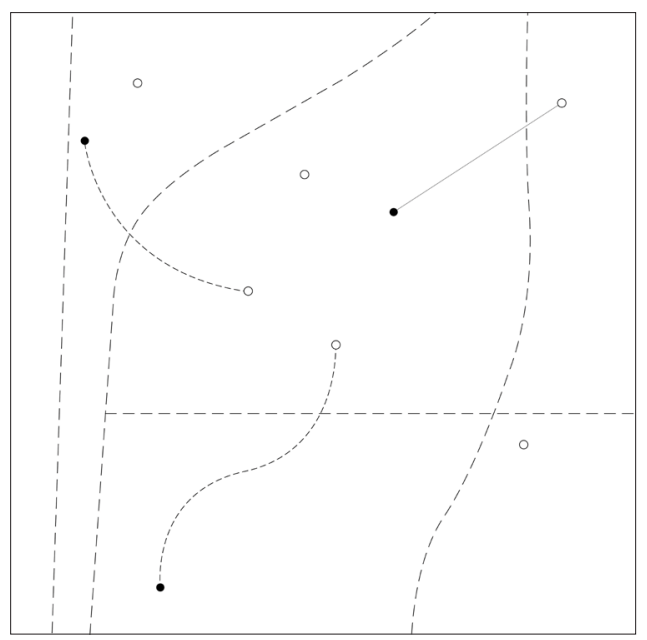

C

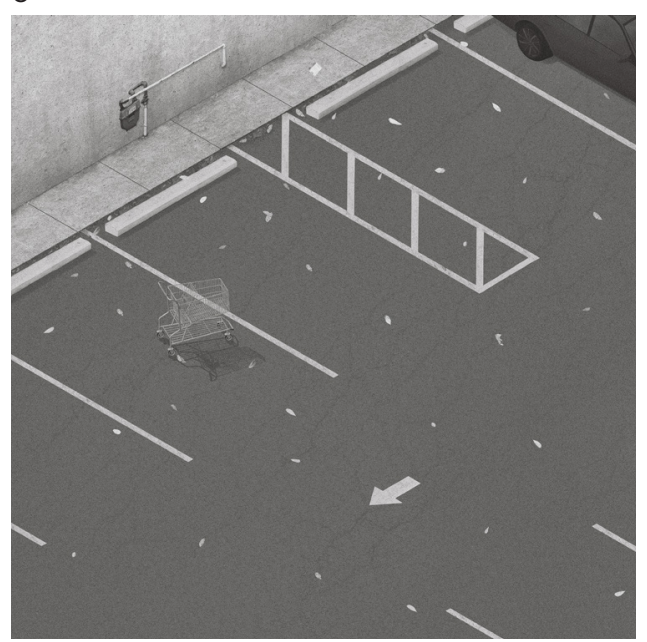

Fig. 43

Triad - Parking Lot 


\section{Sex and the City}

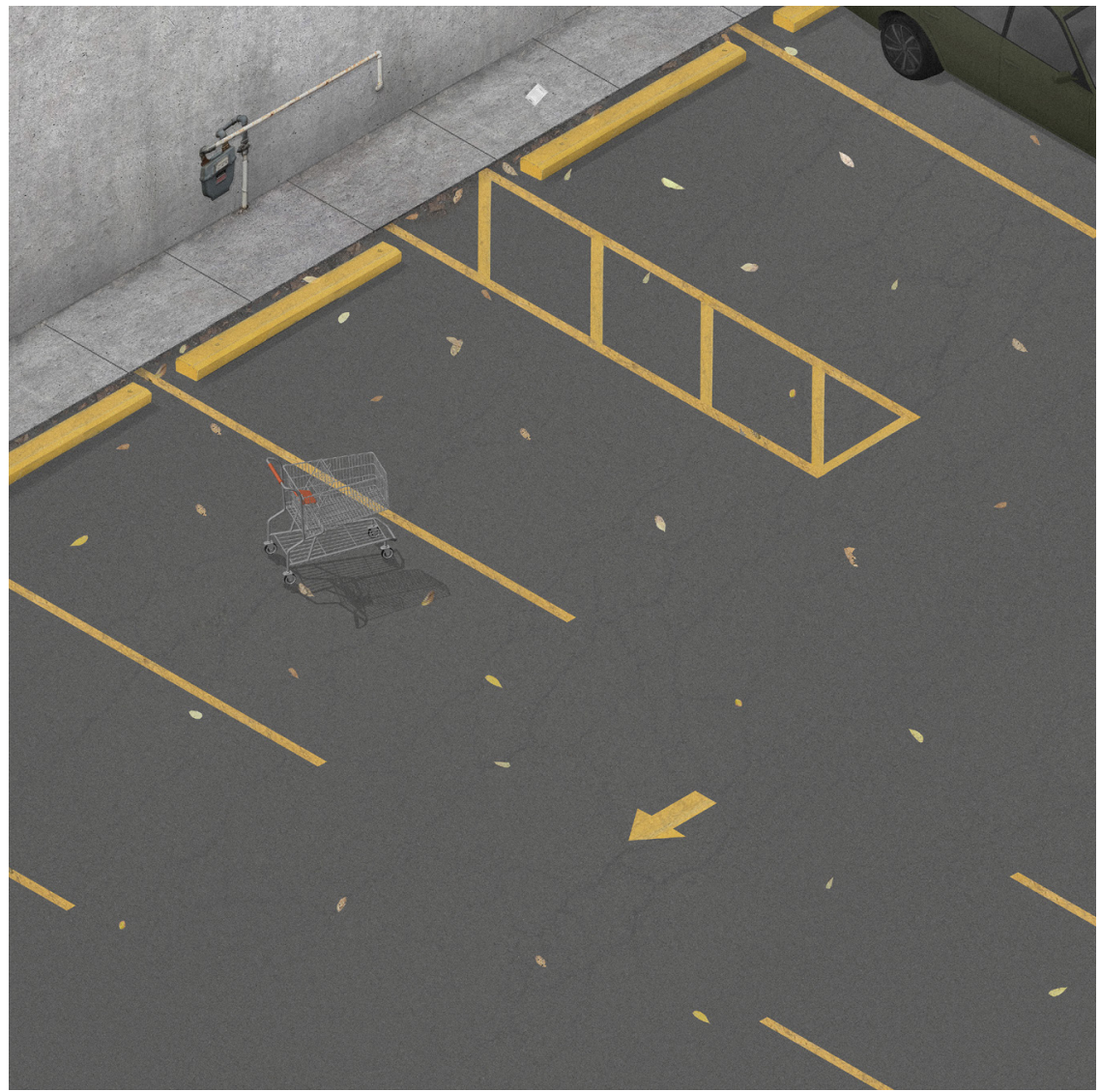

Fig. 44

"Yeah, to be honest l'd rather do it in a car. It's more easier if something does go wrong."22

The parking lot is a charged infrastructural space in the sex work industry. Considered by some a typical spot to meet clients, ${ }^{23}$ the parking lot exists within the realm of a "private" public-they can be conceived of as both public and private places. Throughout Canada's legislative history, cars and parking lots have been considered bawdy-houses as a result of their popularity as sites of sexual exchange, and communicating with clients in these spaces remains criminalized today. Studies have shown that sex workers are often safest when working in outdoor, open spaces, ${ }^{24}$ and parking lots serve as prime locations. Parking lots also offer the potential for working with third parties, or individuals who are there to provide protection if something goes wrong 


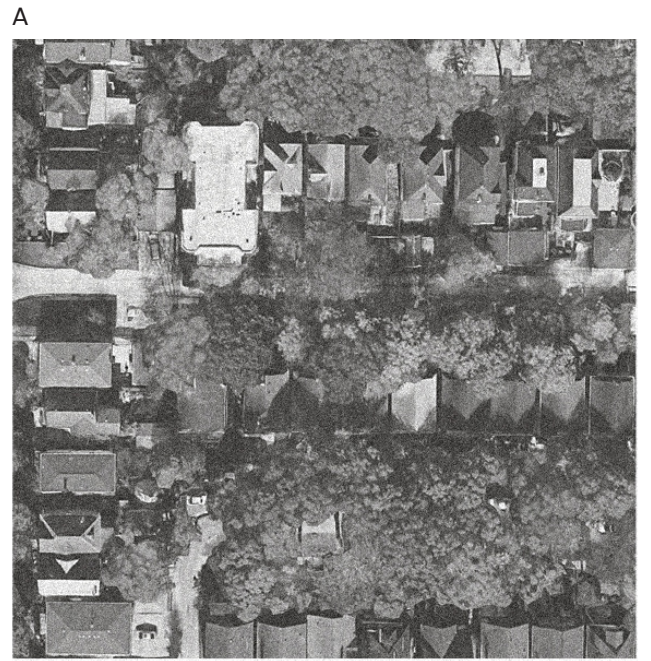

B

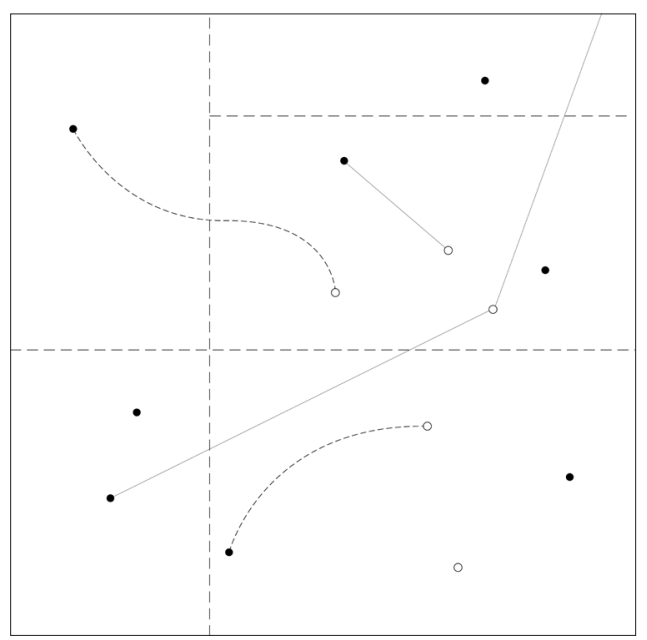

C

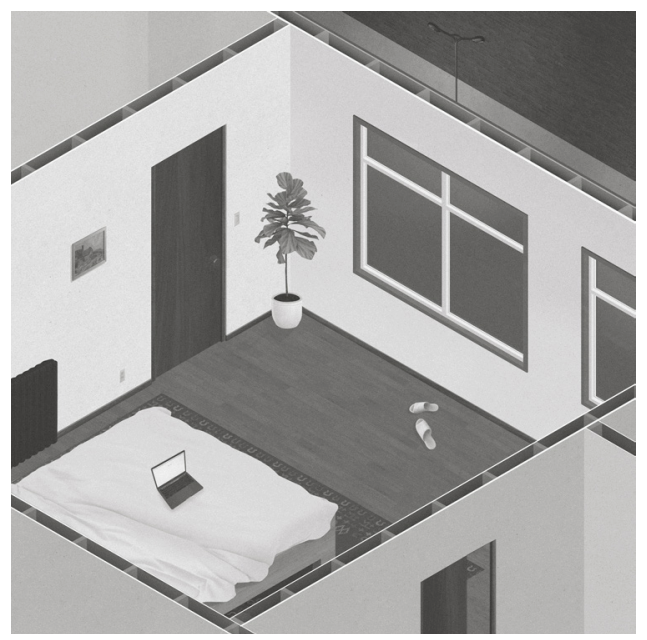

Fig. 45

Triad - Home 


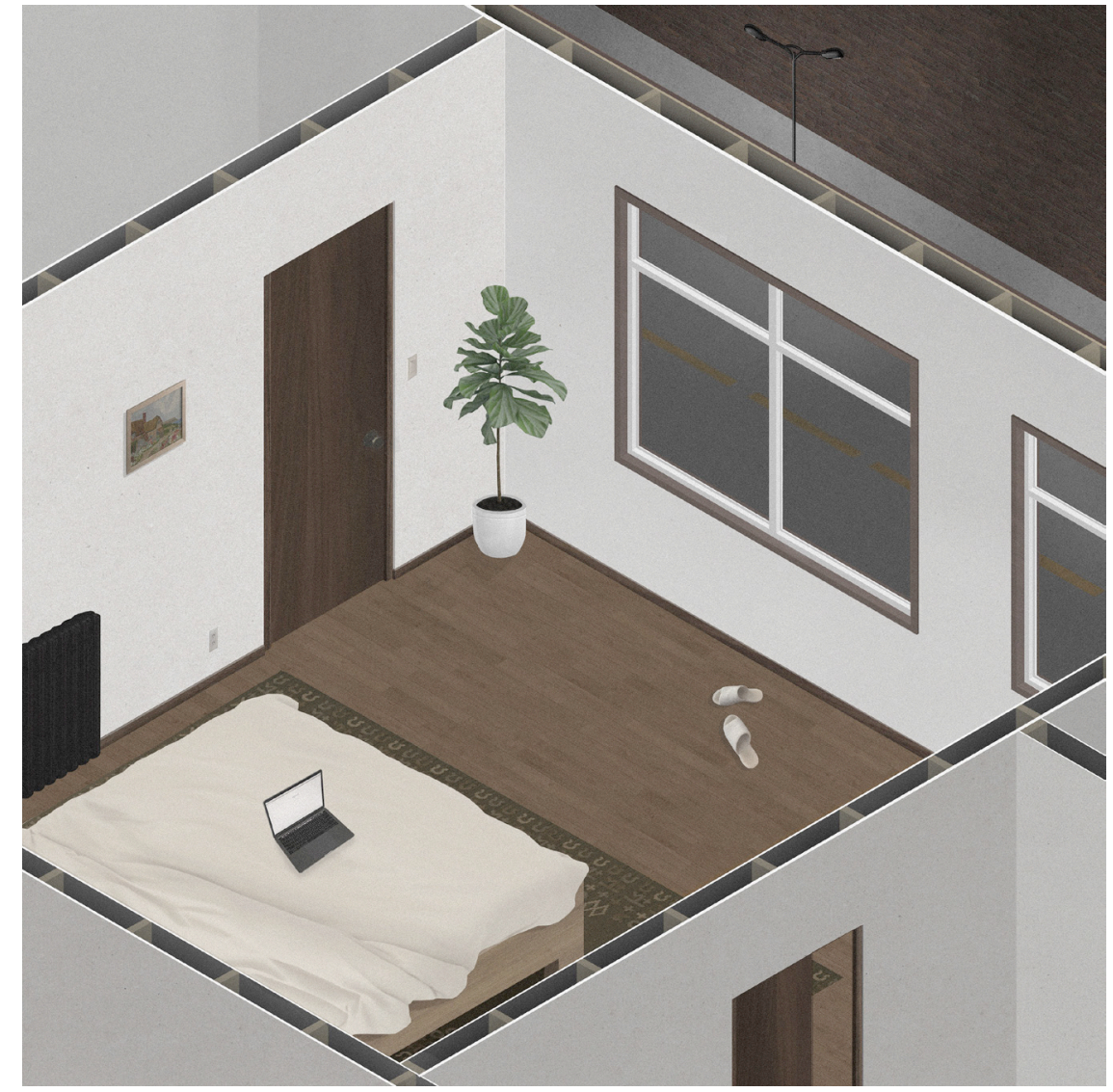

Fig. 46

"Having a self-respect looking place, a respectful environment, gives you a chance at having a better chance at him treating you better or maybe wear a condom 'cause he thinks you respect yourself." ${ }^{25}$

Homes are the pinnacle of 'limited-intimate' space. As sex working environments, they offer numerous opportunities for exploration, safety, security, and autonomy for sex workers. However prior to the introduction of Bill C-36, homes were legally considered bawdy-houses and thus considered public spaces. Regardless of the state of criminalization involved in working from one's home, sex workers must often keep their work a secret from neighbours or other building tenants. Questions of access and visibility thus come to prominence in the space of the home. 
A

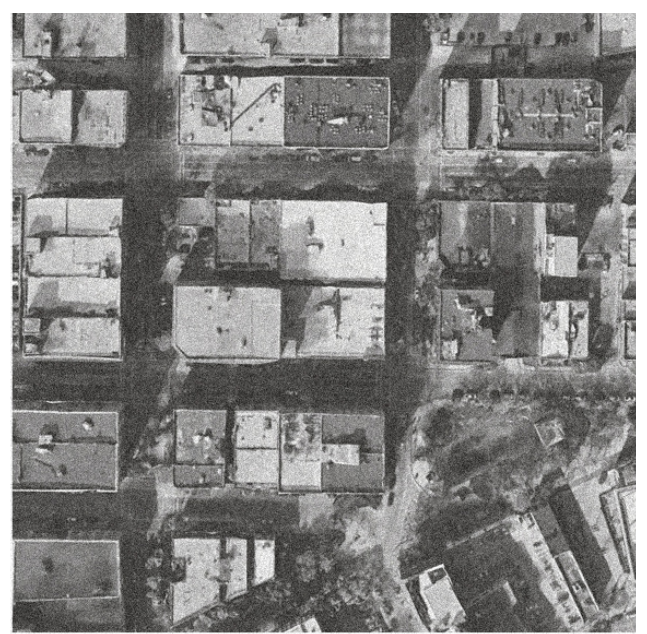

B

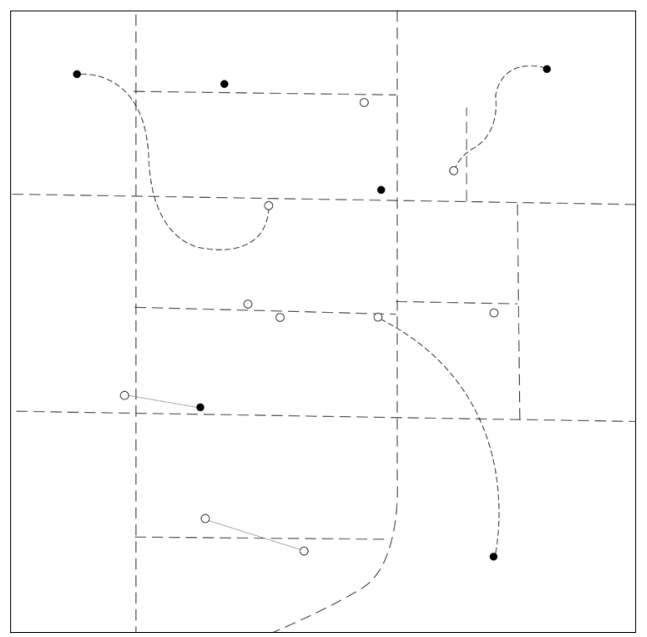

C

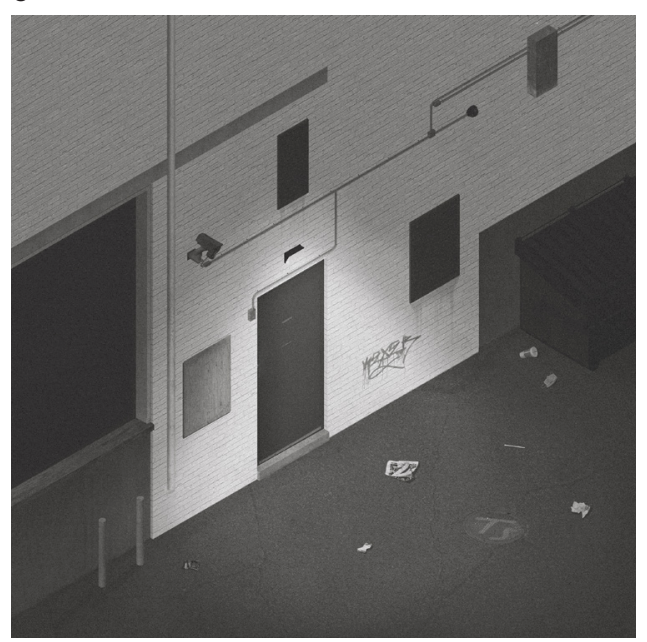

Fig. 47

Triad - Alleyway 


\section{Sex and the City}

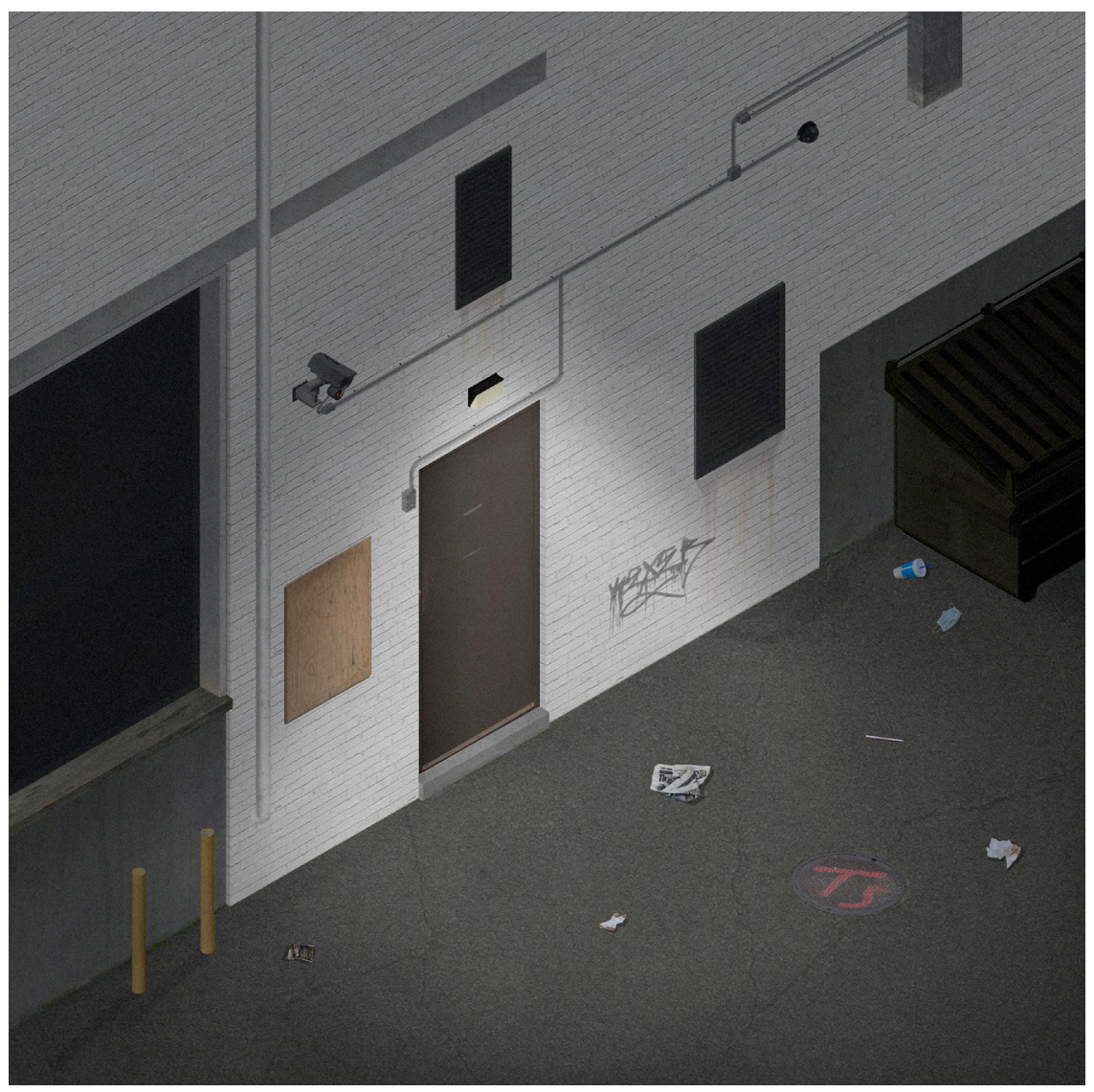

Fig. 48

"All the alleys. I would never go through the alleys, okay. Never there, no, never in the alleys. Never, never..." ${ }^{26}$

Alleyways are spaces that are consistently associated with sex work. This perception feeds into the notion that sex worker's jobs must be inherently invisible, occurring only in the hidden recesses of city space, when in fact spaces of sex work can exist far beyond these dark corners. Alleyways are sites of concealed publicity, making them potentially dangerous places to occupy. While seemingly hidden, alleyways are commonly surveilled spaces. A 2013 Toronto study found that sex working women felt CCTV to be invasive and intrusive to their work, as opposed to making them feel safe and protected. As noted by one Toronto sex worker:

[CCTV] makes our work harder. It makes us more unsafe because...you have to find a place [to work] - the people are already having to work farther and farther out and in darker and darker corners or, you know, more at risk with clients or whatever in their spaces, and so you have to find more corner-y places that don't have a camera. So how does that keep us safer? ${ }^{27}$ 
Lefebvre's tripartite model of social space serves as a productive analytic framework in considering how power shapes the everyday, and more specifically how spatial plurality is socially constructed. In Lefebvre's conception, space is not only a physical locus, but rather a powerful container that negotiates action and perception. Yet there exists an important dialectic tension between the conceptions of space and of place. This tension is necessary in recognizing the multi-directional and multi-scalar flows of power within the public sphere, flows that are powerfully present within the context of sex work. At what point does space become place within conceptions of intimacy and the city? And how can place activate more intimate publics?

The atmosphere of a given place is determined by spatial qualities-the textures, surfaces, sights, and histories-that create the hard and soft rhythms of urban life. These spatial and material qualities enable a host of actorssex workers, clients, police, community members, city officials, and so on-to engage with places as sites of sexuality in different ways ${ }^{28}$ It is also through the dual existence of space and place that sexual space is scripted, offering a range of considerations within the urban setting. How does a client access a sex working space discreetly? What kind of erotic possibilities does a space offer? And how do these erotic forms come to life ${ }^{29}$ For the Canadian sex worker, space is legislated, controlled, and transgressed, but it is place that gets transformed, for better or worse, through intimacy.

Place is ultimately where the affective dimensions of infrastructure resides. It is, in many ways, why infrastructure becomes so important. Infrastructures bridge the gaps between space and place because they exist in both realms concurrently, in that they operate both technically and affectively. Similarly, architecture forges space and place simultaneously, and it is also through architecture that given attachments to spaces and places can be reconstituted. Considering its inherent attachment to intimacy, place becomes the possible site of autonomy, activism, and resistance. By exposing the hidden power structures that govern space and place, we can begin to conceive of insurgent modes of production and thought that rescript the oppressive spatial narratives that enable marginalization. 


\section{Part 02: Endnotes}

1 Phil Hubbard, Andrew Gorman-Murray, and Catherine J. Nash, "Cities and Sexualities," in Handbook of the Sociology of Sexualities, ed. J DeLamater and R.F. Plante (Switzerland: Springer International Publishing, 2015), 291.

Phil Hubbard, "Sex Work, Urban Governance and the Gendering of Cities," in The Routledge Research Companion to Geographies of Sex and Sexualities, ed. Gavin Brown and Kath Browne (London: Routledge, 2016), 315.

Hubbard, Gorman-Murray, and Nash, "Cities and Sexualities," 295.

Canadian Public Health Association, "Sex Work in Canada: The Public Health Perspective," December 2014, https://www.cpha.ca/sites/default/files/assets/policy/sex-work_e.pdf.

Leslie Ann Jeffrey, "Prostitution as Public Nuisance: Prostitution Policy in Canada," in The Politics of Prostitution: Women's Movements, Democratic States and the Globalisation of Sex, ed. Joyce Outshoorn (Cambridge University Press, 2004), 91.

Valerie Scott, "Bill C-66/Sex Workers/Bawdy-house," Senate of Canada, https://sencanada.ca/content/sen/ committee/421/RIDR/Briefs/2018-04-17_C-66_SexProfessionals_e.pdf.

Panopticism here refers to the invisible omnipresence of the surveilling power that thus creates permanent states of visibility and furthers control. See Michel Foucault, Disciple and Punish: the Birth of the Prison, New York: Pantheon Books, 1977

Lauren Berlant and Michael Warner, "Sex in Public," Critical Inquiry 24, no. 2 (1998): 553.

Legacy Russell, Glitch Feminism: A Manifesto (New York: Verso, 2020), 93.

Treena Orchard et al., "You Just Have To Be Smart': Spatial Practices and Subjectivity among Women in Sex Work in London, Ontario," Gender, Place \& Culture 23, no. 11 (2016): 1580.

Setha M. Low, Spatializing Culture: The Ethnography of Space and Place (New York: Routledge, 2016), 32.

Alison Grittner and Kathleen C. Sitter, "The Role of Place in the Lives of Sex Workers: A Sociospatial Analysis of Two International Case Studies," Affilia 35, no. 2 (2020): 276.

Red Schulte, "Sex Working Economies of Space," The Funambulist 33 (2021): 38.

Ibid.

Brian Larkin, "The Politics and Poetics of Infrastructure," Annual Review of Anthropology 42, no. 1 (October, 2013): 336-337.

Treena Orchard et al., "'People Like Us": Spatialised Notions of Health, Stigma, Power, and Subjectivity among Women in Street Sex Work," Culture, Health \& Sexuality 21, no. 4 (2019): 480.

\section{Henri Lefebvre, The Production of Space (Oxford, UK: Blackwell, 1991), 39.}

Ibid.

Low, Spatializing Culture, 18.

Scott, "Bill C-66/Sex Workers/Bawdy-house," 1

Pivot Legal, "Reckless Endangerment: Q\&A on Bill C-36: Protection of Communities and Exploited Persons Act," June 2014, https://www.pivotlegal.org/reckless_endangerment_q_a_on_bill_c_36.

Orchard et al., "'"People Like Us"," (quoted from Mitch), 487.

Nina, "Vacancy," Let Us Stop Living Secret Lives: the Visual Stories of Sex Work, https://www.stoplivingsecret lives.com/the-law?pgid=irnl1n8d-f5df6dc1-2ac7-48f3-bab9-71db6e4a3b6c. 
Andrea Krüsi et al., "Negotiating Safety and Sexual Risk Reduction with Clients in Unsanctioned Safer Indoor Sex Work Environments: A Qualitative Study," American Journal of Public Health (1971) 102, no. 6 (2012): 1157.

Emily Van Der Meulen and Amanda Glasbeek, "The Gendered Lens: A Report on Women's Experiences with Video Surveillance and Urban Security in Toronto," Ryerson University, April 2013,

https://www.ryerson.ca/content/dam/criminology/tank/documents/1.\%20Gendered\%20Lens\%20Report\%20 April\%202013.pdf.

Alex Tigchelaar, "Sex Worker Resistance in the Neoliberal Creative City: An Auto/ethnography," AntiTrafficking Review 12 (2019): 27. 


\section{Part 03:}

Intimacy as Infrastructure 


\section{Exclusion and Autonomy}

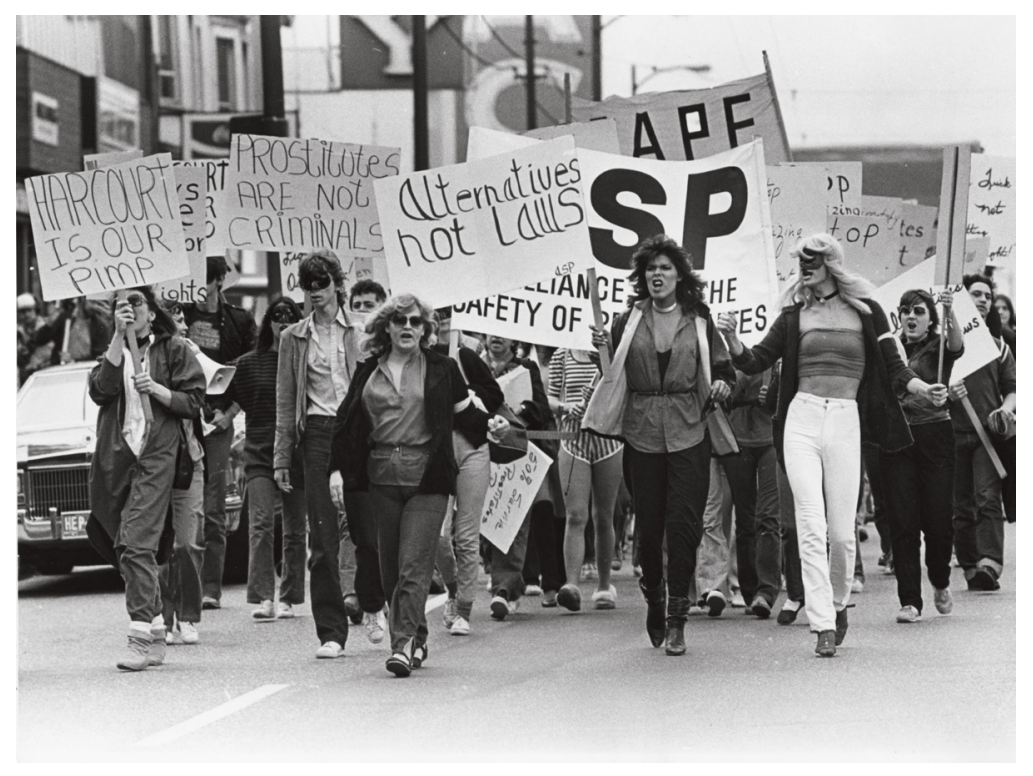

Fig. 49

Sex workers and

allies protest, 1983

Much of the work of this thesis has focused on tactics of violence, exclusion, and invisibility within the built environment. Exposing this violence is a necessary step in furthering spatial justice and in addressing the right to freely access space. As Red Schulte aptly describes, "We cannot discuss the people whose work affects space, without addressing the economic conditions (read: violence) within which workers find themselves struggling." These dynamics are necessary to unpack in order to understand the depth of stigma associated with the profession, but the effect of this unpacking is not to establish sex workers as perpetual victims. On the contrary, sex workers and sex work activists work tirelessly to chip away at deeply ingrained notions of morality and sexuality while fighting for safety and self-determination. Within this sex-positive lens, sex work is seen as an opportunity for exploration, growth, and sexual expression that seeks to alter the moral standards that saturate western culture. ${ }^{2}$ Actualizing these shifts requires sex workers to form places and spaces of autonomy across physical and virtual territories, the likes of which are infrastructural insofar as they utilize intimacy as a binding force. 
Digging into the affective infrastructure of intimacy itself while assessing how it governs sex work requires the focus to evolve from laws and space, to people and place. The intricate web of actors that influence, and are influenced by, sex work expands far beyond sex workers themselves. As depicted in figure 50, sex workers are just one factor within the network of stigma and legal repercussions that hegemony has formulated. Amidst this network lies the potential for solidarity and fundamental movement toward inclusivity and visibility-a potential that can be actualized in and through place.

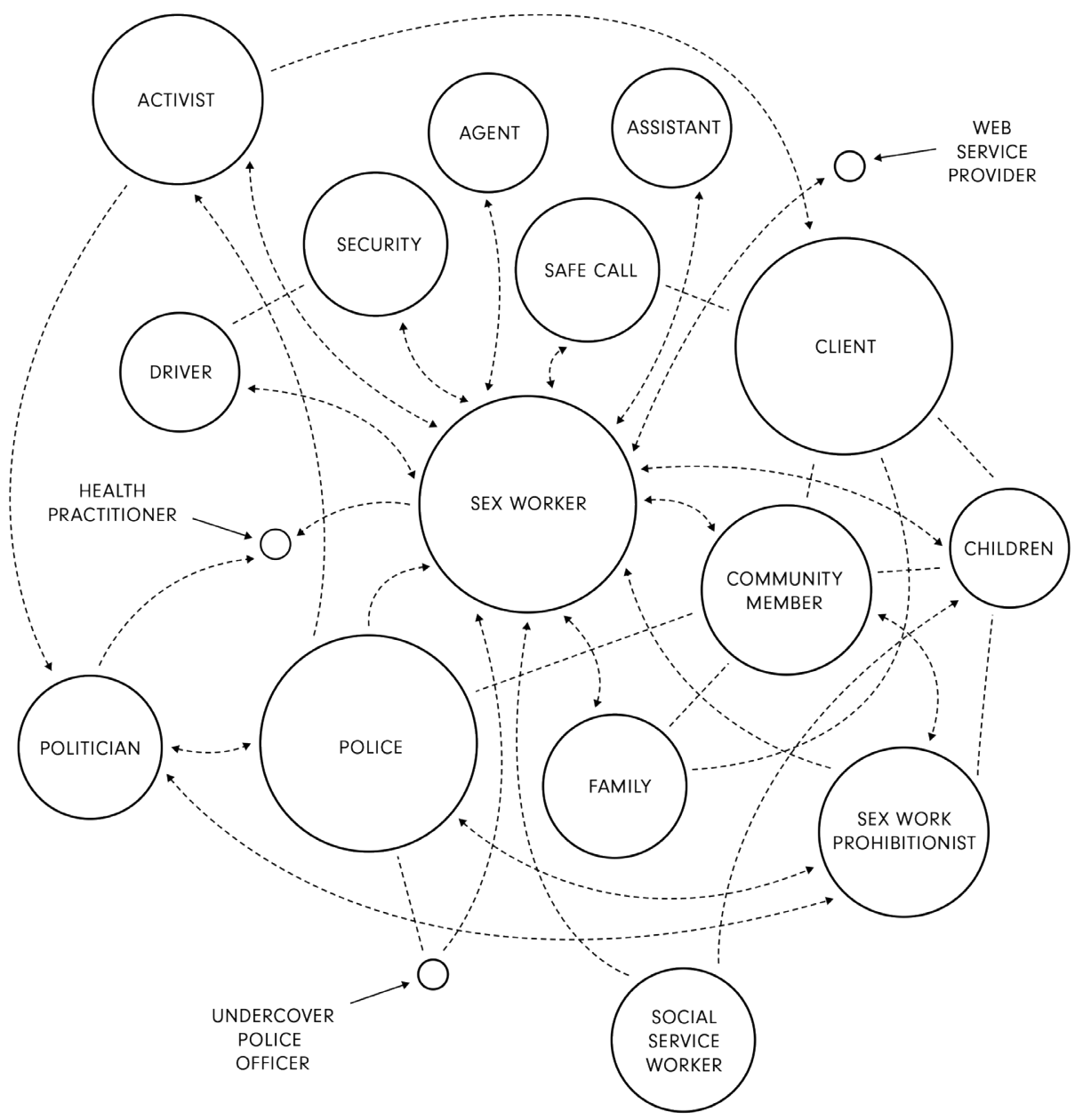

Fig. 50

Diagram of some of the actors involved in the sex industry 


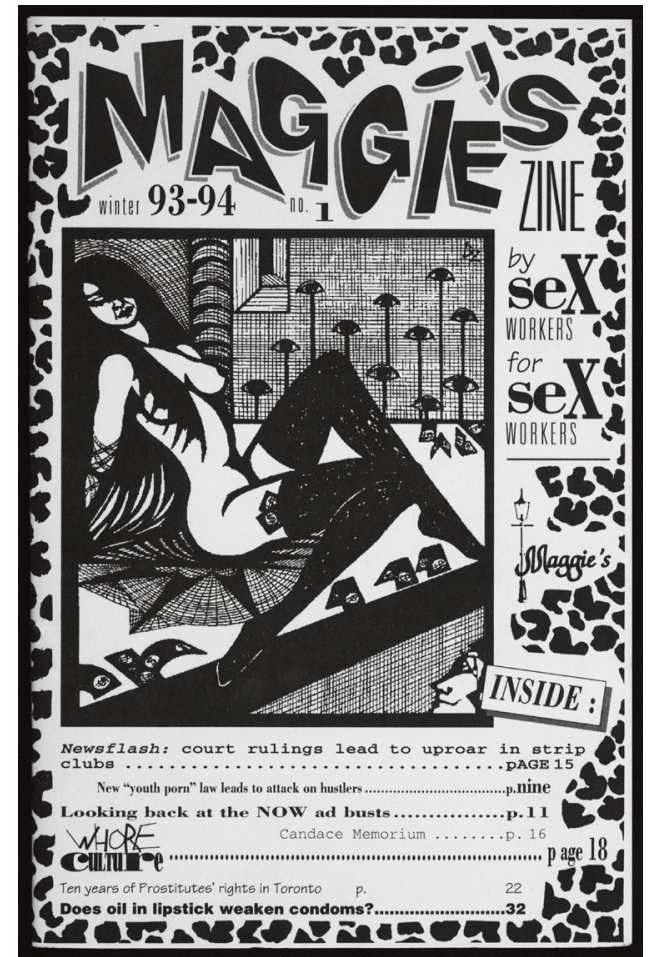

Fig. 51

1993/94 Winter edition of "Maggie's

Zine," produced by Toronto sex work

advocacy organization Maggie's
Atop this foundation of activism, considering intimacy as infrastructure begins to offer ways of reconsidering the relationship between affect, place, and vulnerability. As has been seen, intimacy works infrastructurally to regulate connections much in the same way that a highway works to connect two cities but divide a landscape, or a pipeline works to transfer either water or waste. Its binding nature makes it widely coveted and also widely guarded against, and it becomes a particularly powerful tool when invoked within these spatial contexts. Exposing the roots of intimacy's regulation offers new insights into its capacity to work infrastructurally. In Brian Larkin's assertion of infrastructures as political and poetic devices, he posits them as "objects that create the grounds on which other objects operate, and when they do so they operate as systems. ${ }^{\prime 3}$ Intimacy as infrastructure thus enables care and collectivity to operate in systemic confluence, mingling with atmospheres of place to construct the space of the city. Building on-and in many ways laying the foundation for-understandings of intimacy, Lauren Berlant asserts that to "rethink intimacy is to appraise how we have been and how we live and how we might imagine lives that make more sense than the ones so many are living. ${ }^{44}$ Intimacy as an infrastructure, as a spatial determinant and an affective structure, thus has direct implications on the practice and poetics of architecture and on the constitution of space and place. ${ }^{5}$

Figure 52 is an attempt to embed this sense of atmosphere within cartographic practice, shifting from the body in social space to the body in intimate place. The drawing accesses the concept of place through a multiscalar representation of ambiguous space, juxtaposing erotic attachment with traditional cartographic representations to evoke the indistinguishable limits of sensorial embodiment. The intimate cartography-or, alternatively, affective geography-that is formed through the presence of desire, dream, and memory exposes the city as an assemblage of bodies, constantly affecting one another. It hints at intimacy not only as localized, but also as diffuse, inclusive, and multi-scalar. It is ultimately through processes of exposing invisible connections and expanding upon the space of encounter that these conversations of intimacy's binding qualities comes to light. Exposing the hidden dimensions of the body in-or out of-place establishes intimacy as instrumental in creating the space of the city and in striving toward futures that embrace the intimate in its many forms. 
1.

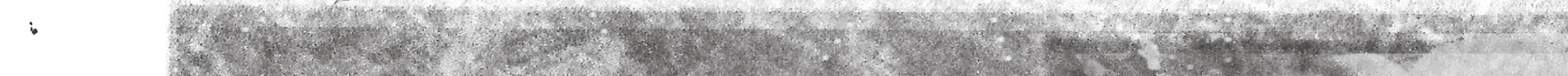

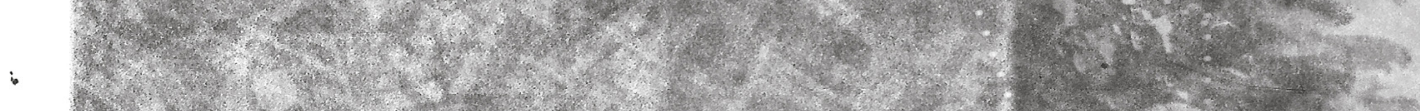

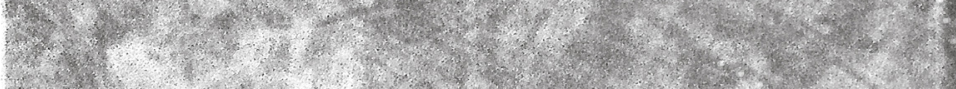
2.

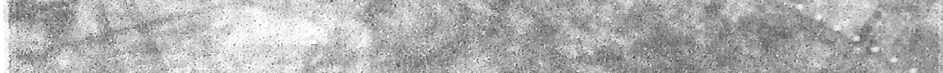

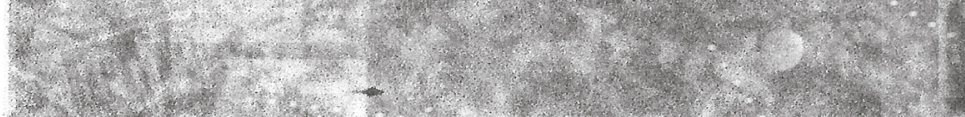

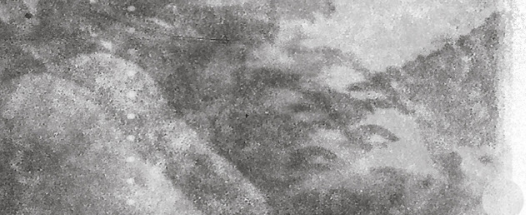

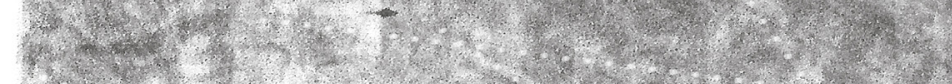

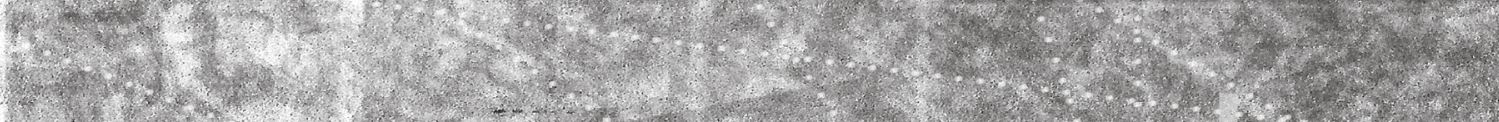

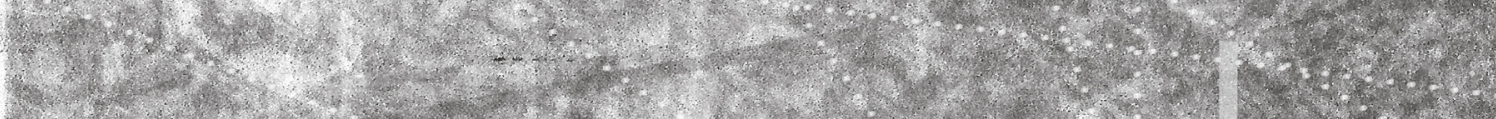

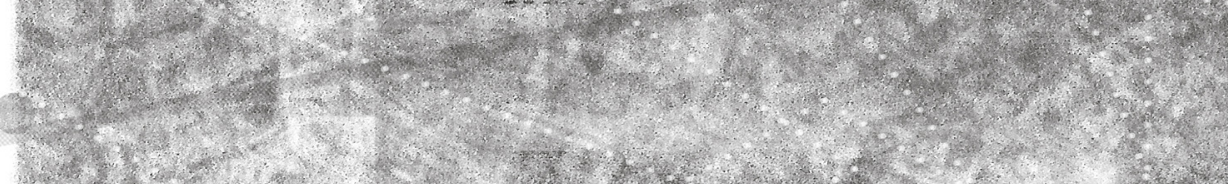

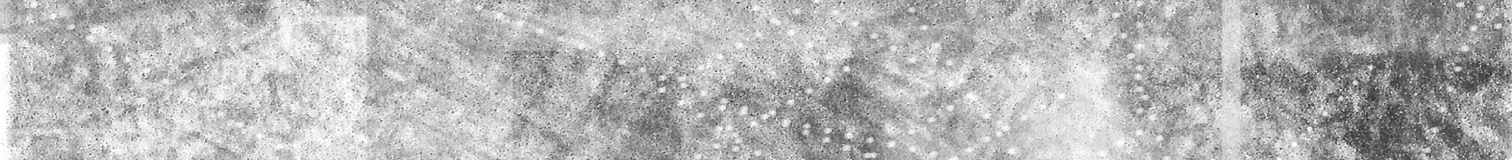

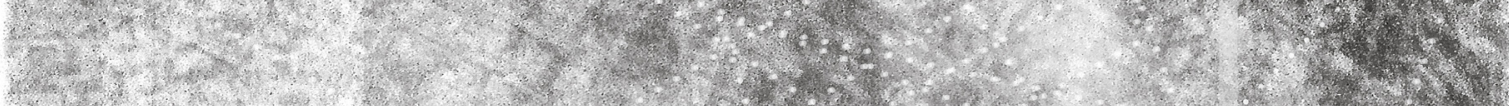

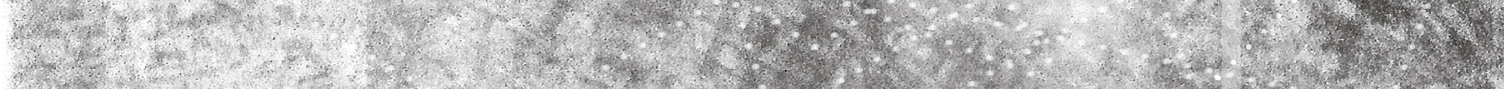
a.

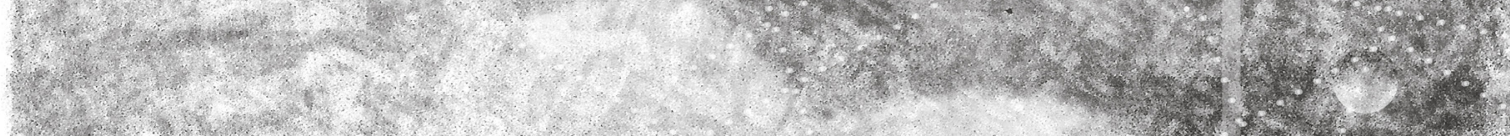

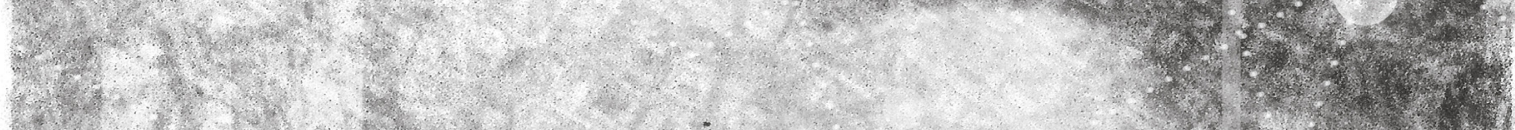

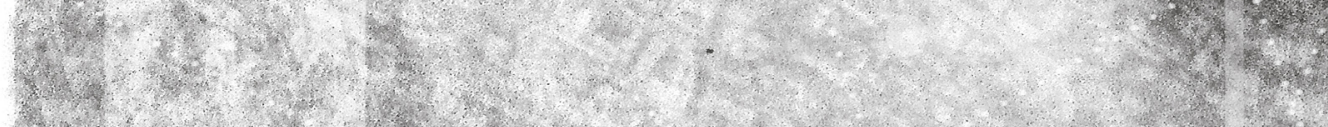

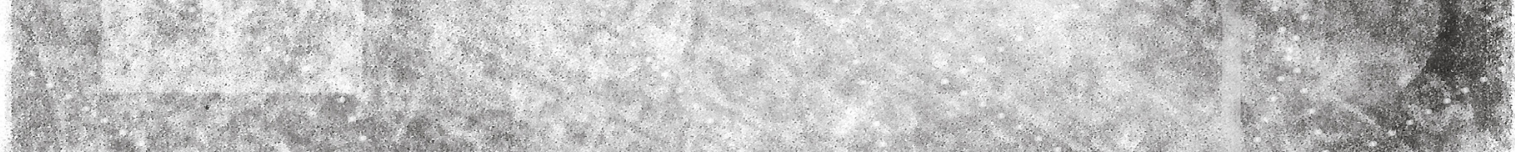

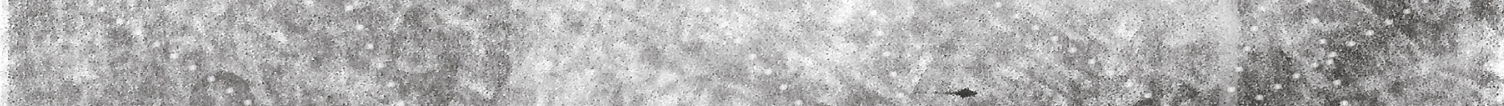

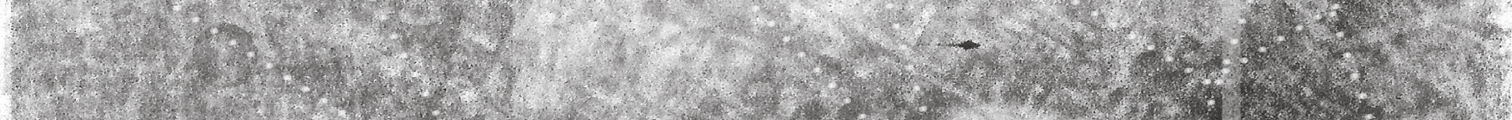

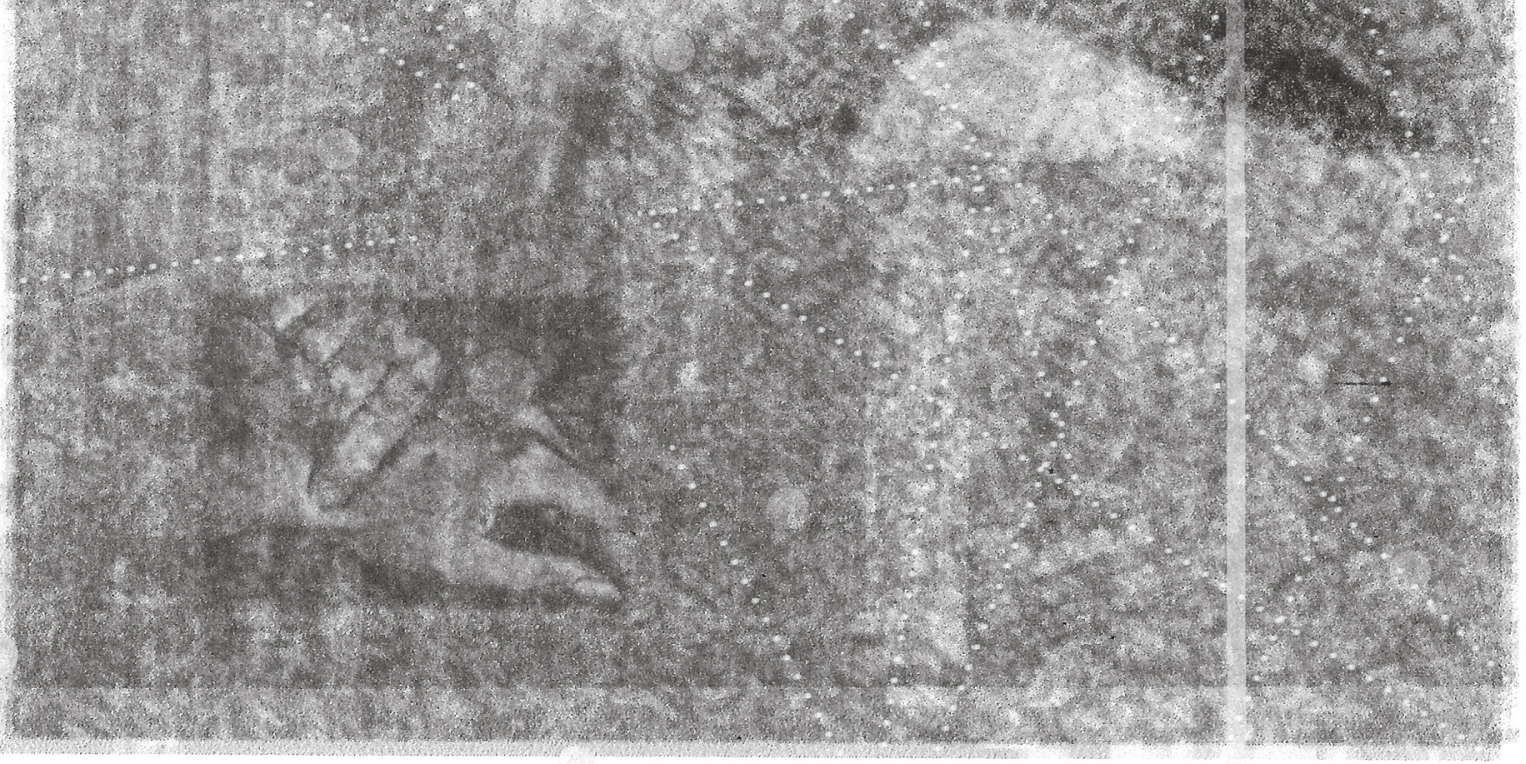




\section{Public Bodies}

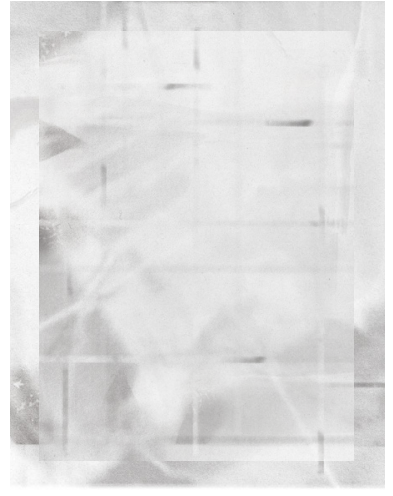

Fig. 53 Intimacy and the body
If we are to consider the city as an assemblage of bodies constantly affecting one another and constructing intimate attachments, we must necessarily define what a body is or can be. This thesis has dealt with numerous scales and geographies, yet the body is, as poet Adrienne Rich notes, "the geography closest in."6 Throughout this thesis, the body and its numerous definitions have been paramount. The work has offered critical insights into the relationships that bodies have to the city, that they have to infrastructure, and that they have to one another, forging connections across disparate scales, temporalities, and modes of existing in the world. It has also examined the way that bodies exist and interact in public space, and the particular performances that they are permitted to enact based on socio-spatial norms. It has considered legislative bodies by unpacking the role of Canadian law in questions of spatial governance. As has been argued, these legislative bodies exist at a critical distance from the subjects over which they preside and the labouring bodies that they regulate. Part 02: Sex and the City addresses this distance through notions of spatial violence and explores what this violence looks like as it traverses scales from that of the country to the bedroom, and the spatial configurations in between. Lefebvre's spatial lens within Sex and the City also emphasizes the way that the human body produces space rather than simply conceiving of or inhabiting it. This work is also a deep meditation on body politics, addressing the roles that both legislation and societal norms play in regulating the presence and articulation of physical bodies in the public sphere. It addresses body politics by calling for the decriminalization of sex work and thus the right for sex workers to control their own bodies. Part 01: Situating Theory and Sex Work introduces the politics enforced on Indigenous bodies through the introduction of Canadian colonial power, while also addressing the ways that infrastructures have direct implications on bodies in space. 


\section{Intimacy as Infrastructure}

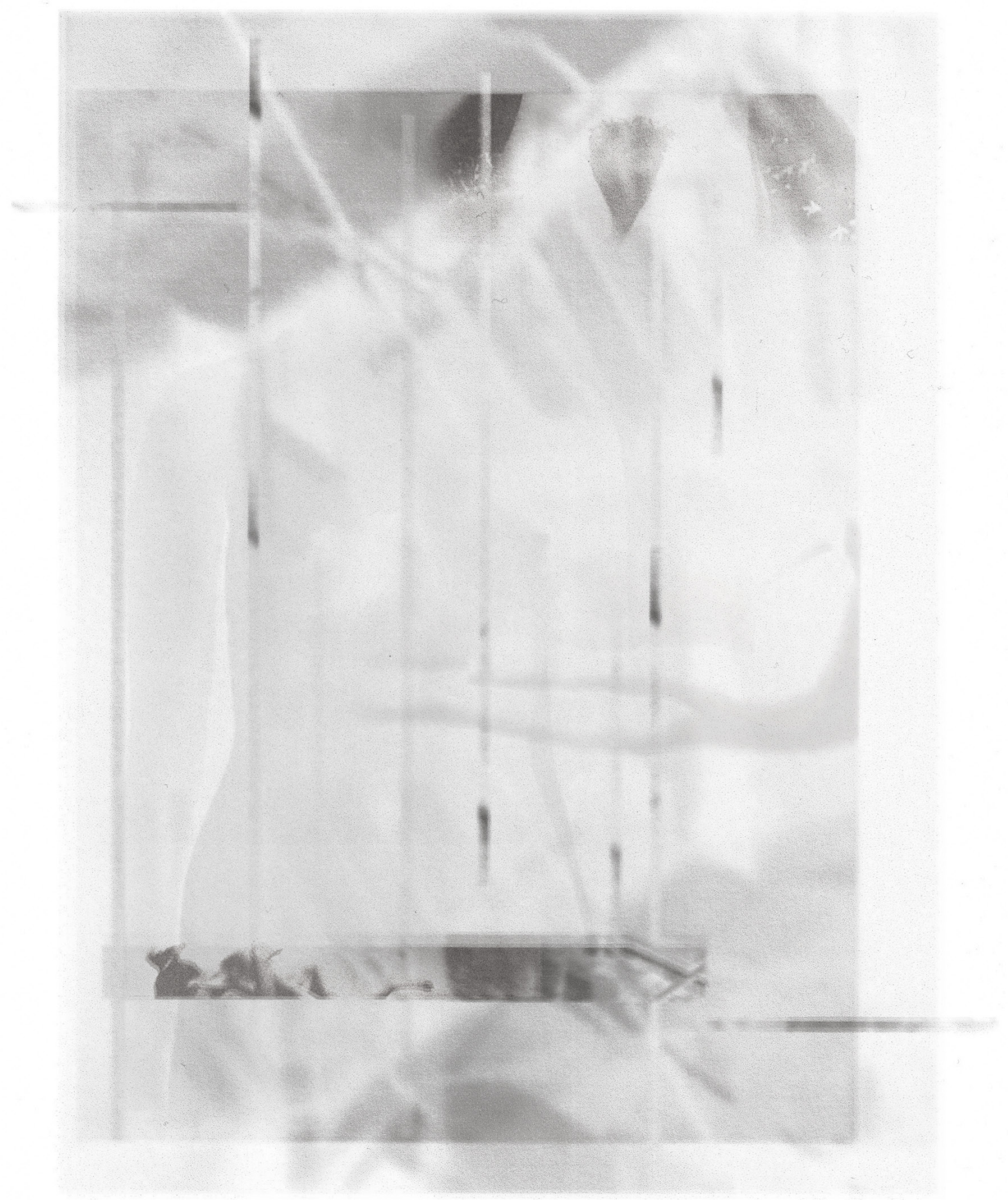

Fig. 54

Articulating the fluid threshold between bodies and space 
There is a certain distance invoked when referring to 'the body', because 'the body' can be thought of both in abstraction and within a specific context. In order to express the presence of the body at a multitude of scales, and as pragmatic subjects as much as emotional ones, the individual body throughout this work has been treated largely as a site: a site of violence, a site of legislation, a site of exchange, and a site of autonomy. Within Canadian legal frameworks, the body is utilized as a site of control, violence, and legislation much in the same way that space and place are. This control is actualized through the attempted restriction of certain bodies from so-called respectable neighbourhoods, the perpetual victimization of those in the sex industry and the implication that they are not in control of their bodies, and the forced marginalization of bodies that gets furthered through policing structures. Control thus shifts from a right to control over one's own body, to having one's body legally and spatially controlled. This legal framing renders certain bodies out of place within city space and reinforces harmful narratives about what a body is allowed to do, as well as what bodies are worth protecting. As Sara Ahmed articulates, the body out of place does not dissolve into its environment the same way that the allowable body does. Safety and comfort allow the body to be accepted in place and thus makes it difficult to discern where the body ends and space begins. Certain bodies fit seamlessly into space, "and by fitting, the surfaces of bodies disappear from view.."

Bodies, and historically female bodies in particular, have been constantly objectified by the societal gaze. The space of objectification is often

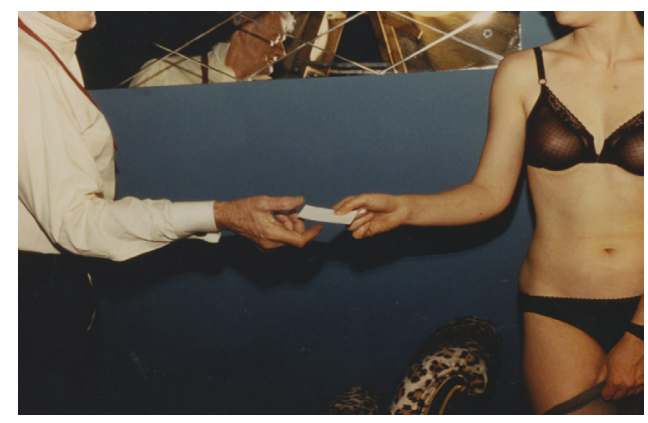

Fig. 55

Still from Lizzie Borden's film Working Girls one void of autonomy, as to objectify is to literally treat or construe the body as an object. Rather than placing the body-as-object throughout this work, the aim has been to express space at various scales of bodily experience. Following cues from Lizzie Borden's 1986 film Working Girls, whose contemporary relevance is striking, this thesis has not sought to fetishize the bodies and labor within the sex industry. Borden's film is a critique of capitalist structures and a commentary on the sexual politics of labour, and although its plot revolves around sex workers in a New York City brothel, it is decidedly unerotic. Borden's attention to the gaze 
seeps beyond the cinematographic view and into each aspect of the film's production, what Borden herself refers to as a "female apparatus." ${ }^{18}$ To avoid the objectification of female, sex working bodies, Borden steers away from eroticized takes and instead focused the attention onto the character's awareness of their own sexual embodiment. The film challenges the common paradigms of sex work, in which a sex worker must either be a victim or an erotic object, and instead focuses attention on dynamics of power and autonomy. By treating the body as a site of power, this thesis echoes Borden's intention in its aim to avoid objectification while maintaining the importance of autonomy and embodiment.

The body within this thesis also exists as a site of affective exchange within the built environment, in that spaces extend bodies and bodies in turn extend spaces. ${ }^{9}$ Intimacy removes the body from the space of objectification, as forging an intimate connection requires a body responsive to affective signals. This sense of embodiment cannot arise from a stagnant body-as-object; instead it is the autonomous body in space that becomes a locus of passion, desire, and beauty. Recognizing the interplay between body and space is critical to moving beyond objectification. In the following subsection, Acts of Exposure, the body assumes the role of actor within the built environment. As actor, the body remains a site of exchange between affect and atmosphere. It is critical to express the exchange between body and place in the portrayal of spatial narrative, because it is at the site of the body that subjectivities arise.

Lastly, the body also serves as an apparatus for extending these conversations to an architectural audience, and has been a way to situate my agency within these themes. The subjects of this work, as well as those who are reading this, all inhabit bodies, and we likely want to think of ourselves as being in control of our bodies. If we think about the ways that our own bodies are sociospatially controlled, the notion of control within the context of sex work can be more easily understood. By delving into the body as a site, we can begin to speak to broader conditions-our bodies are all sites that are impacted by the build environment and they shape the way that we exist in the world. 


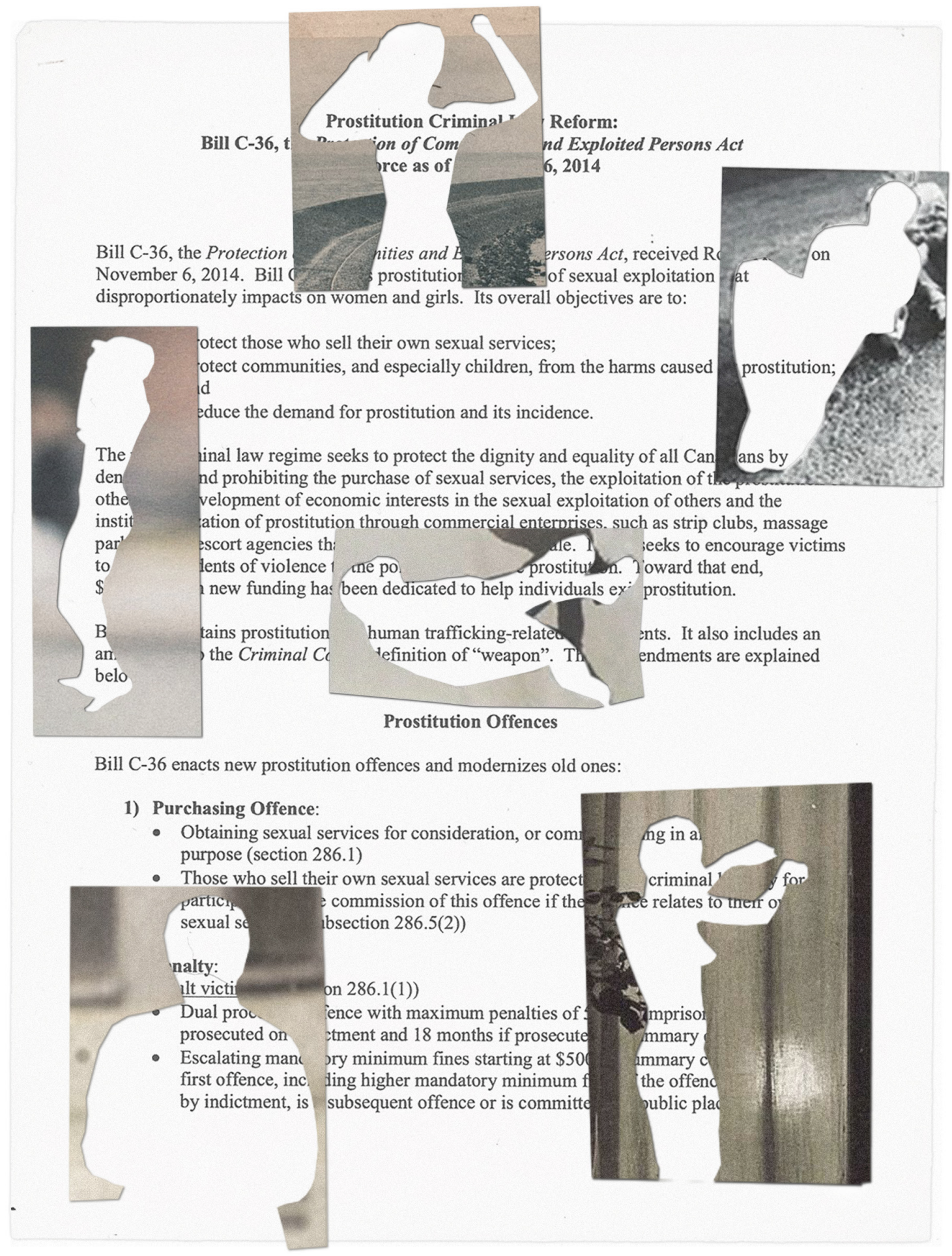

Fig. 56

The body is treated as a site under Canada's current and historical legislative frameworks 


\section{Acts of Exposure}

If intimacy is to be considered infrastructurally, how do its spatial and social relations get quantified? Where does intimacy begin to exceed its commonly conceived definition as something private, proximate, and personal into the realm of connection and world-building? And how does intimacy become an analytic tool to understand both the violent and liberatory effects of, and on, spaces, places, and bodies as they relate to sex work?

The answer to these questions-or perhaps, rather, provocations-lies within the space of perception, and considering intimacy infrastructurally allows its many forms to be more tangibly grasped. And so, the work of this thesis leans into the heuristic capacity of exposure to shift this perception. To expose is, essentially, to make visible. The concept of exposure is utilized as a filter through which to recognize the hidden dimensions of power and plurality inherent in the everyday. There is also a plurality inherent in the word exposure itself, particularly in relation to these understandings of sex work and intimacy:

Exposure in space opens up questions of power, as to be exposed is to be vulnerable to external forces and views. To be exposed to something is to have a new understanding of it. In photography, exposure is the amount of light that reaches the film or sensor, ultimately determining the qualities of a captured image. Along these lines, to expose is to remove the stigma from conversations of intimacy, ultimately determining the qualities of perception of a given scene. For many sex workers, spatial exposure often means increased safety, but also increased surveillance, stigma, and legal force. Exposure conjures images of bareness, exhibitionism, and bodies as they are revealed. Metaphorically, it serves as a mechanism for acceptance, uncovering what is culturally shrouded.

Exposure can arise through glitches in the observed social order, through tapping into the weak points of social constructions to consider relations 


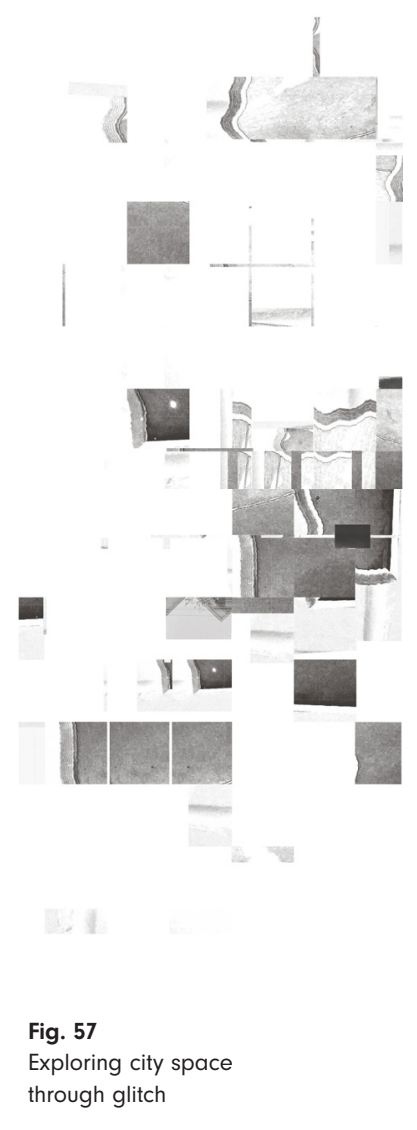

otherwise. In response to Lauren Berlant's evocation of what "the beyond of glitch looks like, ${ }^{\prime 10}$ this meditation on exposure seeks to explore what forms of life arise when the fluid threshold between the intimate and the collective begins to dissolve. These exposures are cultivated through the production of a scripted performance through two spatial acts, comprised of written scripts and corresponding drawings that explore the perception of infrastructures and their intimate attachments within the built environment. Exposure in the case of the acts is the process of uncovering the plurality of space and the ways in which affective bonds between bodies and infrastructures create place. To return again to Lefebvre in order to elaborate on the basis of the acts as mode of investigation, space can be recognized as both a field of action that offers space for productive purposes, and a basis of action in the way that it is both formed through, and facilitates, action. ${ }^{11}$ The acts engage space and place through this notion of action, aiming to bring awareness to the conditions of sex work within the public realm, the tangible imbrication of space and sexuality, and the possibilities that arise when space is rescripted. However before diving into the specific details of these acts and their respective actions, it is necessary to further outline why space and place are being activated as such.

In exploring the ways that people inhabit collective space, philosopher Judith Butler theorizes gender as a social performance, ${ }^{12}$ while Phil Hubbard describes the embodiment of "sexual scripts,"13 in that space inscribes certain allowable performances of sexuality. Although Butler and Hubbard are speaking respectively of the social constructions of gender and sexuality, their theatrical lenses are also deeply implicated in conversations of sexual expression and liberty. Just as gender and sexuality can be seen as socially-constructed and regulated through performance, so too can sexual expression and liberty-and it is against backdrops of space that these performances occur. Space can be seen not only as a factor that produces particular performances, but also as regulating the types of embodied social performances that are accepted within a given place. Performance's referential nature can reinforce dominant norms and social expressions, but can also produce distinctly divergent performances and attachments. ${ }^{14}$ 


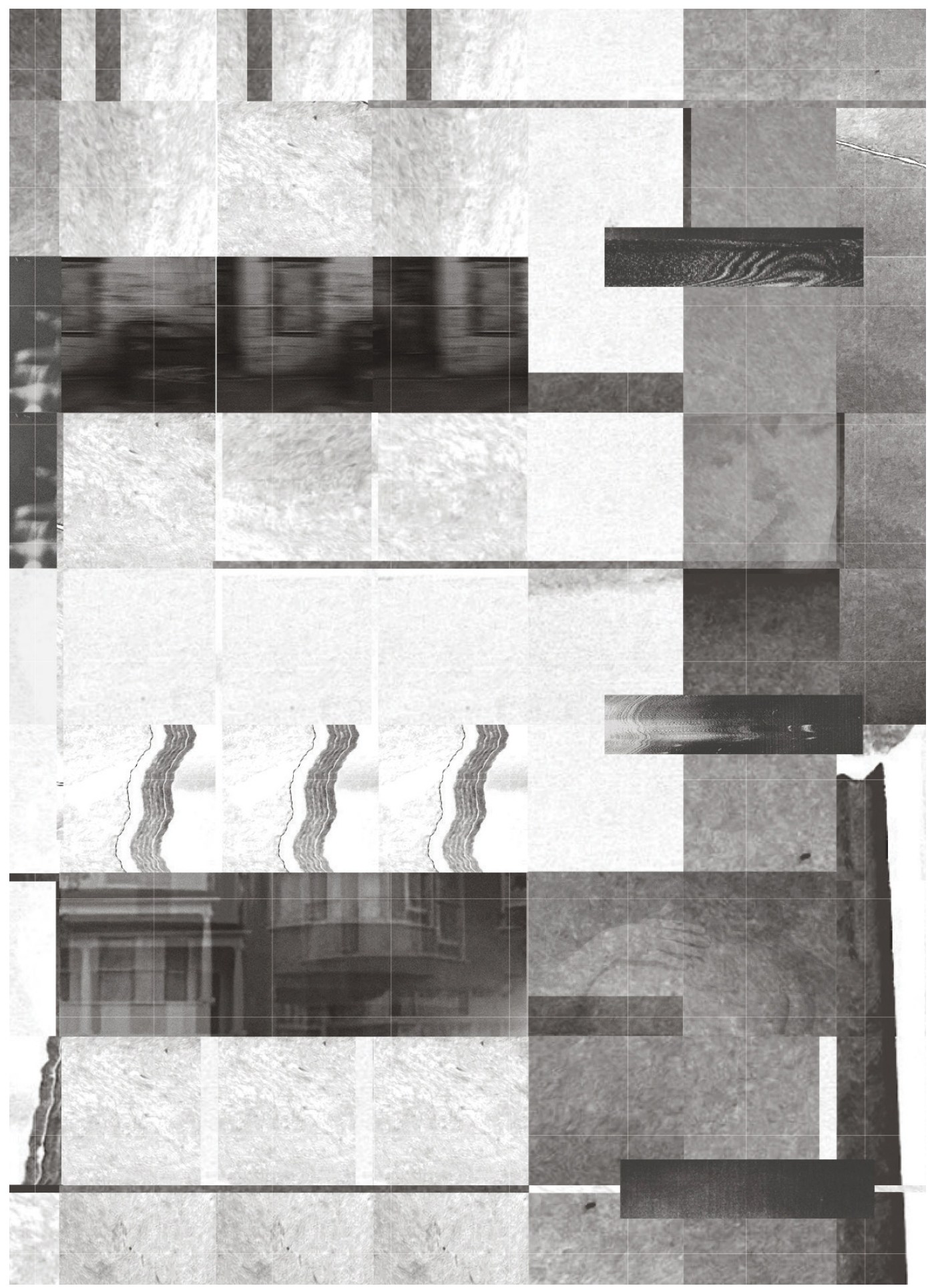

Fig. 58

Exploriation of the patterns of city

space that arise through glitch 


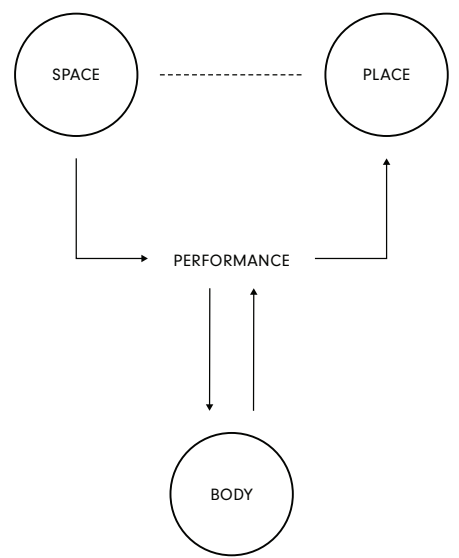

Fig. 59

Diagram depicting relationship between space, place, performance, and the body
Through this emphasis placed on social performance, space becomes coded through its capacity to enable certain performances while limiting others. However, shifting these analyses toward an ontological perspective shows how particular social performances create places. Essentially, space dictates how we perform, but it is our performances in relation to infrastructures which form space that create place (figure 59). There is a necessary interdependence that arises between space and place, in that space must first exist in order for it to be constituted as place through intimate attachment.

Recognizing the role played by infrastructures of the everyday in these intimate scenes becomes a critical basis for understanding place, and as such these infrastructures are central to both of the acts of exposure. Speaking of notions of exposure through the creation of these acts is not to say that they exist as traditionally scripted performances. On the contrary, the absence of a definitive script-and more specifically the absence of dialogue-is what ties the notion of socially-constructed performance to these acts of exposure. The acts are spatial and temporal, and it is through their spatiality that they become the backdrop for action and encounter. Understanding these narratives as 'acts' bridges a gap between social construction and imaginative world-making. In the case of these exposures, performance still exists as a sociological concept-in that there are no actors in the traditional sense-but becomes closely tied to notions of theatre through the scripting of space, and through the possibilities for encounter and visibility. Act I is an exercise in extrapolation, while Act II encourages inhabitation, association, and re-presenting in space. Each act is explored through drawing, and each drawing ascribes a possible performance in space.

Act I sets the stage for a series of implied performances. The scripting of each scene details a background for action, as well as a series of infrastructural characters that get activated through the presence of bodies and intimate association. These infrastructural characters can take on numerous meanings-they remain as latent figures until they are mobilized through action. By approaching Act I as a spatial narrative, the agency of 
architectural analysis comes into view. Analyzing notions of place through the presence of constructed forms, whether physical walls or atmospheric shadows, designates architectural analysis as vital in uncovering the plurality of infrastructure and space. The basis of the scenes are spaces of care, desire, protest, and violence, each of which imply a particular expression of intimacy that extends beyond the division of privacy and publicity. Although these concepts do not all embody forms of intimacy meant to be cultivated, they each engage material and abstract infrastructures at numerous scales and embody a particular narrative about sex work that can be understood through space. The intimate natures of care, desire, protest, and violence and their various associated places make them particularly well-suited to expressing the space of action and encounter. This collision is essential, in that each of these spaces require an exchange between space, bodies, and place that comes into being through action. By peering deeper into what narratives these infrastructures of intimacy can enable, the act begins to expose the softness of the boundaries that have come to govern collective life.

In essence, the scenes are distilled from existing-albeit anonymous-spaces within the Canadian city. Care depicts a place of autonomy and dignity that is transformed by its inhabitants; desire passes sinuously across a shifting urban landscape, creating intimate attachments as the city unfolds; violence highlights the space of marginalization and precarity, forging a cloaked intimacy between opposing bodies and spaces; and protest elaborates on the intimate nature of collective resistance, a connective tissue activating the streetscape anew. Each of these scenes can be tied to numerous geographies, and while they are born from understandings of sex work, the forms of intimacy they describe have the capacities to expand beyond those conceptual bounds. Act I exists within this space of perceived and presupposed action, and resonates in intention with Bernard Tschumi's Manhattan Transcripts: the scenes are not intended to mimetically represent space, but rather to "presuppose a reality already in existence, a reality waiting to be deconstructed-and eventually transformed." ${ }^{\prime 15}$ These realities are activated by weaving numerous possible scenes together to create singular narratives that highlight spatial plurality, real insofar as they have been deduced from existing conditions, yet illusory in their constitutions as specific places. 


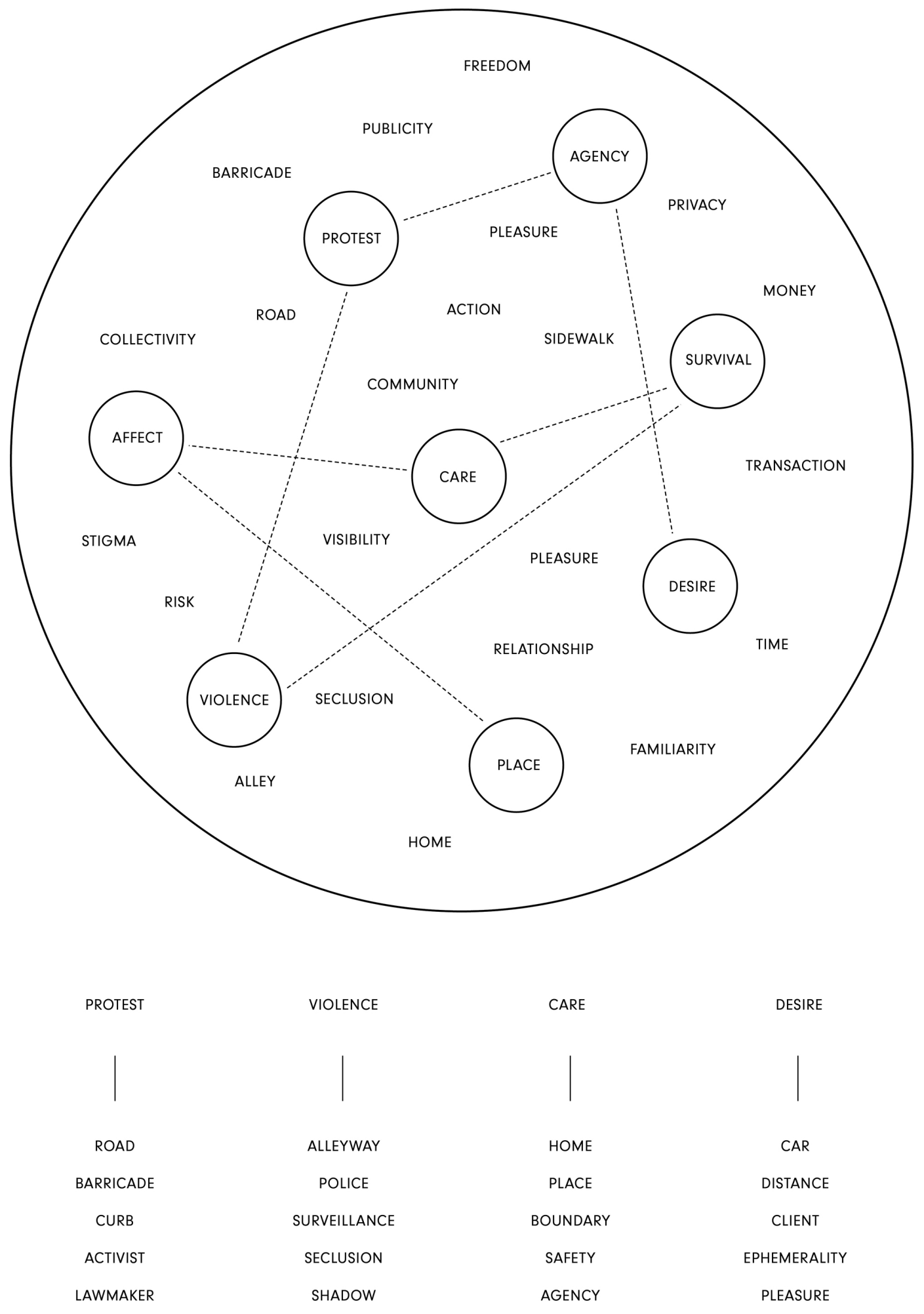

Fig. 60

Thought diagram of what infrastructures of intimacy could be 
Intimacy as Infrastructure
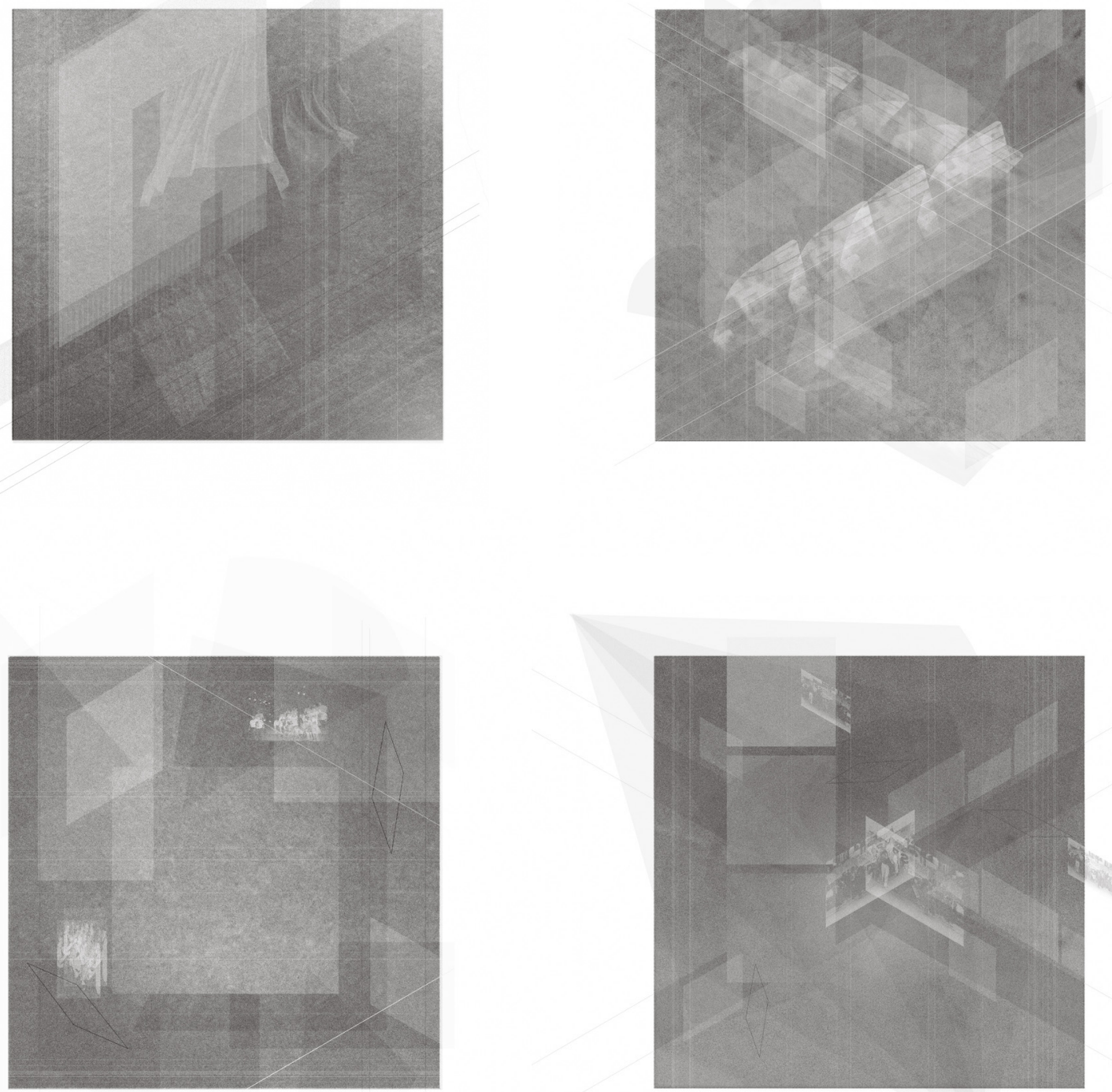

Fig. 61

Initial spatialization of concepts of care, desire, violence, and protest 


\section{ACT I}

\section{SCENE I}

\section{CARE}

public bodies, here yet hidden

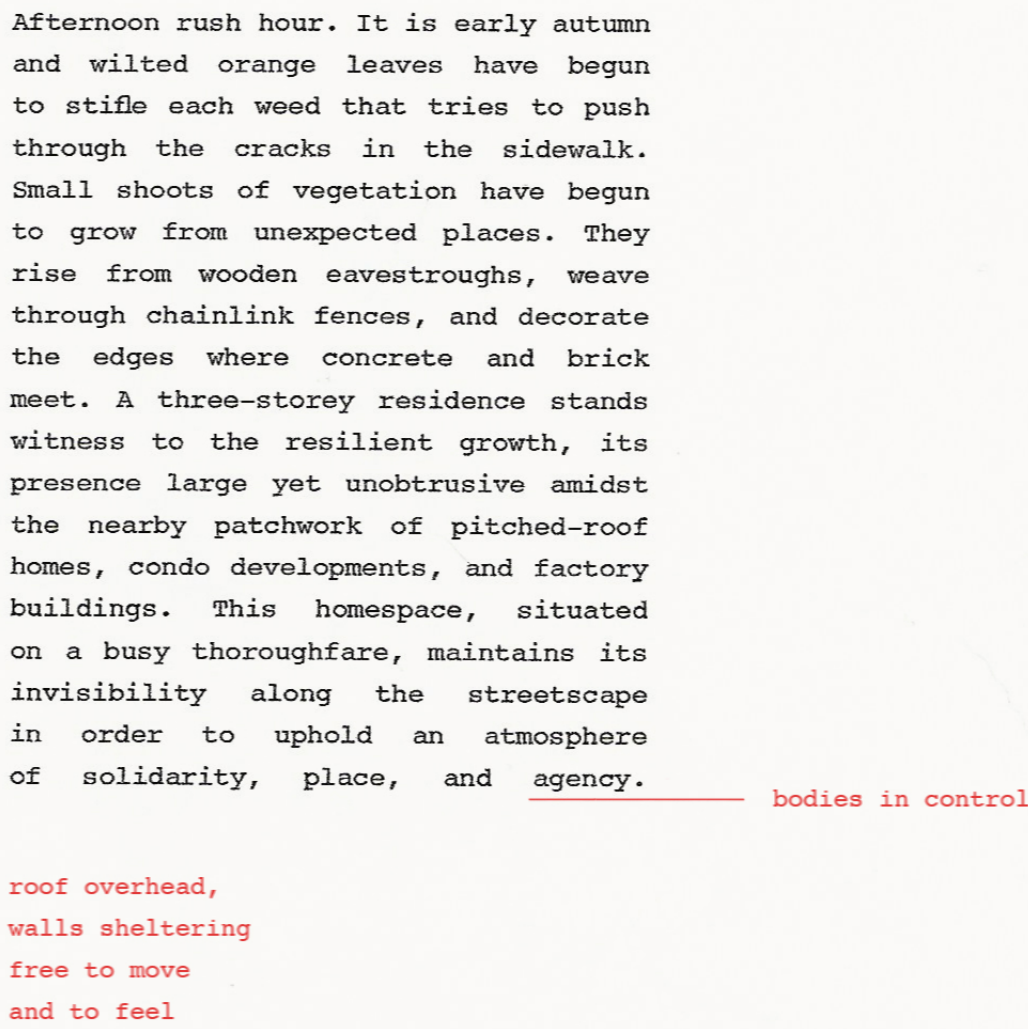

Fig. 62

Act I-Scene I: Care 


\section{THE FACADE}

This is the dividing Iine between the space of safe enclosure and that of stigmatized visibility. It is unremarkable in appearance, adorned with a neutral tone of stucco. Its ubiquity is, in a sense, what makes it safe. Behind its threshold lies a space of autonomy.

\section{THE FENCE}

The fence, painted black, is a physical sign of protection. It is a purposeful barrier between the lower floor and the sidewalk, at the brink of two colliding worlds. The fence shouts "do not cross" yet its subtext reads 'I am protecting something vulnerable and valuable'.

\section{THE DOOR}

The door governs the pregnant threshold between interior and exterior. It is the semi-permeable membrane of a fragile ecosystem. The last door, made of wood, was pried open by intrusive fingers and brute force. This one is made of steel and wire mesh; impenetrable.

\section{THE CURTAIN}

There is one curtain for each bay window that hovers over the streetscape. They are manipulable tools, drawn open or closed to govern what can be seen and what remains obscured. They are sinuous (romantic, even), mediating the space of privacy with gentle ardor. 


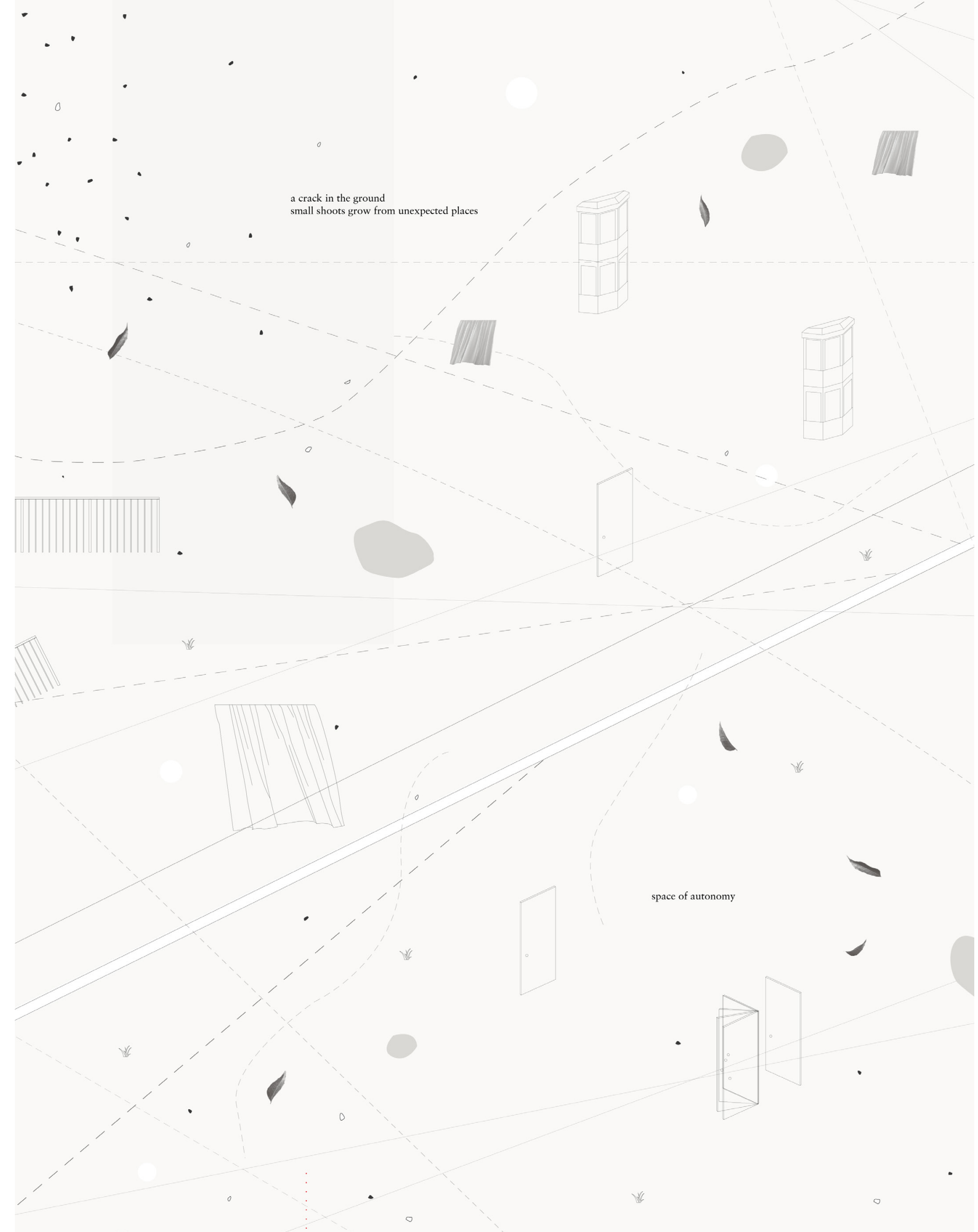

agas

Act I - Scene I: Care 


\title{
ACT I
}

\section{SCENE I I}

\section{DESIRE}

\author{
Evening. The space between here and \\ there is thick. There is an anticipation \\ in each motion, onwards, aiming for \\ heartbeat racing \\ an endpoint. The city unfolds through


THE CAR

The car is visible, yet its insular nature makes it introspective. It is a space of enclosure, with rich leather seats. Its actions are guided by anticipatory pleasure, diving headfirst into the unpredictability of city space in an unchoreographed jolt.

\section{THE WINDOW}

Its fogged-up glass separates colliding environments, teasing them to interact. It sits within the walls of the container, the car, ready to mediate the exchange of voices and sight lines. Tension holds its molecules in order, while it helps decide where the line of privacy lies.

\section{THE ROAD}

The familiar character returns, this time as a rolling substrate. The road is illuminated by headlights, hazy as the car rolls over it. It is the expanse that connects here to there, and it does so along a winding, turning path.

\section{THE WAIL}

The wall is multiplicitous, but its individual characteristics remain unnoticed. It is the scenographic backdrop of both movement and stasis. It encloses, shielding the views and actions of transitory desire and of wanton gaze. 


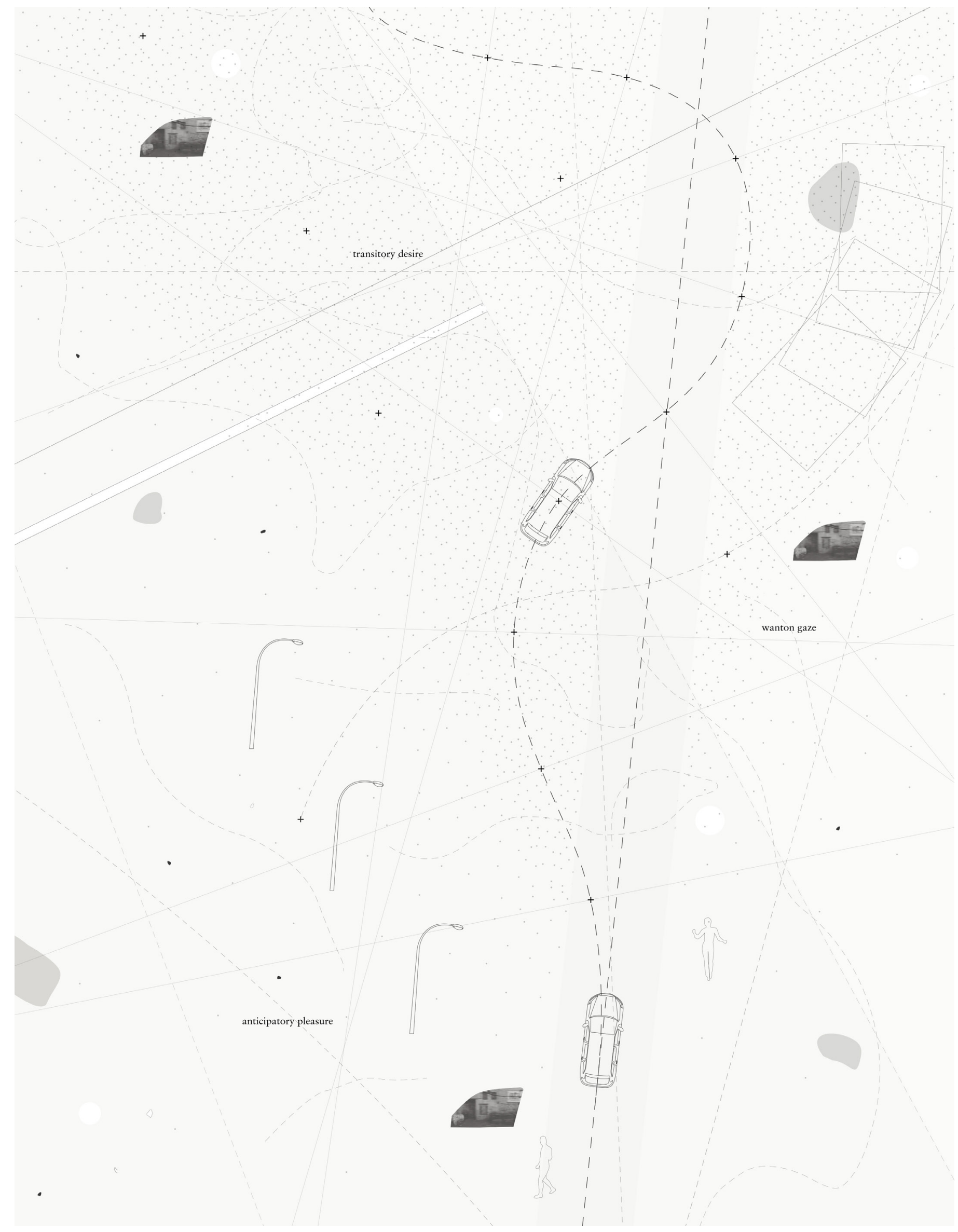

Fig. 67

Act I - Scene I!: Desire 


\section{ACT I}

\section{SCENE III}

\section{VIOLENCE}

the body out of place

Dusk. A dusty haze lingers in the air. Storage facilities, empty lots, and nondescript corrugated metal facades flank the wide, almost-grassy boulevards. Chainlink fences and boom gates sit amidst concrete barricades. There is a duplicitous nature to this space: it is a space of exclusion, home to everything that has been cast aside and mirrored by a dense and populated streetscape, like two sides of a coin. It is simultaneously rich with what is there and what is not.

feeling present yet distant, here and elsewhere

It is groggy, industrial, and banal, place of labour and a place to push, churn, and spit out those who are deemed to be undeserving of visible space.

the body in the margin 
THE EDGE

The edge is that of the street, of the lot, of the building. It is the only space occupied. All action takes place along this edge. From high above, the edge becomes a geographic margin. At street level, it is an unwelcoming and precarious tight-rope of invisibility.

\section{THE SHADOW}

The shadow sits, heavy, like a void. It is not a softedged, delicate outline dancing across variegated surfaces. It is harsh and thick and forceful. It is both a physicality and metaphor. It pervades throughout the scene, even in moments punctured by the setting sun.

\section{THE SECURITY CAMERA}

The watchful eye; the panoptic view. It is mounted to a wall with elaborate hardware, blinking red like morse code telling those below that they are under the watchful eye of the law. Despite its intention, it remains a discriminatory tool.

\section{THE BARRIER}

A rigid emblem of access, the barrier abruptly halts the path of circulation. It is concrete-heavy-and chipped at its edges from years of infringement. It sits as a latent mass until its activation, a rare but violent event, upholding a state of division in perpetual obscurity. 


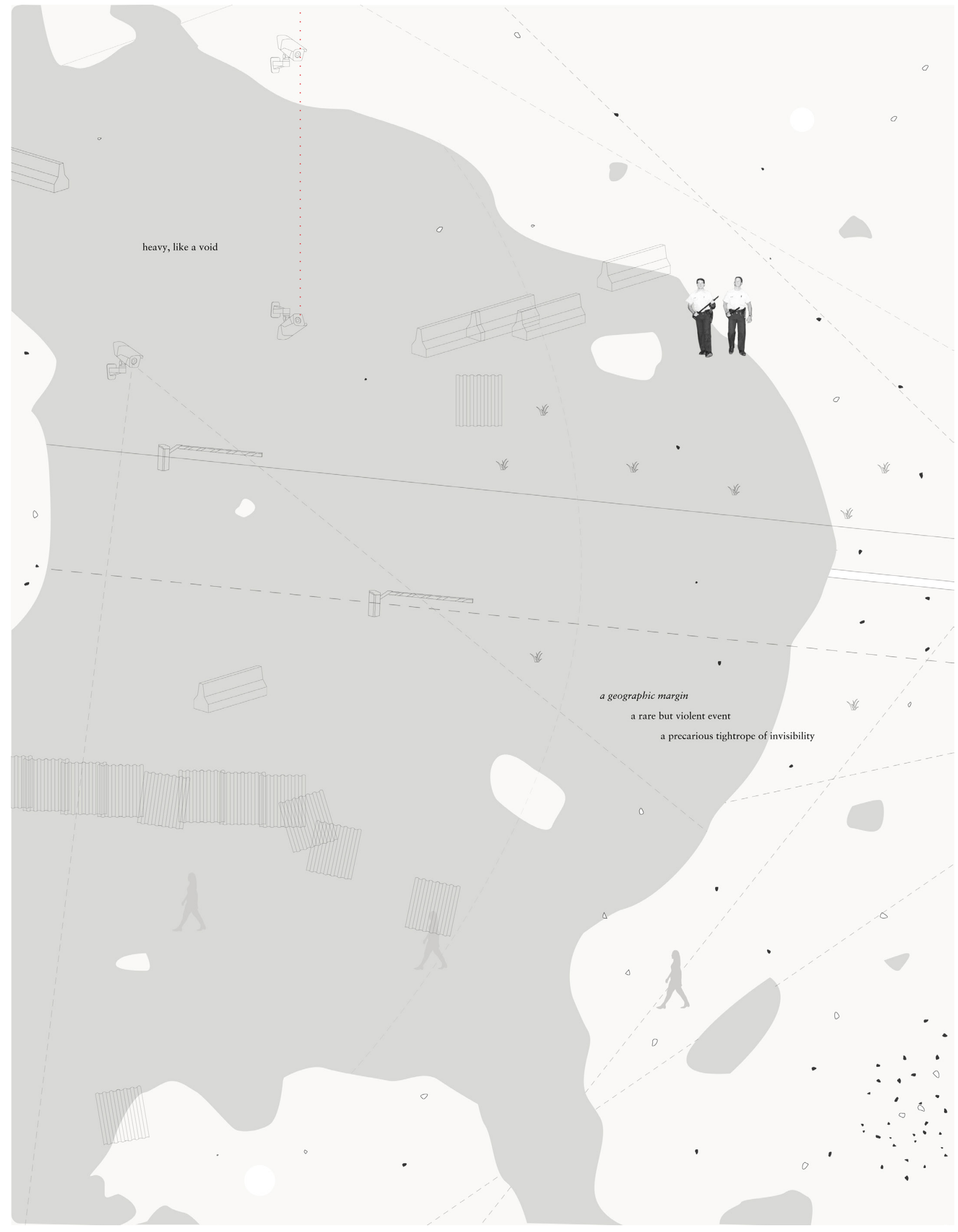

Fig. 70

Act I - Scene III: Violence 
ACT I

\section{SCENE IV}

\section{PROTEST}

Midday. A crowd passes through the street and into the active space of visibility. There is honking and roaring, wheels spinning, blurs of motion, countered with stagnation. Storefronts recede into the background; curbs lose their definition; protestors stake their claim to the space deemed as public. They are bringing their knowledge to the street, harnessing their predetermined capacities to transgress, and lifting the veil of system and structure. Bodies vibrate together in a mass of energy. crowd as collective body The crowd is indignant, as it should be. It moves and chants and its frustrations ring loudly. It asks for dignity, it asks to be heard. It moves like a flock of birds, intuitively shifting with synchronized diligence, pushing back against the forces that have sought to erase it.
To be a body, here, is

to feel the brush of a stranger's arm, warm and fleeting

to feel a crunch of dirt and dust underfoot

to feel the guttural vibration of a call for change 
THE INTERSECTION

The merging of the street with intersectional

worldview. The space of collision and radical cohesion

all at once. The intersection expands beyond its

linguistic framework, at once tangibly permanent and expansively progressive.

THE ROAD

Underfoot, the road is dense-mobilized. Its

physicality is ubiquitous, yet it texture exists in

multitudes. It is cracked, stippled, and painted,

withstanding the vibration of footsteps along its

asphalt surface. It is being seen anew.

THE TRAFFIC LIGHT

Hanging above the swelling crowd like an out-of-touch metronome, the traffic light is unaware of the rhythms below. Ticking green, yellow, and red, it is in an endless loop of mechanical quietudes, alluding to a measure of time that has become temporarily suspended.

THE CAMERA

The lens-based gaze is crucial. Through this lens, the camera point and shoots, either conjuring distance or evoking immediacy. It collapses the space of the city into its single frame, dictating what story will be told. 


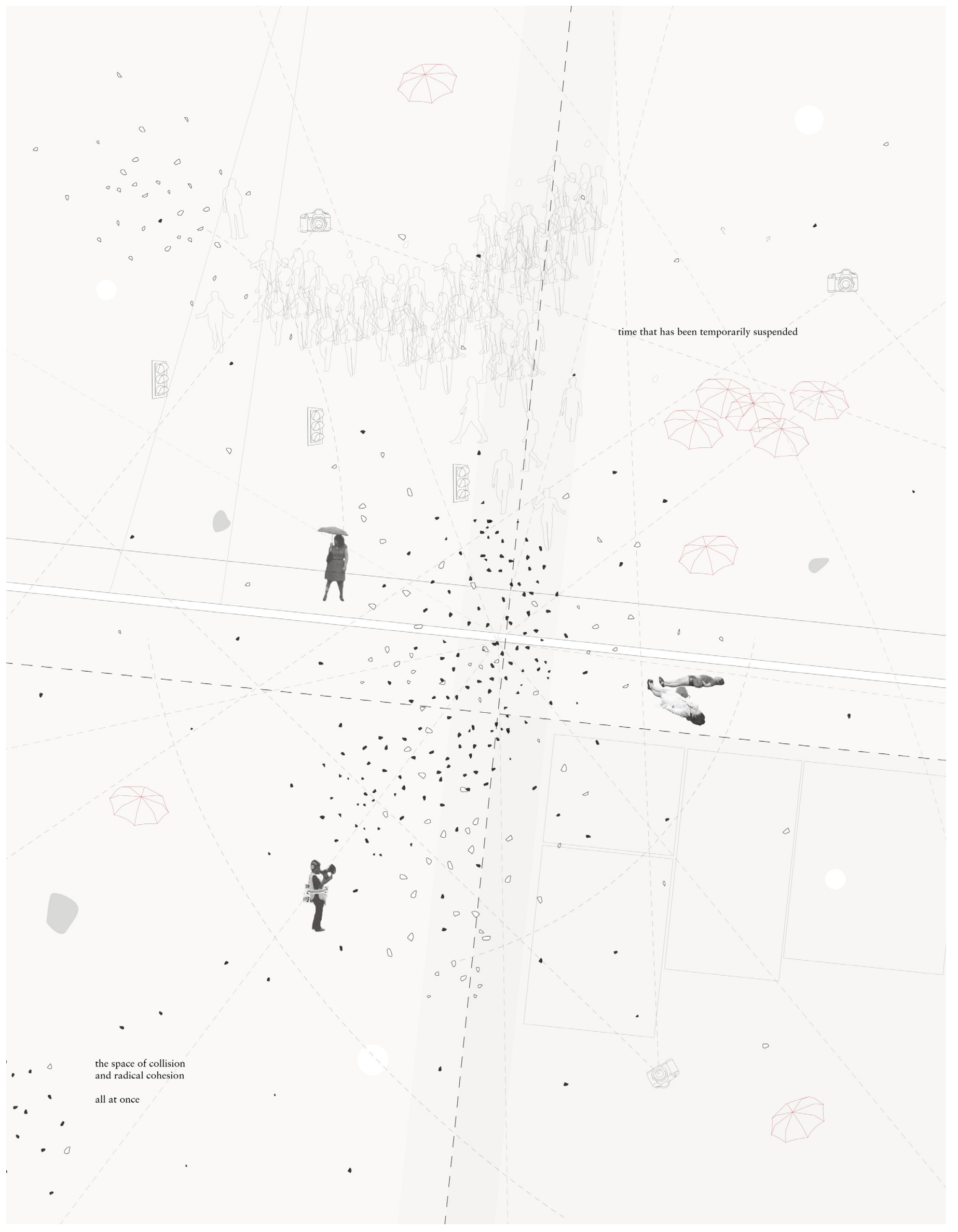

Fig. 73

Act I - Scene IV: Protest 


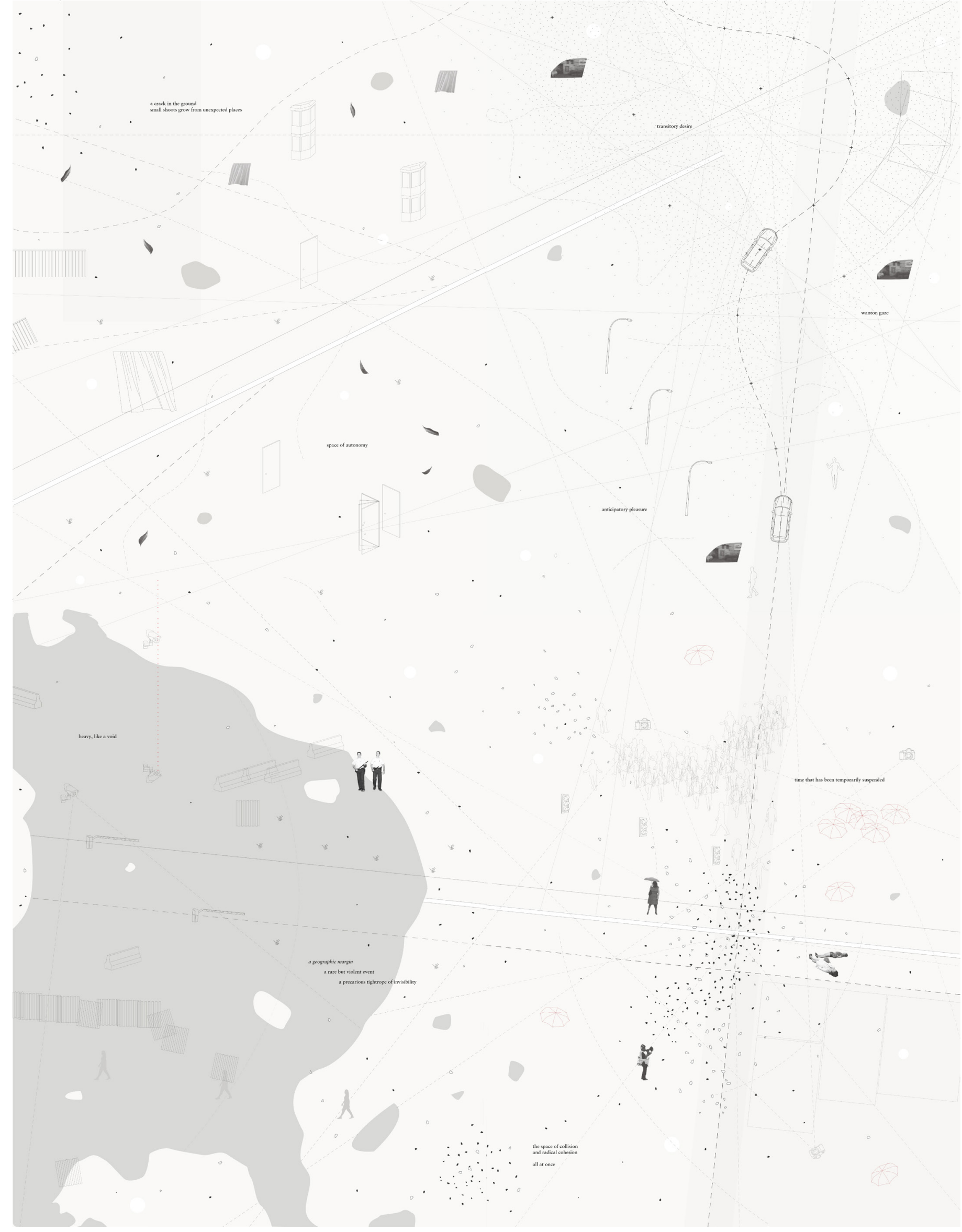

Fig. 74

Scenes I - IV compiled to form a seamless cityscape 
In many ways, Act II is nothing more than a provocation. While Act I was situated in anonymous space, Act II is very specifically sited, stimulating an interplay between act, action, stage, and site, and utilizing locality to help understand universality. The site itself exists within one of Vancouver's early sex working areas, still known today as Shanghai Alley. The Alley became a central component of both the city's red-light district and its Chinatown after a new train stop for the Great Northern Railway displaced numerous Chinese residents and sex workers from their previous establishments in 1906. ${ }^{16}$ Since its time as a sexual hot-spot, Shanghai Alley has become embedded within the historic Chinatown, and as such has become a tourist locale and a space of public visibility. Although the concentrated presence of sex workers in the area lasted for only a short time, the site remains a localized environment through which to understand many broad realities for contemporary sex workers. The site itself, a surface lot situated between two of the last original buildings that remain standing in the Alley, can be read as a legislative space as much as it can be understood as an activated place.

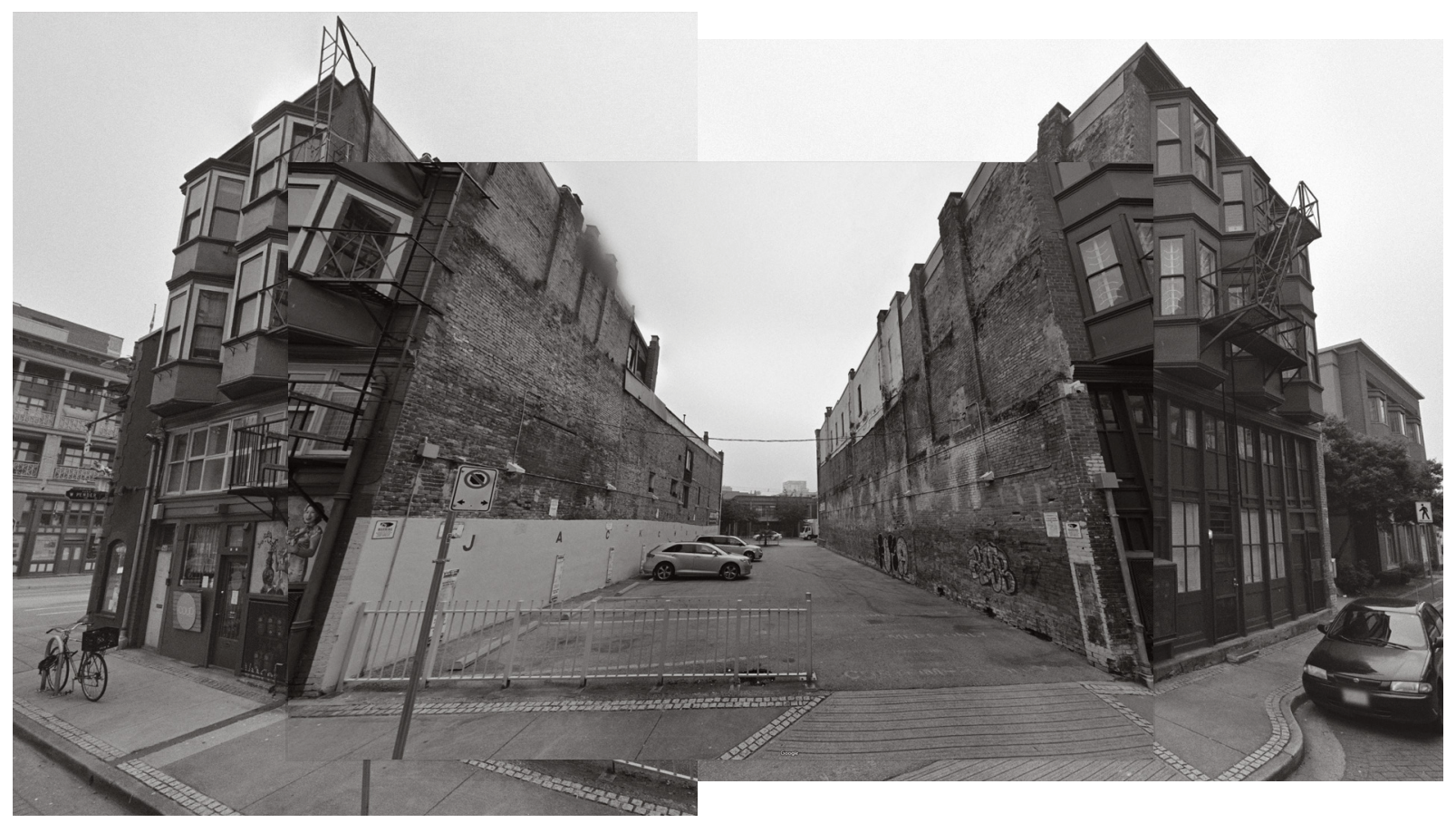

Fig. 75

Collage of Vancouver site 

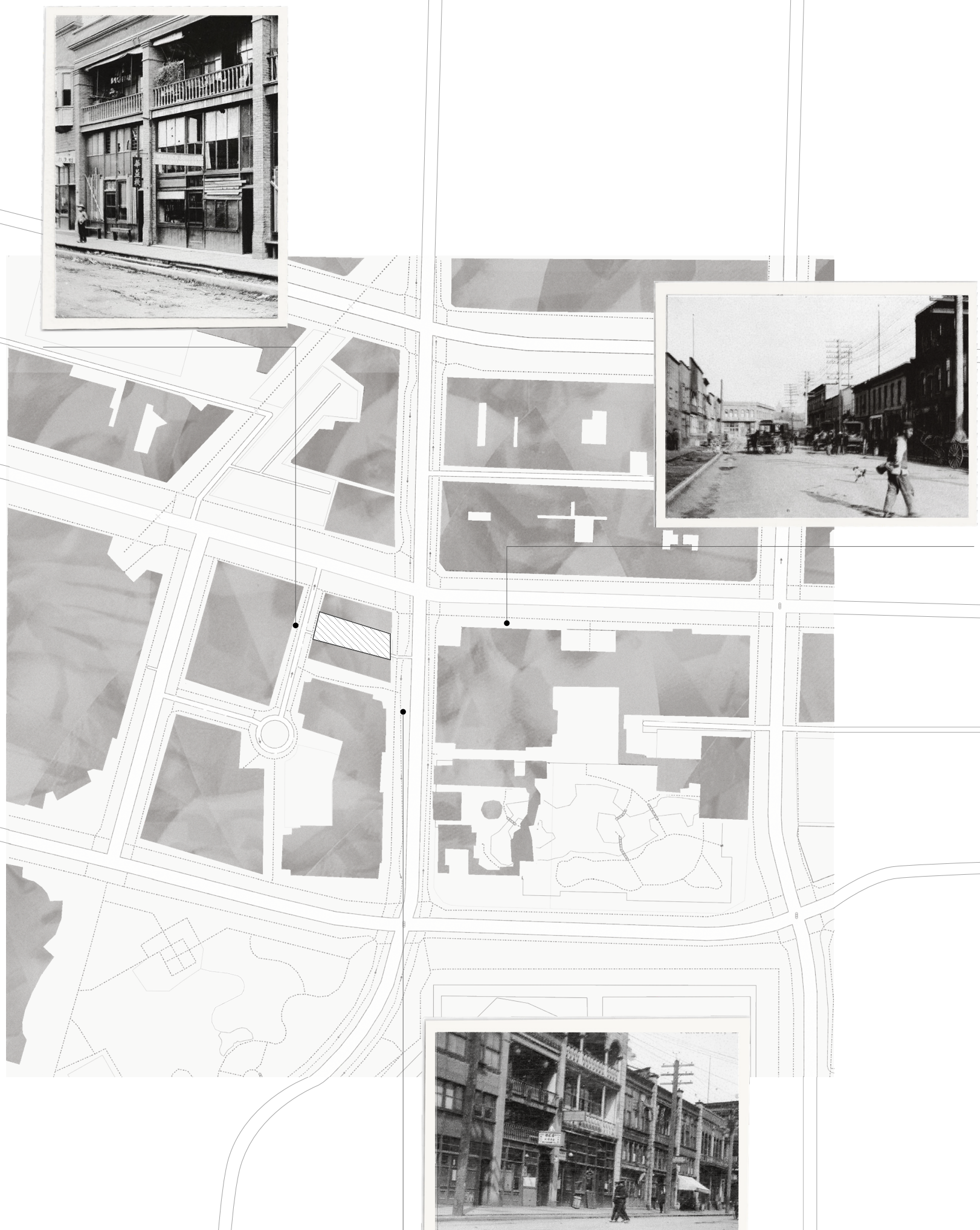

Fig. 76

Vancouver site map 
If we are to extend Judith Butler's call for 'troubling'-which is to say: activating, rescripting, and disrupting-gender categories to space, the redefinition or reconception of urban space can become a way to 'trouble' preconceived notions about the spaces and places of the everyday, ${ }^{17}$ and their capacities to work intimately and infrastructurally. Accessing the intricate feedback loop between infrastructure, intimacy, and space thus becomes instrumental in creating equitable and inclusive futures that actively 'trouble' the divisive patterns of the present.

In order to actualize these futures, Act II returns once again to the policies and regulations that so often render power invisible. However instead of analyzing any particular piece of legislature, Act II creates this 'legislature' anew. In order to shift perceptions in the scripts of daily life, Act II theorizes a series of infrastructural interventions through the creation of a policy act. The Act outlines a series of tactics for rescripting space, simultaneously mobilizing empirical and imaginative space to reconfigure the patterned arrangements of intimacy. The implementation of these tactics on the site implicates bodies as both actors and observers simultaneous, and intimacy is activated in the relationship between living body and material form. Instead of existing as a legislative space, the site is thus transformed to host a range of new intimate attachments. In this way, intimacy becomes a political space of action, and a tool to expose the hidden dimensions of publics and their latent capacities to be transformed.

Fig. 77

Section of the current site conditions 


\section{ACT II \\ INFRASTRUCTURES OF INTIMACY}

\section{RESCRIPTING}

Far too often, cities and publics are designed to cater to some while covertly prohibiting others. Material infrastructures break down, private property is privileged, and bodies are excluded. Overcoming these violent shortfalls involves the rescripting of space, and this rescripting positions care as a collective pursuit. The following tactics are intended as a toolkit for rescripting space to foster more intimate and inclusive publics. The emphasis is placed on cultivating social infrastructures and a sense of belonging through material and immaterial shifts in public spaces. The core principles of this rescripting are connscrron, VISIBILITY, COMFORT, PLACENESS, ENJOYMENT, MAINTENANCE, and IISTENING, each of which extend to both human and non-human actors.

2. TACTICS

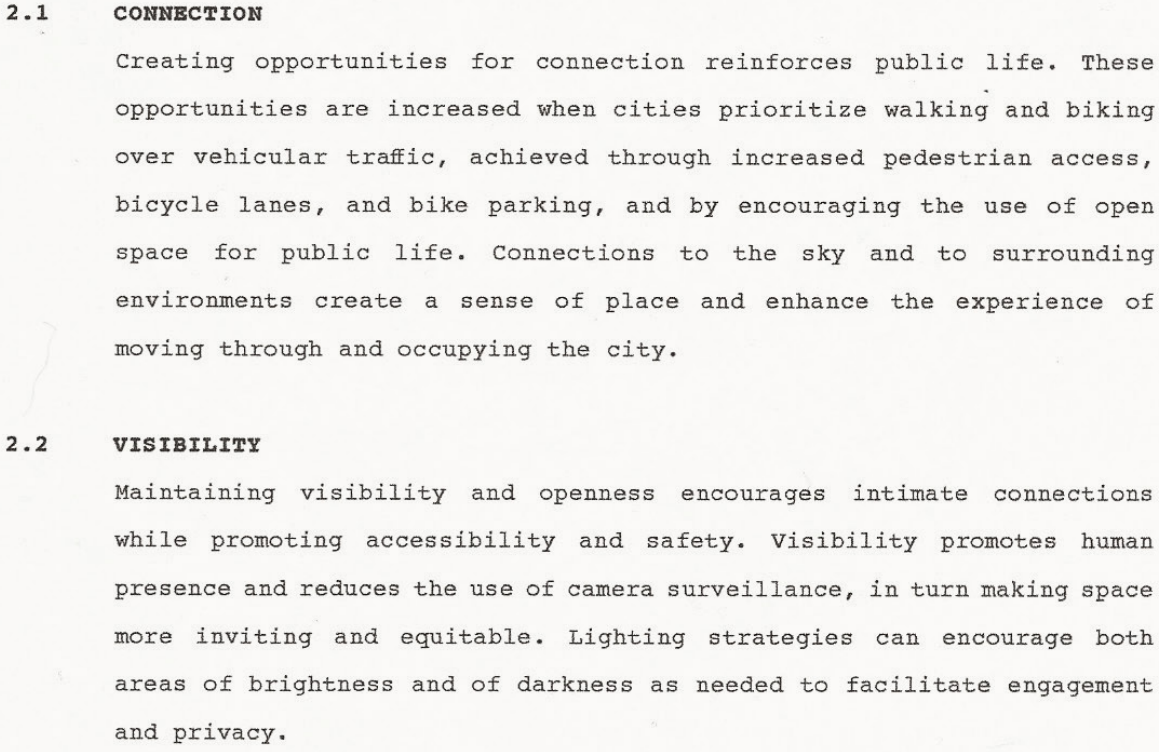


2.3 COMFORT

The basic question when dealing with comfort is recognizing who a place

is being made comfortable for. Harnessing an open approach to public space means creating opportunities for comfort based on use and the scale of various bodies and local environments. Providing areas for sitting, resting, lingering, and gathering encourages inclusion and comfort.

\subsection{PLACENESS}

Intimate connection within the built environment lead to new conceptions of place. Adopting a multidimensional approach to place-making means working with existing patterns of occupation, histories, and cultural contexts to implement inclusive adaptations.

\subsection{ENJOYMENT}

Fostering enjoyment involves both a sense of safety and comfort, and an activation of public space. Ensuring that public space is freely and openly accessible is a first step in creating equitable and enjoyable experiences. Programming like seasonal markets, theatrical performances, and buskers enliven public places and make them destinations for both passive and active engagement.

\subsection{MAINTENANCE}

Maintenance binds people, places, and action together by ensuring that public space is cared for. Maintenance strategies can include formal labour and community participation, both of which help to maintain a sense of stewardship, caretaking, and repair within the built environment. The removal of violent implementations and the incorporation of amenities like garbage and recycling bins all work toward maintaining a welcoming atmosphere.

\subsection{LISTENING}

Receptive engagement is key to any act of rescripting space. Listening offers a chance to engage with those whose patterns of occupation will shape a given place. Listening ensures that space meets the needs of all who occupy it, regardless of age, race, gender, ability, or income. The act of listening includes listening to community, but also includes listening to site and to needs at every scale of occupation. 
Intimacy as Infrastructure

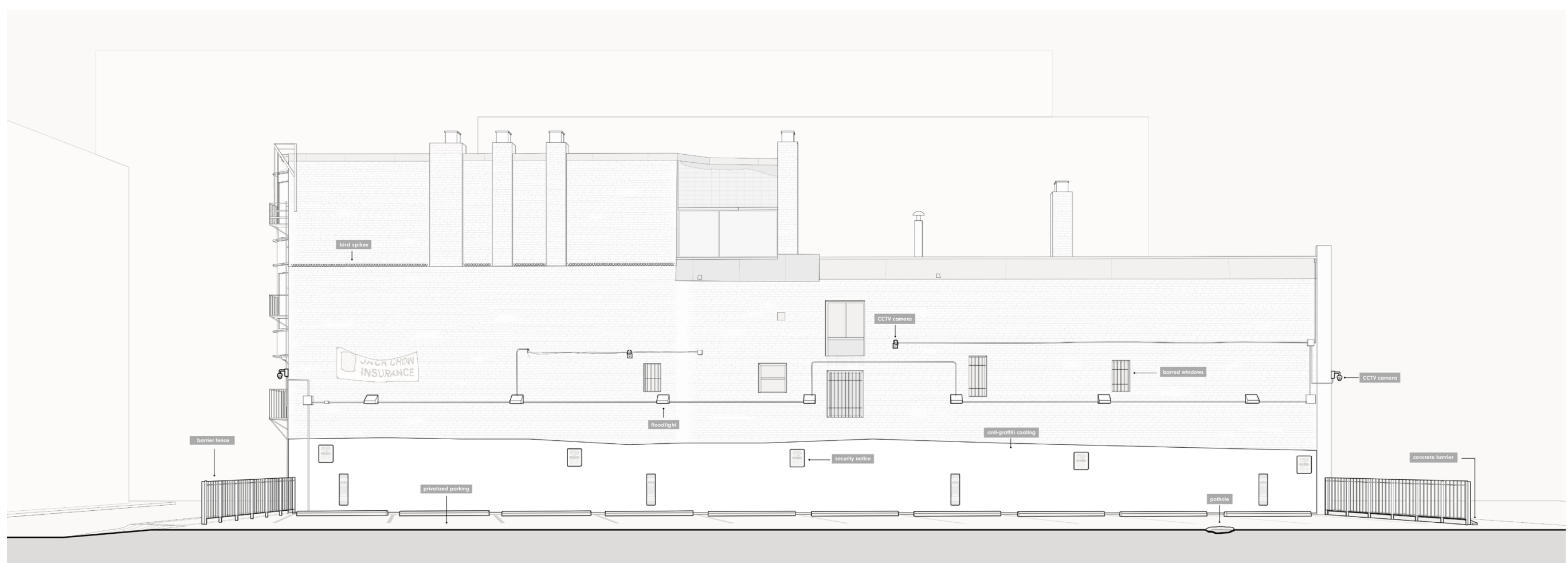

Fig. 80

Vancouver site as it currently exists, a space of control and surveillance

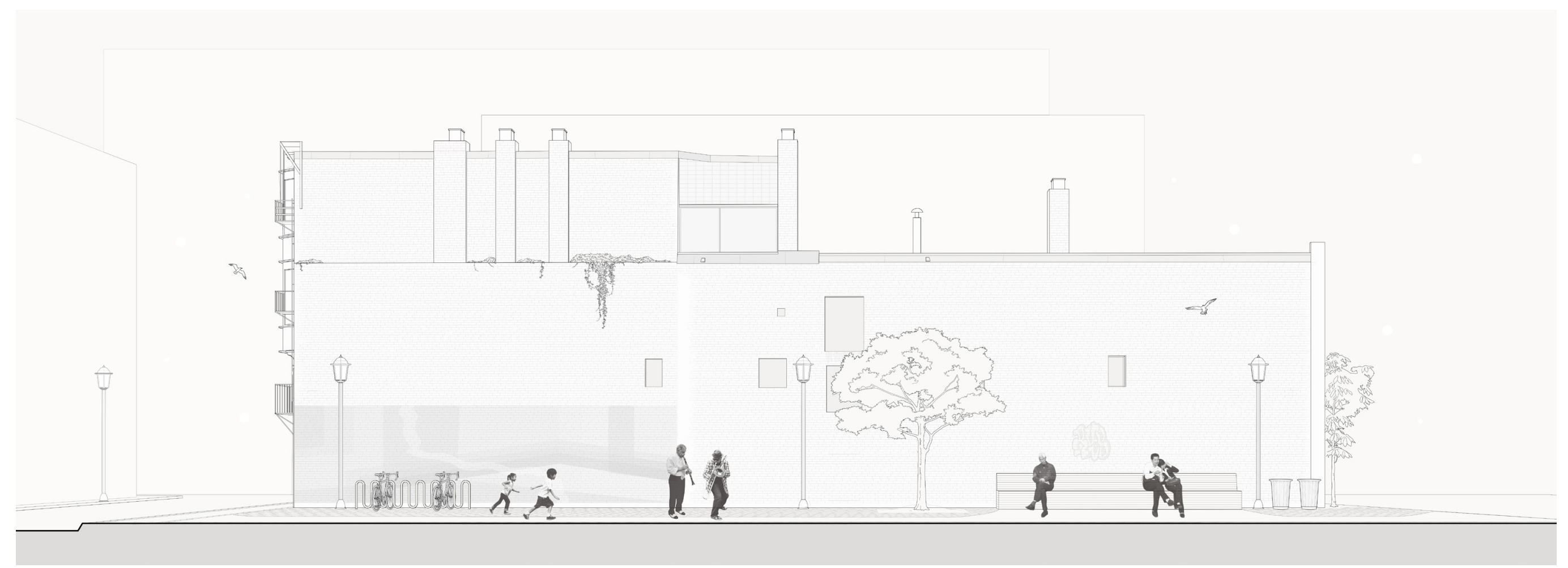

Fig. 81

Vancouver site theoretically transformed through a series of rescripting

tactics to foster greater intimacy

103 
These acts are not the definitive culmination of an unfolding conceptual thought, nor are they a concrete suggestion for how to engage intimacy in space. Instead they exist as possibilities to be continually grappled with, and as reflections on the numerous actors at play within the space of the commons. These actors have wide and varied ways of existing in the world that call to attention the possibilities to conceive of space differently. Much in the same way that this thesis has argued for the conception and actualization of bodies as autonomous subjects, the Acts offer insight into how cities, too, can be conceived of and actualized as autonomous. They offer the potential to explore the spatiality of public intimacies, and the capacities of these intimacies to transform public space. David Harvey has written of the right to the city in a similar tone, noting: "The freedom to make and remake ourselves and our cities is, I want to argue, one of the most precious yet most neglected of our human rights. ${ }^{18}$ Understanding the city as an infinitelymutable space that can be autonomously co-produced opens up a world of possibilities for thinking outside of heteropatriarchal norms.

Act I offers a loose rubric for envisioning the spatial arrangements that are formed as intimacy weaves into and out of public view alongside everyday infrastructures, while the creation of a policy act-or in the case of Act II, what we may begin to conceive of as an 'anti-policy'is a response to the complexly-legislative restrictions at play within our cities. Sex workers and advocacy organizations are consistently creating infrastructures of intimacy as well as extralegal solutions to counter marginalization and erasure, ${ }^{19}$ and there are infinite lessons to be learned from these tactical actions. The Acts within this thesis are a contemplation on how we read and perceive space, how we interact with it, how it orients us, and how we take action within it. In the simplest of terms, digging into intimacy and exposure allows us to understand how space means different things to different people, how bodies interact with places differently, and how infrastructure remains the essential factor in forging these meanings. 


\section{Part 03: Endnotes}

Red Schulte, "Sex Working Economies of Space," The Funambulist 33 (2021): 35

Jacqueline Comte, "Decriminalization of Sex Work: Feminist Discourses in Light of Research," Sexuality \& Culture 18, no. 1 (2014): 201

Brian Larkin, "The Politics and Poetics of Infrastructure," Annual Review of Anthropology 42, no. 1 (October, 2013): 329.

$$
\text { Lauren Berlant, "Intimacy: A Special Issue," Critical Inquiry 24, no. } 2 \text { (1998): } 286 .
$$

Alexandra Pereira-Edwards, "Rethinking Intimacy and the City," CARTHA (2020): 3, https://www.carthamaga zine.com/wp-content/uploads/2021/02/Alexandra_Pereira-Edwards.pdf.

Adrienne Rich, "Notes Toward a Politics of Location (1984)," in Blood, Bread, and Poetry: Selected Prose 1979-1985 (New York: Norton, 1986), 212.

Sara Ahmed, "A Phenomenology of Whiteness," Feminist Theory 8, no. 2 (2007): 158.

Chloe Lizotte, "News to Me: Lizzie Borden, Greta Gerwig, Ryuichi Sakamoto," Film Comment, July 2, 2018, https://www.filmcomment.com/blog/news-lizzie-borden-greta-gerwig-ryuichi-sakamoto/.

Ahmed, "A Phenomenology of Whiteness," 158

Lauren Berlant, "The Commons: Infrastructures for Troubling Times," Environment and Planning D: Society and Space 34, no. 3 (2016): 393.

Henri Lefebvre, The Production of Space (Oxford, UK: Blackwell, 1991), 191.

Judith Butler, Gender Trouble: Feminism and the Subversion of Identity (New York: Routledge, 1990), 6.

Phil Hubbard, Andrew Gorman-Murray, and Catherine J. Nash, "Cities and Sexualities," in Handbook of the Sociology of Sexualities, ed. J DeLamater and R.F. Plante (Switzerland: Springer International Publishing, 2015), 290.

Nicholas Blomley, "Law, Property, and the Geography of Violence: The Frontier, the Durvey, and the Grid," Annals of the Association of American Geographers 93, no. 1 (March 2003): 122.

Bernard Tschumi, The Manhattan Transcripts (London: Academy Editions, 1994), 8.

Lani Russwurm, "A History of Sex Work in Early Vancouver," Forbidden Vancouver, https://forbiddenvancouver. $\mathrm{ca} / \mathrm{blog} /$ history-prostitution-vancouver/.

Heather E. McLean, "The Politics of Ceative Performance in Public Space: Toward a Critical Geography of Toronto Case Studies," in Spaces of Vernacular Creativity: Rethinking the Cultural Economy, ed. Tim Edensor et al. (Taylor \& Francis Group, 2009), 203.

David Harvey, "The Right to the City," 2008, 2-3, https://davidharvey.org/media/righttothecity.pdf.

We can look to organizations across Canada like Peers Victoria, SWAN Vancouver, Shift Calgary, Sex Workers of Winnipeg Action Coalition, Maggie's Toronto, POWER Ottawa, Stella Montreal, the Canadian Alliance for Sex Work Law Reform, and numerous others to locate community initatives and resources. The Global Network of Sex Work Projects offers insight into sex work activism on a global scale (https://www.nswp.org). 


\section{Epilogue}

In the weeks leading up to the final submission of this thesis, a white man entered a massage parlour in Atlanta and murdered eight people with the intent of specifically targeting Asian, female workers. Although it is not known if these women were sex workers or self-identified as such, their deaths were the result of a sexualized violence and a hatred for sex workers and Asian women. ${ }^{1}$ The violence perpetrated by the shooter has been portrayed by Atlanta law enforcement as the result of a sex addiction and "a really bad day." 2 There has been international coverage, and the conversations of sex worker rights and anti-Asian racism have entered mainstream discourse with potent urgency. This violence was misogynistic, this violence was racial, and this violence was spatial. These individuals were sought out and killed in their place of work. Ultimately, it should not take more violence to recognize the depths of the stigma associated with sex work, and the ongoing injustices against Asian, Black, Indigenous, and other racialized communities within North America. The tragedy has called attention to the biases that are continually met by those in the sex work industry, and the ways that these biases attempt to render these criminalized labourers invisible. It has been a prominent consideration within this thesis to express how assumptions, stigma, laws, and violence are fundamentally shaped by infrastructures, architectures, and space.

This work has been an exercise in exposing the dominant sociospatial structures that govern marginalized bodies, and in offering new conceptions of space and place that can facilitate more expansive, intimate publics. It has sought to expose the hidden spatial processes that enable acts of visible and invisible violence, but also to address how stigma can be subverted through acts of intimacy. The purpose has not been to offer a solution-in fact, I do not have a solution to offer. Instead, it has been a means to expose the ways that laws, geographies, cities, bodies, and actions are all shaped by space and place. The work has charted a trajectory from the omnipresence of theory and law, to 
the scale of the city through space and geography, and finally to place and action-all scales that deeply implicate the body. It has explored numerous conceptual and tangible worlds through these scalar shifts and has expressed that the work of decriminalization must happen at each and every moment along this scalar gradation. It has expressed that it is only through exposing and gathering evidence that we may begin to build a case and analyze how these systems are upheld, and that we then may be able to successfully dismantle them. Through this conception, design and research become political sites of struggle.

Early in this process, I had numerous instances of hesitation in approaching a 'taboo' subject. Would an architectural audience be responsive to speaking about sex work? I quickly came to realize that the subject is only 'taboo' because it is constructed to be. I have explored the ways that the powers governing sex work and intimacy appear in the most banal of material and spatial forms, an exploration that has been incredibly transformative in my conceptions of design and research. I have tuned in to the politically-charged experience of being in the world anew, and hope to inspire at least a fraction of this recognition within my audience.

A lingering question that this work has unveiled is that of what constitutes an infrastructural practice:

How can architectural research and practice exceed dominant knowledge structures to create more inclusive, receptive, intersectional, and equitable spaces? And when I say spaces in this regard, I mean histories, writings, pedagogies, buildings, practices, and mindsets. I believe the key to this question involves the continual speaking with, rather than speaking for. I have tried to cultivate the former within a field that so often defaults to the latter; but I have also approached this work fresh-faced and eagerly adaptable, recognizing that there is much to be learned both about and through processes of speaking with. I have sought to find a balance between theory and lived testimony, incorporating the first-hand experiences of sex workers to enrich both my knowledge and the depth of my subject matter. The activist work of sex workers and advocacy 
organizations have served as the most fundamental of sources for my inquiries, while the theoretical frameworks within which I have situated these inquiries are largely implicated within queer and feminist discourse. Lefebvre's work has been foundational to my spatial analyses, but I recognize the limitations of his theories and have made a concerted effort to bolster my inclusion of his theories with sex-positive feminist perspectives, both from prominent theorists and sex workers themselves.

As someone who is conducting these inquiries for the fulfillment of an academic degree, and with the inevitability of relaying my research to a largely academic audience, I consider it my responsibility to use the academic platform to investigate injustices and to boost the voices of those who have not often been considered within conversations of space. I have engaged in a spatial practice that acknowledges the spatial implications on a specific group of people's oppression, and I have considered this a consistently self-reflective process; one that seeks to find resonances between academia and activism, but does not attempt to conflate the two. The work of this thesis will gain tremendous value with direct input from sex workers and advocates in the future. Sex workers and other criminalized labourers are constantly working to create spaces that foster new ways of existing in the world, and this thesis has set the stage to be able to engage alongside these vital conceptions-not to eclipse them. I remain open and enthusiastic about the potential to reflect back on this work with the introduction of new perspectives and outlooks. I recognize that this work is only a starting point to exploring the entanglements of intimacy, infrastructure, sex work, power, and space. I view it as an opportunity to open a conversation about the power of acceptance, and to reposition the reader to acknowledge the hidden power of the spaces, places, and infrastructures that they interact with each and every day. 


\section{Epilogue: Endnotes}

1 Tracy Quan, "Don't Forget-the Georgia Shootings are a Hate Crime against Sex Workers," Los Angeles Times, March 19, 2021, https://www.latimes.com/entertainment-arts/books/story/2021-03-19/tracy-quan-dontforget-the-atlanta-shooting-is-a-hate-crime-against-sex-workers.

2 Nicholas Bogel-Burroughs, "Atlanta Shootings Life Updates: Suspect Had Visited Targeted Spa Before, Police Say," The New York Times, March 19, 2021, https://www.nytimes.com/live/2021/03/18/us/atlan ta-shootings-massage-spa. 


\section{List of Figures}

Fig. 1 CORP (Canadian Organization for the Rights of Prostitutes, "Get Your Fucking Laws Off Our Bodies," c. 1983, posted @harlothistory, August 13, 2020, https://www.instagram.com/p/CD1gqt1pn7l/.

Fig. 2 CORP (Canadian Organization for the Rights of Prostitutes, "Recruitment Ad in Stiletto," 1986, posted @harlothistory, July 2020, https://www.instagram.com/stories/highlights/17871091714851610/?hl=en.

Fig. 3 Alexandra Pereira-Edwards, "Colonization diagram," 2020, diagram, adapted from Rupa Marya, Instagram, June 2020, https://www.instagram.com/p/CDz5U6LBUmM/.

Fig. 4 Jessica McDiarmid, "Sex Workers Protest in Toronto Against Proposed Legislation," Toronto Star, June 14, 2014 https://www.thestar.com/news/gta/2014/06/14/sex_workers_protest_in_toronto_against_proposed_legislation. html.

Fig. 5 Julius Shulman, "Neutra, Singleton House, Los Angeles, 1959," photograph, in Sylvia Lavin, "Open the Box: Richard Neutra and the Psychology of the Domestic Environment," Assemblage, no. 40 (Dec. 1999): 21.

Fig. 6 Pierre Chenal, L'Architecture d'aujhourd'hui, 1929, film stills, https://vimeo.com/67793221.

Fig. 7 Adolf Loos, "Josephine Baker House," 1928, floor plans, in Beatriz Colomina, Sexuality and Space (New York: Princeton Architectural Press), 89, fig. 15.

Fig. 8 Aterlier Sautier, "Josephine Baker, France," c.1920s, photograph, https://lisawallerrogers.files.wordpress. com/2019/10/jo-baker-atelier-sautier.jpg.

Fig. 9 Thomas Cugini, "Christo and Jean-Claude in Christo's Studio with "Green Store Front, 1964," 1966, photograph, accessed Septemer 21, 2020, https://www.archpaper.com/2018/02/christo-jeanne-claude-storefronts-early-sculpture/.

Fig. 10 Gordon Matta-Clark, "Splitting," 1974, Fonds: Gordon Matta-Clark collection, 1914-2008, Canadian Centre for Architecture, Montreal, https://www.cca.qc.ca/en/search/details/collection/object/379692.

Fig. 11 Jeet Malhotra, "View of birds on power lines in Chandigarh, India," 1951-1961, Pierre Jeanneret fonds Canadian Centre for Architecture, Montreal, accessed August 9, 2020, https://www.cca.qc.ca/en/search/details/ collection/object/509343.

Fig. 12 Boorne \& May, "Constructing the CPR," photograph, Library and Archives Canada, C-006686B, accessed March 26, 2021, https://www.thecanadianencyclopedia.ca/en/article/canadian-pacific-railway.

Fig. 13 Rockstar Games, Grand Theft Auto 5, IGN, https://www.ign.com/wikis/gta-5/Receive_a_Prostitute_Service.

Fig. 14 Garry Marshall, Pretty Woman, 1990, film still, Movie Mezzanine, http://moviemezzanine.com/pretty-woman25th-anniversary-essay/.

Fig. 15 Darren Aronofsky, Requiem for a Dream, 2000, film still, Steam, https://steamcommunity.com/app/421430

Fig. 16 Sean Baker, Tangerine, 2015, film still, The Verge, https://www.theverge.com/2015/1/28/7925023/sundance-filmfestival-2015-tangerine-iphone-5s.

Fig. 17 Sean Baker, Tangerine, 2015, film still, Film Grab, https://film-grab.com/2020/01/15/tangerine/.

Fig. 18 Unknown, "Laundry.," Exhibits, accessed October 18, 2020, https://exhibits.library.utoronto.ca/items/show/1501

Fig. 19 The National Ad Hoc Action Committee on the Status of Women in Canada, "Submission to the Government of Canada," February, 1972, https://riseupfeministarchive.ca/wp-content/uploads/NAC-Adhoccommitteesubmissionto-government-of-canada-1972.pdf.

Fig. 20 Sheilagh O'Connell, "The Impact of Bill C-49 on Street Prostitution: "What's Law Got to Do with It," Journal of Law and Social Policy 4 (1988): 109. 
Fig. 21 "Synopsis for guilty plea," 1981, arrest record, Active History, https://activehistory.ca/2018/01/c66bathraids/.

Fig. 22 "Bedford v. Canada, 2010 ONSC 4264 (CanLII)," September 28, 2010, Ontario Superior Court of Justice, https:// www.canlii.org/en/on/onsc/doc/2010/2010onsc4264/2010onsc4264.pdf.

Fig. 23 Bill C-36, An Act to amend the Criminal Code in response to the Supreme Court of Canada decision in Attorney General of Canada v. Bedford and to make consequential amendments to other Acts, Second Session, Fortyfirst Parliament. Assented to November 6, 2014. https://www.parl.ca/Content/Bills/412/Government/C-36/C36_4/C-36_4.PDF.

Fig. 24 Unknown, "Venereal infections acquired in the City of Montreal," 1943, map, https://i.imgur.com/nkhDZn8.jpg.

Fig. 25 Philip Timms, "Shanghair Alley boarded up after the 1907 Asiatic Exclusion League Riot," photograph, UBC Chung Collection, https://forbiddenvancouver.ca/blog/history-deviant-alleys-vancouver/.

Fig. 26 "Reference re ss. 193 and 195.1(1)(C) of the criminal code (Man.)," 1990, Supreme Court of Canada, https:// scc-csc.lexum.com/scc-csc/scc-csc/en/611/1/document.do.

Fig. 27 David Meyers, "Calling the mayor a pimp," Exhibits, accessed October 18, 2020, https://exhibits.library.utoronto. ca/items/show/1511.

Fig. 28 The Body Politic, "The Body Politic, No. 71, March 1981," Exhibits, accessed October 18, 2020, https://exhibits. library.utoronto.ca/items/show/1512.

Fig. 29 "Canada (Attorney General) v. Bedford," 2013, Supreme Court of Canada, https://scc-csc.lexum.com/scc-csc/ scc-csc/en/13389/1/document.do.

Fig. 30 Charlie Smith, "Sex workers are not happy that the law treats their clients as criminals," October 13, 2015, https://www.straight.com/news/554986/sex-workers-press-liberals-ndp-greens-repeal-prostitution-law-broughtconservatives.

Fig. 31 Alexandra Pereira-Edwards, "Violence," 2020, collage. Images used (clockwise):

Fig. 31.1 Missing Women Commission of Inquiry, "Chronology of Involvement with the Missing Women Investigations: Maggie de Vries, Wayne Leng, and Jamie Lee Hamilton," February 27, 2012, https:// missingwomen.library.uvic.ca/wp-content/uploads/2011/10/EXHIBIT-110.pdf.

Fig. 31.2

Linda Dawn Hammond, "Sex Garage further united a generation already fighting homophobia and issues related to HIV and AIDS," photograph, Goethe Institut, https://www.goethe.de/ins/ca/en/kul/ Fig. 31.3 ges/50s/qlf/21568866.html.

Unknown, "Cell Corridor," 1902, photograph, Exhibits, accessed October 18, 2020, https://exhibits. library.utoronto.ca/items/show/1499.

Fig. 31.4

Unknown, "Jamie Lee Hamilton," photograph, https://www.citynews1130.com/2019/12/23/

controversial-vancouver-activist-jamie-lee-hamilton-dies-at-64/.

Fig. 31.5 Adolf Loos, "Project for a house for Josephine Baker in Paris, 1928," in Beatriz Colomina, Sexuality and Space (New York: Princeton Architectural Press), 89, fig. 14.

Fig. 32 Alexandra Pereira-Edwards, "Surveillance," 2020, collage. Images used (clockwise):

Fig. 32.1 René Descartes, inverted diagram from Traité de Passions, 1596-1650, Wikimedia Commons, https://commons.wikimedia.org/wiki/File:Descartes_diagram.png.

Fig. 32.2 Lizzie Borden, Working Girls, 1986, film still, Sundance Institute, https://www.sundance.org/ initiatives/womenatsundance/four-decades/working-girls.

Fig. 32.3 The National Ad Hoc Action Committee on the Status of Women in Canada, "Submission to the Government of Canada," February, 1972, https://riseupfeministarchive.ca/wp-content/uploads/ NAC-Adhoccommittee-submissionto-government-of-canada-1972.pdf

Fig. 32.4 Linda Dawn Hammond, "Police ante portas," photograph, Goethe Institut, https://www.goethe.de/ ins/ca/en/kul/ges/50s/qlf/21568866.html.

Fig. 32.5 Adolf Loos, "Moller House," 1928, diagram, in in Beatriz Colomina, Sexuality and Space (New York: Princeton Architectural Press), 79, fig. 7. 
Fig. 33 Unknown, "Canton Alley looking south from Pender Street, c. 1910," photograph, City of Vancouver Archives \#689-56, https://forbiddenvancouver.ca/blog/history-deviant-alleys-vancouver/.

Fig. 34 Fulton, G.w. \& Vermette, L., "L'arrondissement historique du boulevard Saint-Laurent ("La Main")," 1996, Federal Heritage Buildings Review Office.

Fig. 35 Alexandra Pereira-Edwards, "Images of Historic Red Light Districts, Google Maps, 2019.

Fig. 36 Alexandra Pereira-Edwards, "Map of Vancouver," 2020, map.

Fig. 37 Alexandra Pereira-Edwards, "Map of Toronto," 2020, map.

Fig. 38 Alexandra Pereira-Edwards, "Map of Montreal," 2020, map.

Fig. 39 Google Maps, "Montreal, Quebec," 2019, https://www.google.com/maps/@45.5098776,73.5599408,3a,90y,40.07h,95.59t/data=!3m7!1e1!3m5!1s-75YeJQnF49aaiqDWVZX3g!2e0!6s\%2F\%2Fgeo1.ggpht. com\%2Fcbk\%3Fpanoid\%3D-75YeJQnF49aaiqDWVZX3g\%26output\%3Dthumbnail\%26cb_client\%3Dmaps_sv.tactile.

Fig. 40 Alexandra Pereira-Edwards, "Space/Place Diagram," 2021, diagram, adapted from Setha Low, Spatializing Culture: The Ethnography of Space and Place (New York: Routledge, 2016), 4.

Fig. 41 Alexandra Pereira-Edwards, "Triad: Park," 2020, drawing.

Fig. 42 Alexandra Pereira-Edwards, "Park," 2020, colour rendering.

Fig. 43 Alexandra Pereira-Edwards, "Triad: Parking lot," 2020, drawing.

Fig. 44 Alexandra Pereira-Edwards, "Parking lot," 2020, colour rendering.

Fig. 45 Alexandra Pereira-Edwards, "Triad: Home," 2020, drawing.

Fig. 46 Alexandra Pereira-Edwards, "Home," 2020, colour rendering.

Fig. 47 Alexandra Pereira-Edwards, "Triad: Alleyway," 2020, drawing.

Fig. 48 Alexandra Pereira-Edwards, "Alleyway," 2020, colour rendering.

Fig. 49 Deborah McNeill, "Sex workers and supporters march on Broadway Street to mark the first demonstration against amendments to the Criminal Code in April 1983," Exhibits, accessed October 18, 2020, https://exhibits. library.utoronto.ca/items/show/1510.

Fig. 50 Alexandra Pereira-Edwards, "Actor diagram," 2020.

Fig. 51 Maggie's, "Maggie's Zine, Winter 93-94, No. 1," Exhibits, accessed October 18, 2020, https://exhibits.library. utoronto.ca/items/show/1509.

Fig. 52 Alexandra Pereira-Edwards, "Intimate cartography," 2020, drawing.

Fig. 53 Alexandra Pereira-Edwards, "Intimacy and the body," 2021, drawing.

Fig. 54 Alexandra Pereira-Edwards, "Bodies in space," 2021, drawing

Fig. 55 Lizzie Borden, Working Girls, 1986, film still, Sabzian, https://www.sabzian.be/film/working-girls.

Fig. 56 Alexandra Pereira-Edwards, "The body as site of control," 2021, drawing.

Fig. 57 Alexandra Pereira-Edwards, "Study: Glitch Cityscape," 2021, drawing.

Fig. 58 Alexandra Pereira-Edwards, "Glitch Cityscape," 2021, drawing.

Fig. 59 Alexandra Pereira-Edwards, "Space, Place, Body, Performance," 2021, digram.

Fig. 60 Alexandra Pereira-Edwards, "Infrastructure and Intimacy," 2020, diagram. 
Fig. 61 Alexandra Pereira-Edwards, "Study: Care, Desire, Violence, Protest," 2021, drawing.

Fig. 62 Alexandra Pereira-Edwards, "Act I-Scene I: Care, Part I," 2021, drawing.

Fig. 63 Alexandra Pereira-Edwards, "Act I - Scene I: Care, Part II," 2021, drawing.

Fig. 64 Alexandra Pereira-Edwards, "Care," 2021, drawing.

Fig. 65 Alexandra Pereira-Edwards, "Act I-Scene II: Desire, Part I," 2021, drawing.

Fig. 66 Alexandra Pereira-Edwards, "Act I-Scene II: Desire, Part II," 2021, drawing.

Fig. 67 Alexandra Pereira-Edwards, "Desire," 2021, drawing.

Fig. 68 Alexandra Pereira-Edwards, "Act I - Scene III: Violence, Part I," 2021, drawing.

Fig. 69 Alexandra Pereira-Edwards, "Act I - Scene III: Violence, Part II," 2021, drawing.

Fig. 70 Alexandra Pereira-Edwards, "Violence," 2021, drawing

Fig. 71 Alexandra Pereira-Edwards, "Act I - Scene IV: Protest, Part I," 2021, drawing.

Fig. 72 Alexandra Pereira-Edwards, "Act I - Scene IV: Protest, Part II," 2021, drawing.

Fig. 73 Alexandra Pereira-Edwards, "Protest," 2021, drawing.

Fig. 74 Alexandra Pereira-Edwards, "Care, Desire, Violence, Protest," 2021, drawing.

Fig. 75 Alexandra Pereira-Edwards, "Collage of Vancouver site," 2021, collage.

Fig. 76 Alexandra Pereira-Edwards, "Vancouver Site Map," 2021, drawing.

Fig. 77 Alexandra Pereira-Edwards, "Site Section," 2021, drawing.

Fig. 78 Alexandra Pereira-Edwards, "Act II - Infrastructures of Intimacy," 2021, policy document.

Fig. 79 Alexandra Pereira-Edwards, "Act II - Infrastructures of Intimacy," 2021, policy document.

Fig. 80 Alexandra Pereira-Edwards, "Vancouver Site Before," 2021, drawing.

Fig. 81 Alexandra Pereira-Edwards, "Vancouver Site After," 2021, drawing. 


\section{Bibliography}

Action Canada for Sexual Health \& Rights. "Open Letter: 300 Researchers Call for Decriminalization of Sex Work in Canada." https://www.actioncanadashr.org/news/2014-03-26-open-letter-300-researchers-calldecriminalization-sex-work-canada.

Ahmed, Sara. "Affective Economies." Social Text 22, no. 2 (2004): 117-139.

Ahmed, Sara. "A Phenomenology of Whiteness." Feminist Theory 8, no. 2 (2007): 149-168.

Bennett, Darcie. "Canada v. Bedford - The decision in 705 words." Pivot Legal. December 20, 2013. https://www.pivotlegal.org/canada_v_bedford_a_synopsis_of_the_supreme_court_of_canada_ruling.

Benoit, Cecilia, Mikael Jansson, Michaela Smith, and Jackson Flagg. "'Well, It Should Be Changed for One, Because It's Our Bodies": Sex Workers' Views on Canada's Punitive Approach Towards Sex Work." Social Sciences 6, no. 2 (2017): 52-.

Berlant, Lauren. "Intimacy: A Special Issue." Critical Inquiry 24, no. 2 (1998): 281-288.

Berlant, Lauren. "The Commons: Infrastructures for Troubling Times." Environment and Planning D: Society and Space 34 no. 3 (2016): 393-419.

Berlant, Lauren and Michael Warner. "Sex in Public." Critical Inquiry 24, no. 2 (1998): 547-566.

Berlatsky, Noah. "Pixelated Prostitution: Feminist Sex Work Debate Bleeds Into Video Games." Newsweek. December 20, 2014. https://www.newsweek.com/pixelated-prostitution-feminist-sex-work-debate-bleeds-videogames-293311.

Blomley, Nicholas. "Law, Property, and the Geography of Violence: The Frontier, the Durvey, and the Grid." Annals of the Association of American Geographers 93, no. 1 (March 2003): 121-141.

Bogel-Burroughs, Nicholas. "Atlanta Shootings Life Updates: Suspect Had Visited Targeted Spa Before, Police Say." The New York Times. March 19, 2021. https://www.nytimes.com/live/2021/03/18/us/atlanta-shoot ings-massage-spa.

Boyer, Yvonne."First Nations Women's Contributions to Culture and Community through Canadian Law." in Restoring the Balance: First Nations Women, Community, and Culture, ed. G. G. Valaskakis, Madeleine Dion Stout, and Eric Guimond, 69-96. Winnipeg: University of Manitoba Press, 2009.

Bruckert, Chris. "Brief Submitted to The Senate Committee on Legal and Constitutional Affairs: Bill C-36 The Protection of Communities and Exploited Persons Act." https://sencanada.ca/content/sen/committee/412/ Icjc/briefs/c-36/sm_c-36_chris_bruckert_brief_u_of_ott)_e.pdf.

Butler, Judith. Gender Trouble: Feminism and the Subversion of Identity. New York: Routledge, 1990.

Canadian Public Health Association. "Sex Work in Canada: The Public Health Perspective." December 2014. https://www.cpha.ca/sites/default/files/assets/policy/sex-work_e.pdf.

Colomina, Beatriz. "The Split Wall: Domestic Voyeurism." In Sexuality and Space, 72-128. New York: Princeton Architectural Press, 1992.

Comte, Jacqueline. "Decriminalization of Sex Work: Feminist Discourses in Light of Research." Sexuality \& Culture 18, no. 1 (2014): 196-217.

Cowen, Deborah. "The City and the City (and the City): Infrastructure in the Breach." Society and Space. October 10, 2017. https://www.societyandspace.org/articles/the-city-and-the-city-and-the-city-infrastructure-in-the-breach.

Crane, Antonia. "The Most Realistic Sex-Worker Portrayals in Pop Culture, According to Sex Workers." Mel Magazine. 2019. https://melmagazine.com/en-us/story/the-most-realistic-sex-worker-portrayals-in-pop-culture-according-tosex-workers. 
Davies, Jacqueline M. "The Criminalization of Sexual Commerce in Canada: Context and Concepts for Critical Analysis." The Canadian Journal of Human Sexuality 24, no. 2 (2015): 78-91.

Grittner, Alison and Kathleen C. Sitter. "The Role of Place in the Lives of Sex Workers: A Sociospatial Analysis of Two International Case Studies." Affilia 35, no. 2 (2020): 274-293.

Harvey, David. "The Right to the City." 2008. https://davidharvey.org/media/righttothecity.pdf.

Hubbard, Phil, Andrew Gorman-Murray, and Catherine J. Nash. "Cities and Sexualities." In Handbook of the Sociology of Sexualities, ed. J DeLamater and R.F. Plante, 287-303. Switzerland: Springer International Publishing, 2015.

Hubbard, Phil. "Sex Work, Urban Governance and the Gendering of Cities." In The Routledge Research Companion to Geographies of Sex and Sexualities, ed. Gavin Brown and Kath Browne, 313-320. London: Routledge, 2016.

Jeffrey, Leslie Ann. "Prostitution as Public Nuisance: Prostitution Policy in Canada." In The Politics of Prostitution: Women's Movements, Democratic States and the Globalisation of Sex, ed. Joyce Outshoorn, 83-102 Cambridge University Press, 2004.

Krüsi, Andrea, Jill Chettiar, Amelia Ridgway, Janice Abbott, Steffanie A. Strathdee, and Kate Shannon. "Negotiating Safety and Sexual Risk Reduction with Clients in Unsanctioned Safer Indoor Sex Work Environments: A Qualitative Study." American Journal of Public Health (1971) 102, no. 6 (2012): 1154-1159.

LaDuke, Winona, and Deborah Cowen. "Beyond Wiindigo Infrastructure." The South Atlantic Quarterly 119, no. 2 (2020): 243-268.

Larkin, Brian. "The Politics and Poetics of Infrastructure." Annual Review of Anthropology 42, no. 1 (October, 2013): 327343.

Lavin, Silvia. "Open the Box: Richard Neutra and the Psychology of the Domestic Environment." Assemblage no. 40 (1999): 7-25.

Lefebvre, Henri. The Production of Space. Oxford, UK: Blackwell, 1991.

Lizotte, Chloe. "News to Me: Lizzie Borden, Greta Gerwig, Ryuichi Sakamoto." Film Comment. July 2, 2018. https://www.filmcomment.com/blog/news-lizzie-borden-greta-gerwig-ryuichi-sakamoto/.

Low, Setha M. Spatializing Culture: The Ethnography of Space and Place. New York: Routledge, 2016.

McLean, Heather E. "The Politics of Ceative Performance in Public Space: Toward a Critical Geography of Toronto Case Studies." In Spaces of Vernacular Creativity: Rethinking the Cultural Economy, ed. Tim Edensor et al., 200-213. Taylor \& Francis Group, 2009.

McRuer, Robert. Crip Theory Cultural Signs of Queerness and Disability. New York: New York University Press, 2006.

Murphy, Michelle. "Chemical Infrastructures of the St. Clair River." In Toxicants, Health and Regulation since 1945, edited by Soraya Boudia and Nathalie Jas, 103-115. London: Pickering \& Chatto, 2013.

Nina. "Vacancy." Let Us Stop Living Secret Lives: the Visual Stories of Sex Work. https://www.stoplivingsecretlives.com/ the-law?pgid=irnl1n8d-f5df6dc1-2ac7-48f3-bab9-71db6e4a3b6c.

Orchard, Treena, Jennifer Vale, Susan Macphail, Cass Wender, and Tor Oiamo. "'You Just Have To Be Smart': Spatial Practices and Subjectivity among Women in Sex Work in London, Ontario." Gender, Place \& Culture 23, no. 11 (2016): 1572-1585.

Orchard, Treena, Angela Murie, Holli-Lynn Elash, Mary Bunch, Cathy Middleton, Danielle Sadakhom, Tor Oiamo, and Cecilia Benoit. "'People Like Us": Spatialised Notions of Health, Stigma, Power, and Subjectivity among Women in Street Sex Work." Culture, Health \& Sexuality 21, no. 4 (2019): 478-494.

Pablo, Carlito. "New prostitution law leaves sex workers "invisible and anonymous," advocate says." The Georgia Straight. November 6, 2014. https://www.straight.com/news/347526/new-prostitution-law-leavessex-workers-invisible-and-anonymous-advocate-says.

Pereira-Edwards, Alexandra. "Rethinking Intimacy and the City." CARTHA (2020): 1-3. https://www.carthamagazine.com/wp-content/uploads/2021/02/Alexandra_Pereira-Edwards.pdf. 
Pitcher, Jane and Marjan Wijers. "The Impact of Different Regulatory Models on the Labour Conditions, Safety and Welfare of Indoor-Based Sex Workers." Criminology \& Criminal Justice 14, no. 5 (2014): 549-564.

Pivot Legal. "Reckless Endangerment: Q\&A on Bill C-36: Protection of Communities and Exploited Persons Act." June 2014. https://www.pivotlegal.org/reckless_endangerment_q_a_on_bill_c_36.

Quan, Tracy. "Don't Forget-the Georgia Shootings are a Hate Crime against Sex Workers." Los Angeles Times. March 19, 2021. https://www.latimes.com/entertainment-arts/books/story/2021-03-19/tracy-quan-dont-forget-the-atlantashooting-is-a-hate-crime-against-sex-workers.

Rich, Adrienne. "Notes Toward a Politics of Location (1984)." In Blood, Bread, and Poetry: Selected Prose 1979-1985, 210-231. New York: Norton, 1986.

Russell, Legacy. Glitch Feminism: A Manifesto. New York: Verso, 2020.

Russwurm, Lani. "A History of Sex Work in Early Vancouver." Forbidden Vancouver. https://forbiddenvancouver.ca/blog/ history-prostitution-vancouver/.

Sayers, Naomi. "The (Un)Constitutionality of PCEPA: A Necessary Discussion." In Sex Work Activism in Canada: Speaking Out, Standing Up, ed. Amy Lebovitch and Shawna Ferris, 20-35. Winnipeg: Arp Books, 2019.

Sayers, Naomi. "Canada's Anti-Prostitution Laws: A Method for Social Control." kwetoday. December 28, 2013. https://kwetoday.com/2013/12/28/canadas-anti-prostitution-laws-a-method-for-social-control/.

Schulte, Red. "Sex Working Economies of Space." The Funambulist 33 (2021): 36-41.

Scott, Valerie. "Bill C-66/Sex Workers/Bawdy-house." Senate of Canada. https://sencanada.ca/content/sen/ committee/421/RIDR/Briefs/2018-04-17_C-66_SexProfessionals_e.pdf.

Star, Susan Leigh. "The Ethnography of Infrastructure." The American Behavioral Scientist (Beverly Hills) 43, no. 3 (1999): 377-391.

Tigchelaar, Alex. "Sex Worker Resistance in the Neoliberal Creative City: An Auto/ethnography." Anti-Trafficking Review 12 (2019): 15-36.

Trouillot, Michel-Rolph. Silencing the Past: Power and the Production of History. Boston, Mass: Beacon Press, 1995.

Trudeau, Pierre. CBC Television News. December 21, 1967. https://www.cbc.ca/archives/entry/omnibus-bill-theres-noplace-for-the-state-in-the-bedrooms-of-the-nation.

Tschumi, Bernard. The Manhattan Transcripts. London: Academy Editions, 1994.

Van Der Meulen, Emily and Amanda Glasbeek. "The Gendered Lens: A Report on Women's Experiences with Video Surveillance and Urban Security in Toronto." Ryerson University. April 2013. https://www.ryerson.ca/content/ dam/criminology/tank/documents/1.\%20Gendered\%20Lens\%20Report\%20April\%202013.pdf.

Wilson, Ara. "The Infrastructure of Intimacy." Signs: Journal of Women in Culture and Society 41, no. 2 (January, 2016): 247-280.

Zhou, Alison. "The Sweetening of Public Infrastructures, Or Tangerine." Society and Space. November 27, 2018. https://www.societyandspace.org/articles/the-sweetening-of-public-infrastructures-or-tangerine. 


\section{Appendix I}

\section{Timeline of Sex Work in Canada}

1867

1873

\begin{abstract}
Canada inherets British anti-prostitution laws with the creation of the new federal government at Confederation. These laws prohibit "common prostitutes," keeping or frequenting a bawdy house, and supporting oneself by the avails of prostitution. The Vagrancy Act is also passed at this time, stating that police had the authority to arrest a woman "if she could not give a good account of herself." The Indian Act is also enacted at this time.
\end{abstract}

The North West Mounted Police (NWMP) is established. The NWMP exists today as the Royal Canadian Mounted Police (RCMP). The NWMP were early enforcers of the Canadian colonial agenda and were responsible for policing and regulating the movement and activities of Indigenous bodies on Indigenous lands.

Sections were added to the Indian Act that targeted keepers of "houses of prostitution." These laws targeted women who had "the intention of prostituting herself."

The Criminal Code of Canada is enacted. The federal government removed all prostitution legislations from the Indian Act and imported them to the Criminal Code.

Homosexuality is decriminalized in Canada after amendments to the Criminal Code proposed by Prime Minister Pierre Trudeau.

Homes can be considered as bawdy-houses after a decision by the Supreme Court of Canada in The King v. Betty Cohen.

The Vagrancy Act is repealed. It is replaced by a law that criminalizes soliciting in a public place.

The City of Montreal enacts a by-law that forbids remaining in a public place for the purpose of prostitution. Calgary, Vancouver, Niagra Falls, and Halifax enact similar laws in the following years. 
Over 100 police officers armed with crowbars and sledgehammers raid multiple gay bathhouses in Toronto, arresting nearly 300 people. The raids, known as 'Operation Soap', are a catalyst for the gay rights movement in the community and for the fight against bawdy-house laws.

The Canadian Charter of Rights and Freedoms is signed into law. The Charter, part of the Canadian Constitution, protects the rights and freedoms that constitute Canada as a democratic society.

Men can now be considered sex workers under Bill C-127.

Sex work is prohibited in Vancouver's West End. The prohibition stemmed from complaints about public nuisance and traffic congestion.

Bill C-49 is passed. The new bill makes it an offence to buy or sell sexual services in a public place, with the aim to diminish the "nuisance caused to ordinary members of the public." Public places included places that were only accessible by invitation, such as hotels, vehicles, clubs, etc. After C-49 was passed, violence against street-based sex workers increased.

A nationwide protest against Bill C-49 brings out hundreds of sex workers and adovcates across the country. The protests lead to a series of arrests.

The Manitoba government questions whether the bawdy-house and communications laws are inconsistent with the Charter. The government's appeal is dismissed. for sex workers amidst growing fears of a serial killer in the area.

"Grandma's House" is shut down by police for violating bawdy-house laws. Jamie Lee Hamilton, who opened Grandma's House, was charged with keeping a common bawdy-house. first degree murder of local sex workers. He would later be charged with first degree murder of another 27 women. unsolved. A House of Commons sub-committee concludes that the number is "almsot certainly lower than the real figures." 
Sex workers Terri Jean Bedford, Amy Lebovitch, and Valerie Scott initiate a case to strike down three provisions of the law for violating section 7 "Life, liberty and security of person" from the Charter.

Judge Susan Himel strikes down the three provisions in Canada (AG) v Bedford, 2013 SCC 7:

s. 210 - Keeping a common bawdy-house

s. 212 (1)(j) - Living on the avails of prostitution

s. $213(1)(c)$ - Communicating in public for the purpose of prostitution

The Supreme Court of Canada throws out all three provisions (s. 210; s. $212(1)(j) ;$ s. 213 (1)(c)) in a unanimous ruling after deciding they are unconstitutional. The justices give parliament one year to craft a set of replacement laws that comply with the Charter. This is a milestone win for sex workers, as it signals the total decriminalization of sex work should no further legislation be introduced.

Following the 2013 Supreme Court decision, Minister of Justice Peter MacKay introduces Bill C-36, the Protection of Communities and Exploited Persons Act (PCEPA). Rather than target sex workers themselves, C-36 targets those who purchase sex. PCEPA makes it illegal to obtain sexual services, to receive material benefits for sexual services, and to advertise for sexual services. Sex workers adamently argue that these new restrictions will make their jobs considerably more dangerous. reviewing prostitution laws after being appointed to cabinet by the newlyelected Liberal government. 